\title{
Hydration differences explain the large variations in the complexation thermodynamics of modified $\gamma$ - cyclodextrins with bile salts.
}

Jonatan Køhler ${ }^{1,2}$, Christian Schönbeck ${ }^{1,2}$, Peter Westh ${ }^{2}$, and René Holm ${ }^{1, *}$

Supporting information 


\section{Content}

1. Chemical structures of investigated bile salts .......................................................................... 3

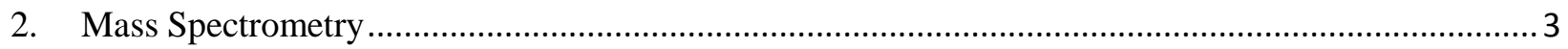

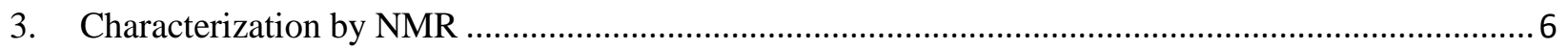

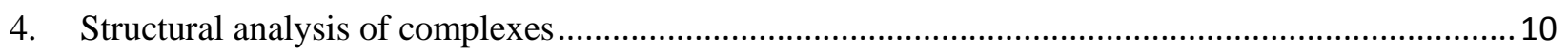

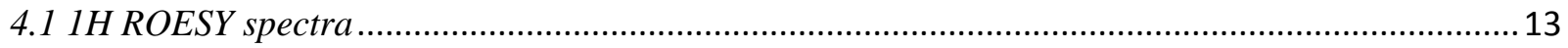

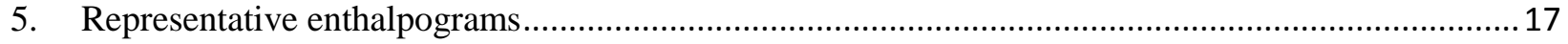

6. Stability constants and thermodynamic parameters for the complexation .......................................2 21

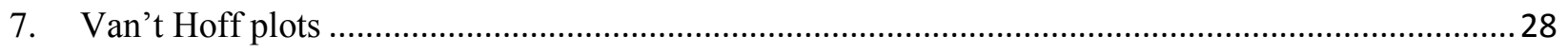

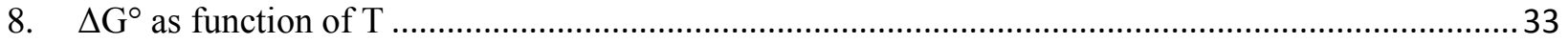

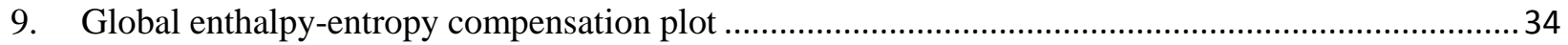

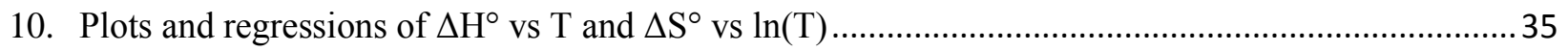

11. Plots and regressions used to calculate dehydrated surface area .................................................... 42

12. Alternative way of calculating amount of dehydrated surface area per HP chain ........................... 45

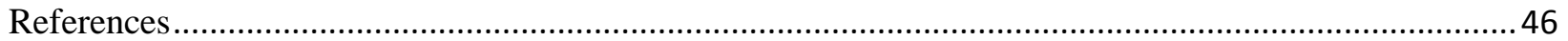




\section{Chemical structures of investigated bile salts}

Three bile salts were investigated in the present study, the structure together with the numbering for the NMR studies are provided below.

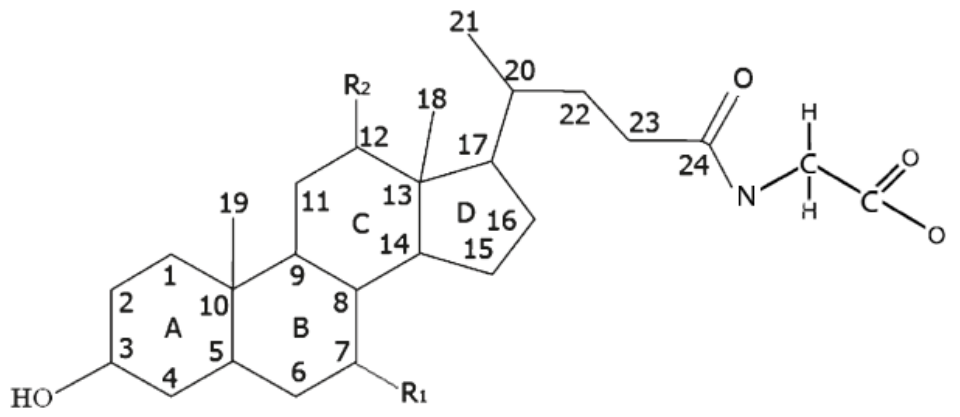

\begin{tabular}{|l|c|c|c|}
\hline Bile salt anion & Abbreviation & $\mathbf{R}_{\mathbf{1}}$ (C-7) & $\mathbf{R}_{\mathbf{2}}$ (C-12) \\
\hline Glycocholate & $(\mathrm{GC})$ & $\mathrm{OH}$ & $\mathrm{OH}$ \\
\hline Glycodeoxycholate & $(\mathrm{GDC})$ & $\mathrm{H}$ & $\mathrm{OH}$ \\
\hline Glycochenodeoxycholate & (GCDC) & $\mathrm{OH}$ & $\mathrm{H}$ \\
\hline
\end{tabular}

\section{Mass Spectrometry}

Below mass spectra of the various $\gamma$ CDs are shown. Tables with peak areas and calculated DS are shown next to the respective mass spectra.

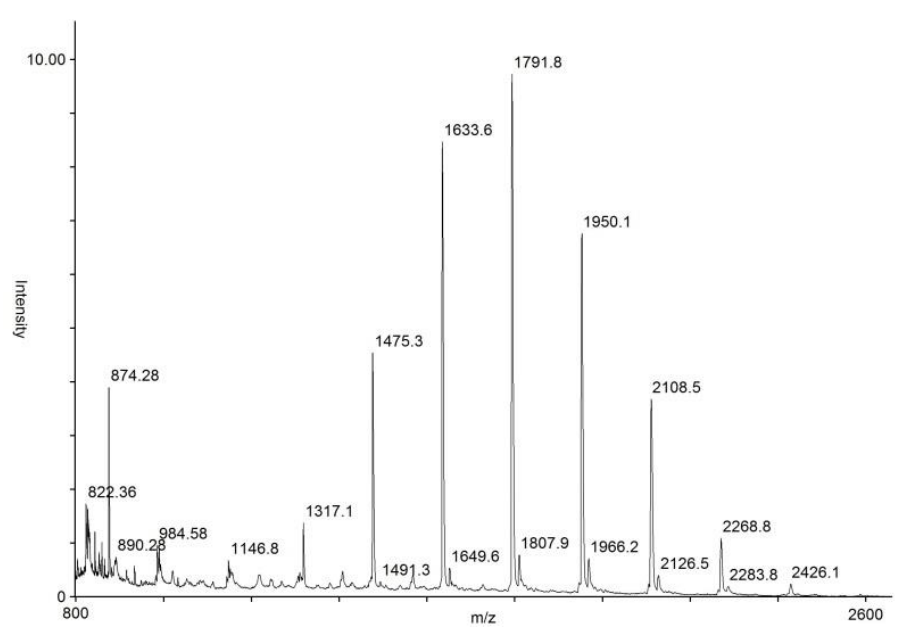

\begin{tabular}{|c|c|c|}
\hline DS & Measured I & DS*I \\
\hline 0 & 20542 & 0 \\
\hline 1 & 68127 & 8515.875 \\
\hline 2 & 138395 & 34598.75 \\
\hline 3 & 154381 & 57892.875 \\
\hline 4 & 106621 & 53310.5 \\
\hline 5 & 57644 & 36027.5 \\
\hline 6 & 18623 & 13967.25 \\
\hline 7 & 4522 & 3956.75 \\
\hline SUM & 568855 & 208269.5 \\
\hline \multicolumn{2}{|c|}{ Overall DS } & 0.36612054 \\
\hline
\end{tabular}

Figure 1S. Mass spectrum of SBE- $\gamma \mathrm{CD}$ and table of peak areas used to calculate overall DS. 


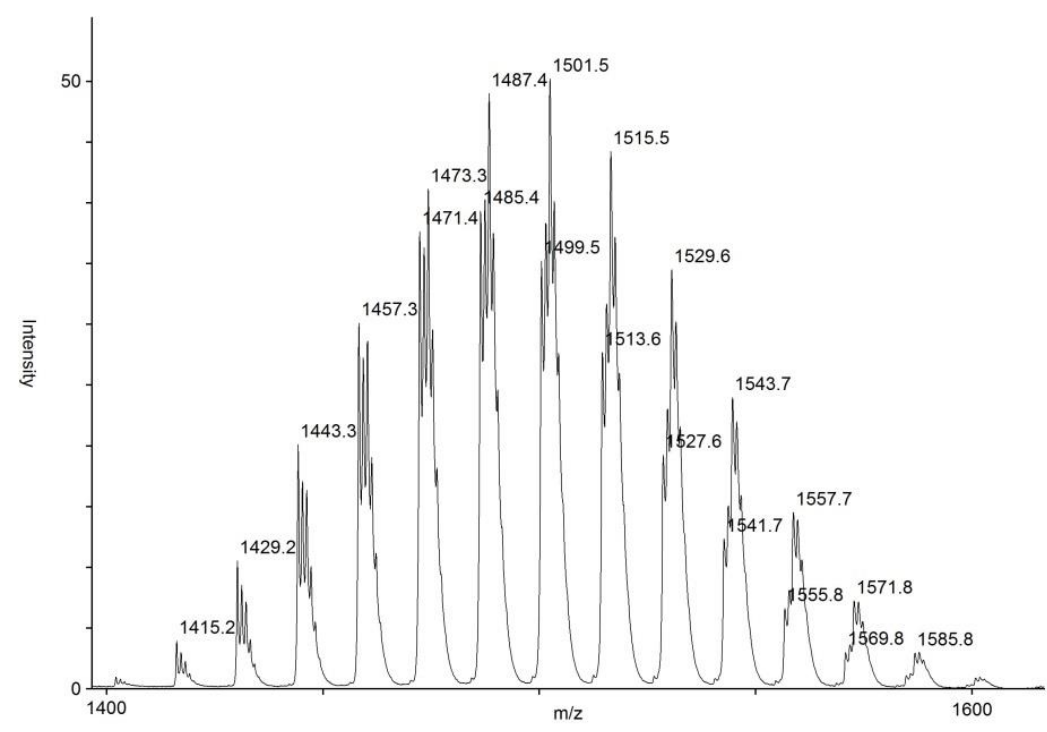

Figure 2S. Mass spectrum of Me135- $\gamma \mathrm{CD}$ and table of peak areas used to calculate overall DS.

\begin{tabular}{|c|c|c|}
\hline DS & Measured I & DS*I \\
\hline 6 & 28604 & 21453 \\
\hline 7 & 100447 & 87891.13 \\
\hline 8 & 262654 & 262654 \\
\hline 9 & 500149 & 562667.6 \\
\hline 10 & 751244 & 939055 \\
\hline 11 & 1031030 & 1417666 \\
\hline 12 & 1233148 & 1849722 \\
\hline 13 & 1262045 & 2050823 \\
\hline 14 & 1114884 & 1951047 \\
\hline 15 & 869419 & 1630161 \\
\hline 16 & 608091 & 1216182 \\
\hline 17 & 369376 & 784924 \\
\hline 18 & 186645 & 419951.3 \\
\hline 19 & 78456 & 186333 \\
\hline 20 & 28541 & 71352.5 \\
\hline 21 & 9723 & 25522.88 \\
\hline \multicolumn{2}{|l|}{} & \\
\hline SUM & 8434456 & 13477405 \\
\hline Overall DS & $\mathbf{1 . 5 9 7 8 9 9}$ \\
\hline
\end{tabular}

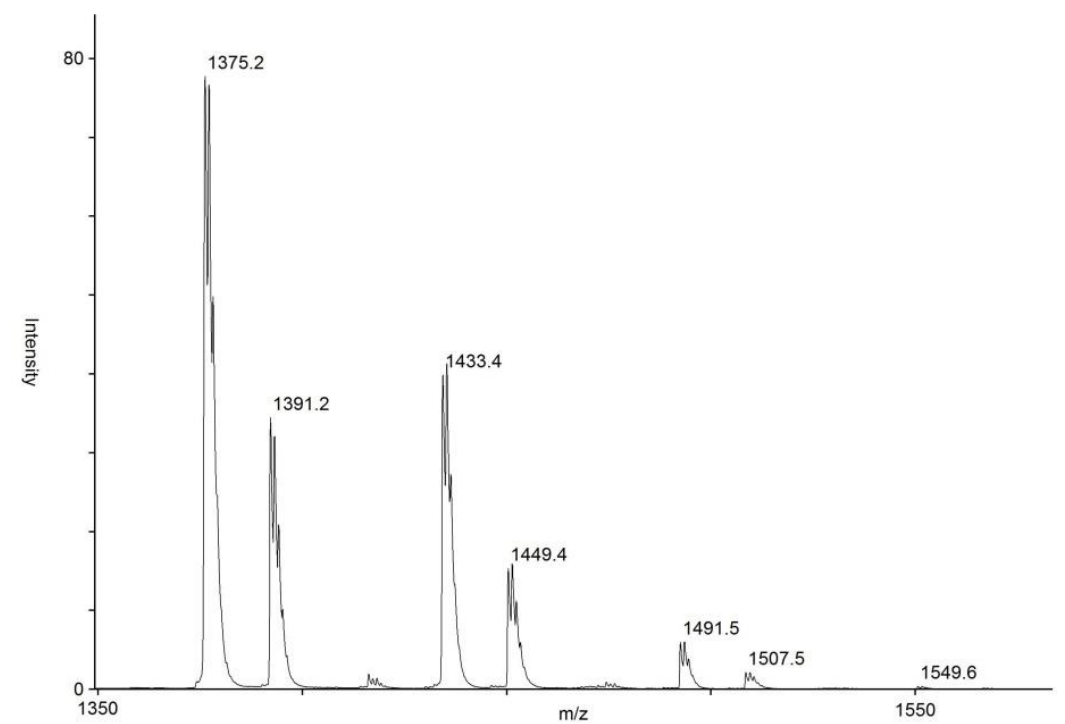

\begin{tabular}{|c|c|c|}
\hline DS & Measured I & DS*I \\
\hline 1 & 1929401 & 241175.1 \\
\hline 2 & 1040868 & 260217 \\
\hline 3 & 152245 & 57091.88 \\
\hline 4 & 11174 & 5587 \\
\hline & & \\
\hline SUM & 3133688 & 564071 \\
\hline \multicolumn{2}{|l|}{ Overall DS } & $\mathbf{0 . 1 8 0 0 0 2}$ \\
\hline
\end{tabular}

Figure 3S. Mass spectrum of HP016- $\gamma \mathrm{CD}$ and table of peak areas used to calculate overall DS. 


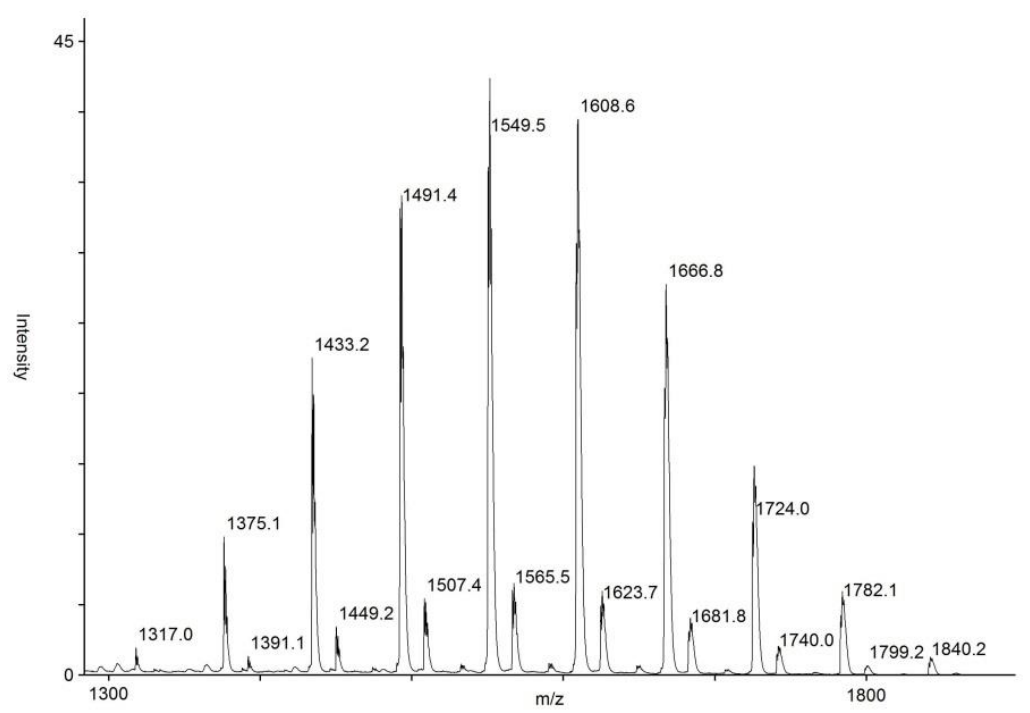

\begin{tabular}{|c|c|c|}
\hline DS & Measured I & DS*I \\
\hline 0 & 34984 & 0 \\
\hline 1 & 192213 & 24026.63 \\
\hline 2 & 498531 & 124632.8 \\
\hline 3 & 854129 & 320298.4 \\
\hline 4 & 1063352 & 531676 \\
\hline 5 & 796786 & 497991.3 \\
\hline 6 & 603516 & 452637 \\
\hline 7 & 375215 & 328313.1 \\
\hline 8 & 150338 & 150338 \\
\hline 9 & 23348 & 26266.5 \\
\hline \multicolumn{2}{|l|}{} & \\
\hline SUM & 4592412 & 2456180 \\
\hline Overall DS & $\mathbf{0 . 5 3 4 8 3 4}$ \\
\hline
\end{tabular}

Figure 4S. Mass spectrum of HP054- $\gamma \mathrm{CD}$ and table of peak areas used to calculate overall DS.

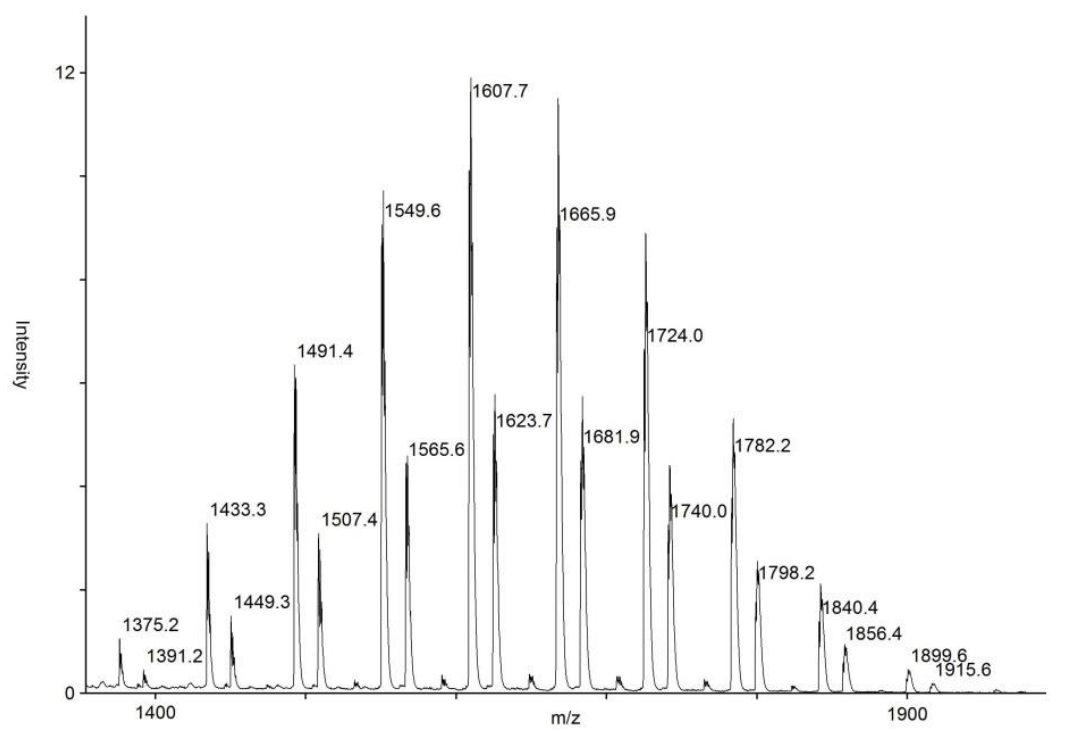

\begin{tabular}{|c|c|c|}
\hline DS & Measured I & DS*I \\
\hline 1 & 19764 & 2470.5 \\
\hline 2 & 69060 & 17265 \\
\hline 3 & 152384 & 57144 \\
\hline 4 & 242513 & 121256.5 \\
\hline 5 & 298669 & 186668.1 \\
\hline 6 & 226473 & 169854.8 \\
\hline 7 & 167052 & 146170.5 \\
\hline 8 & 95323 & 95323 \\
\hline 9 & 35529 & 39970.13 \\
\hline 10 & 11578 & 14472.5 \\
\hline & & \\
\hline SUM & 1318345 & 850595 \\
\hline Overall DS & $\mathbf{0 . 6 4 5 1 9 9}$ \\
\hline
\end{tabular}

Figure 5S. Mass spectrum of HP060- $\gamma \mathrm{CD}$ and table of peak areas used to calculate overall DS. 


\section{Characterization by NMR}

The ${ }^{1} \mathrm{H}$ and ${ }^{13} \mathrm{C}$ NMR spectra of the investigated $\gamma \mathrm{CDs}$ used to determine degrees and patterns of substitution are presented below. For the HP-substituted $\gamma \mathrm{CDs}$ only the ${ }^{1} \mathrm{H}$ spectra were used. Integrals in the ${ }^{13} \mathrm{C}$ spectra are only shown for those peaks used in calculations of DS and pattern of DS. Protons on a BS are denoted "P", whereas protons on a CD are denoted "H".

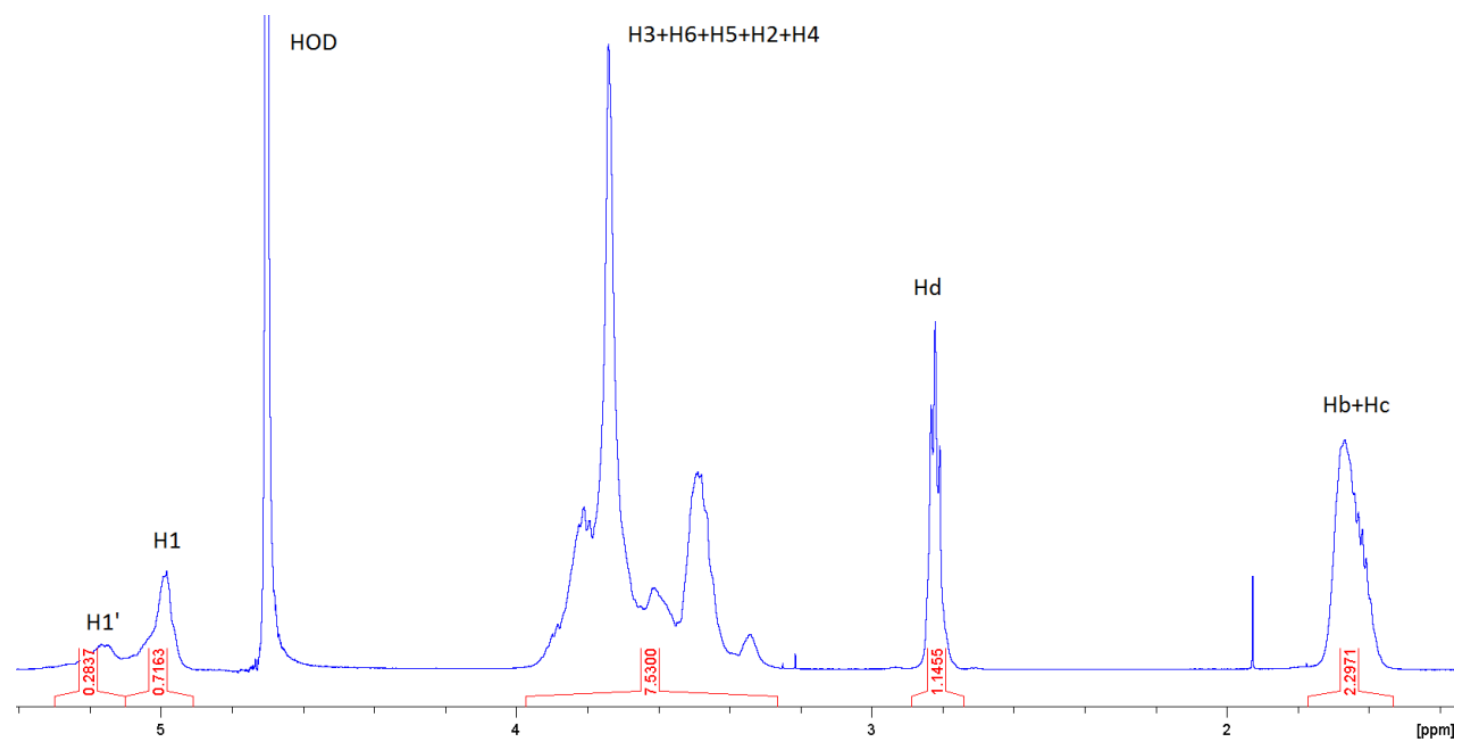

Figure 6S. Assigned ${ }^{1} \mathrm{H}$ NMR spectrum of SBE- $\gamma \mathrm{CD}$.

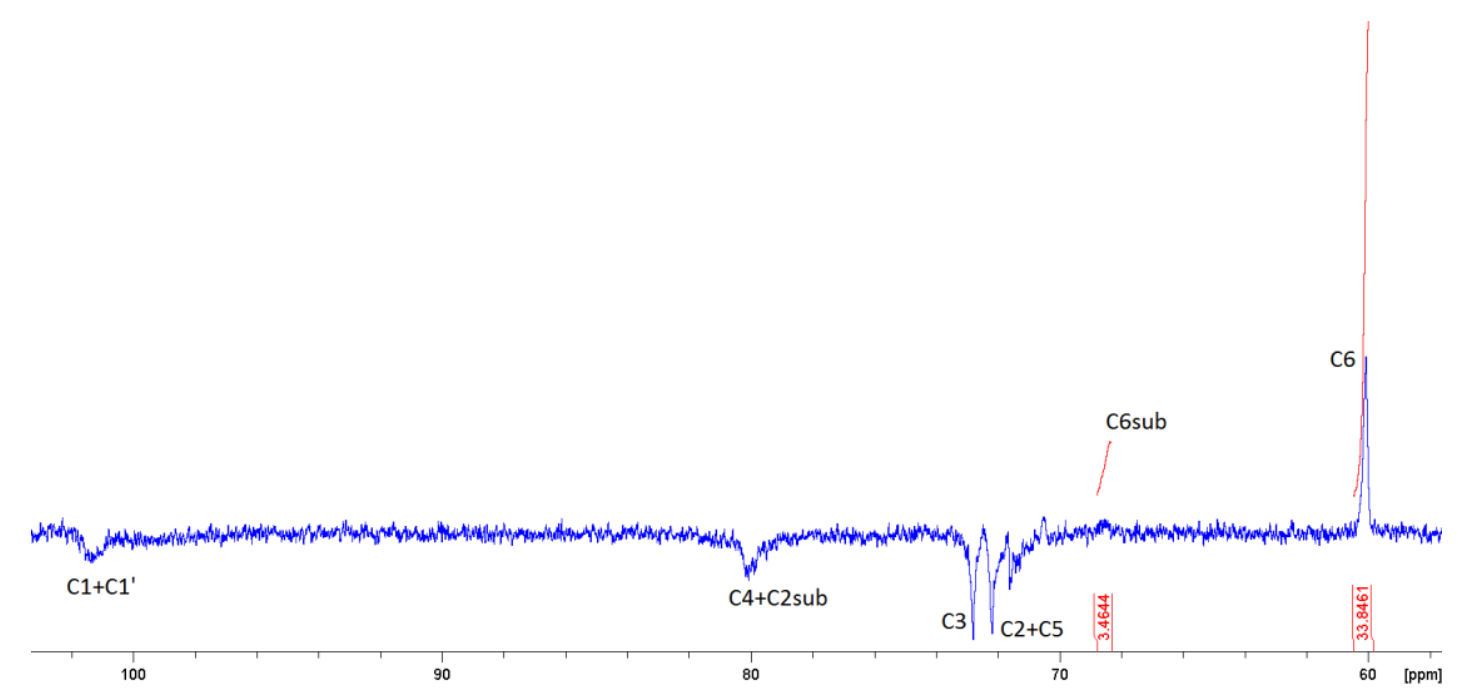

Figure 7S. Assigned ${ }^{13} \mathrm{C}$ NMR spectrum of SBE- $\gamma \mathrm{CD}$. 


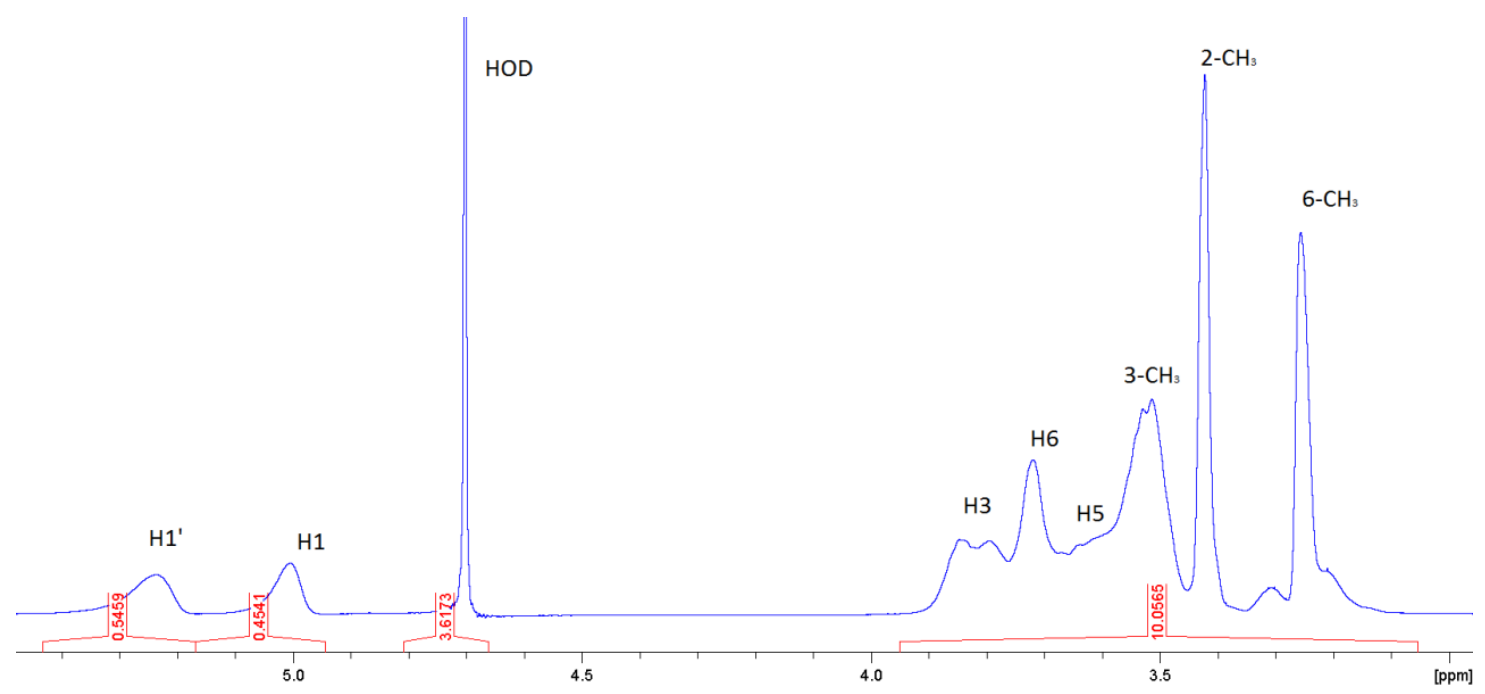

Figure 8S. Assigned ${ }^{1} \mathrm{H}$ NMR spectrum of Me135- $\gamma \mathrm{CD}$.

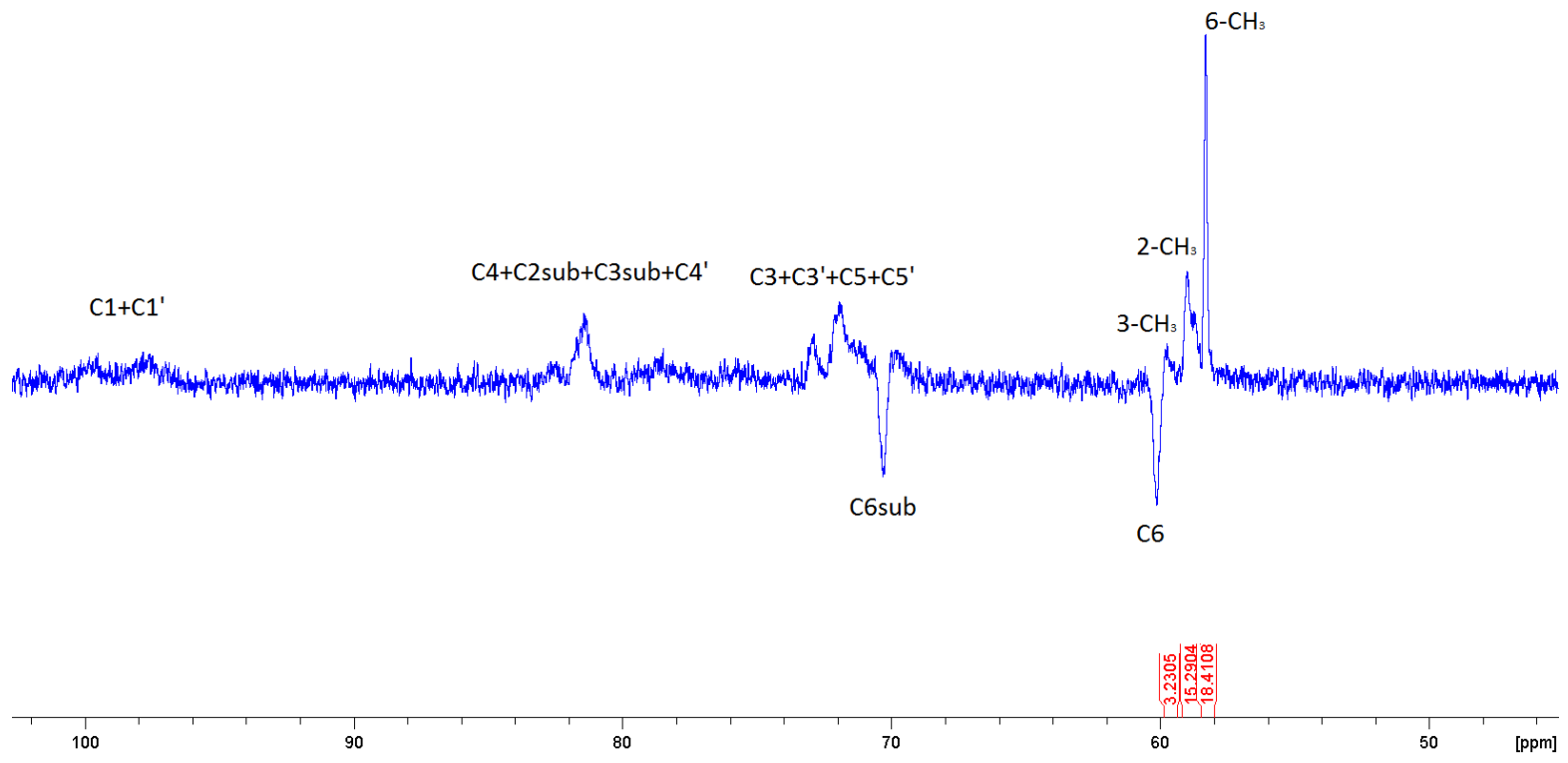

Figure 9S. Assigned ${ }^{13} \mathrm{C}$ NMR spectrum of Me135- $\gamma \mathrm{CD}$. 


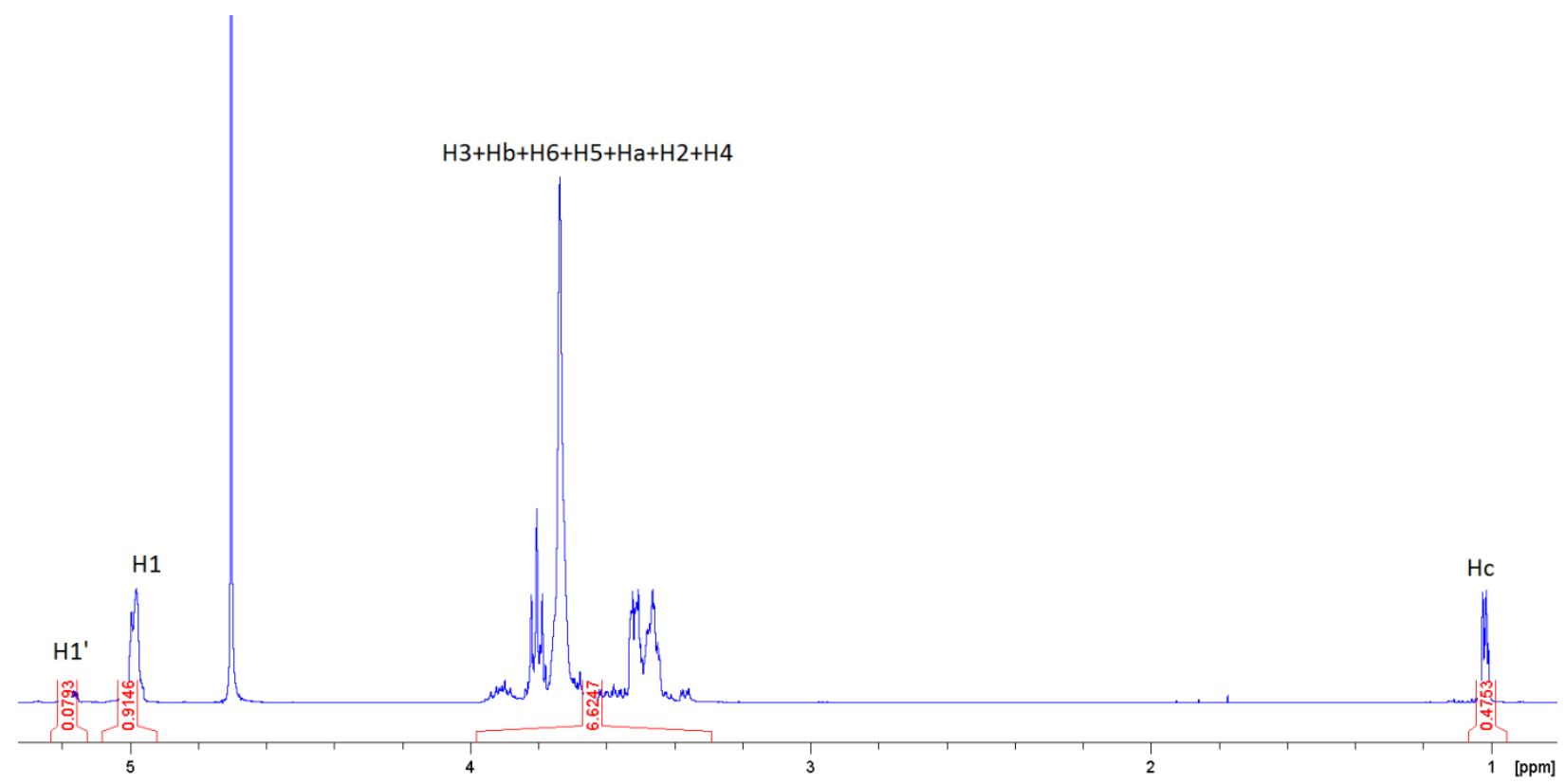

Figure 10S. Assigned ${ }^{1} \mathrm{H}$ NMR spectrum of HP016- $\gamma$ CD.

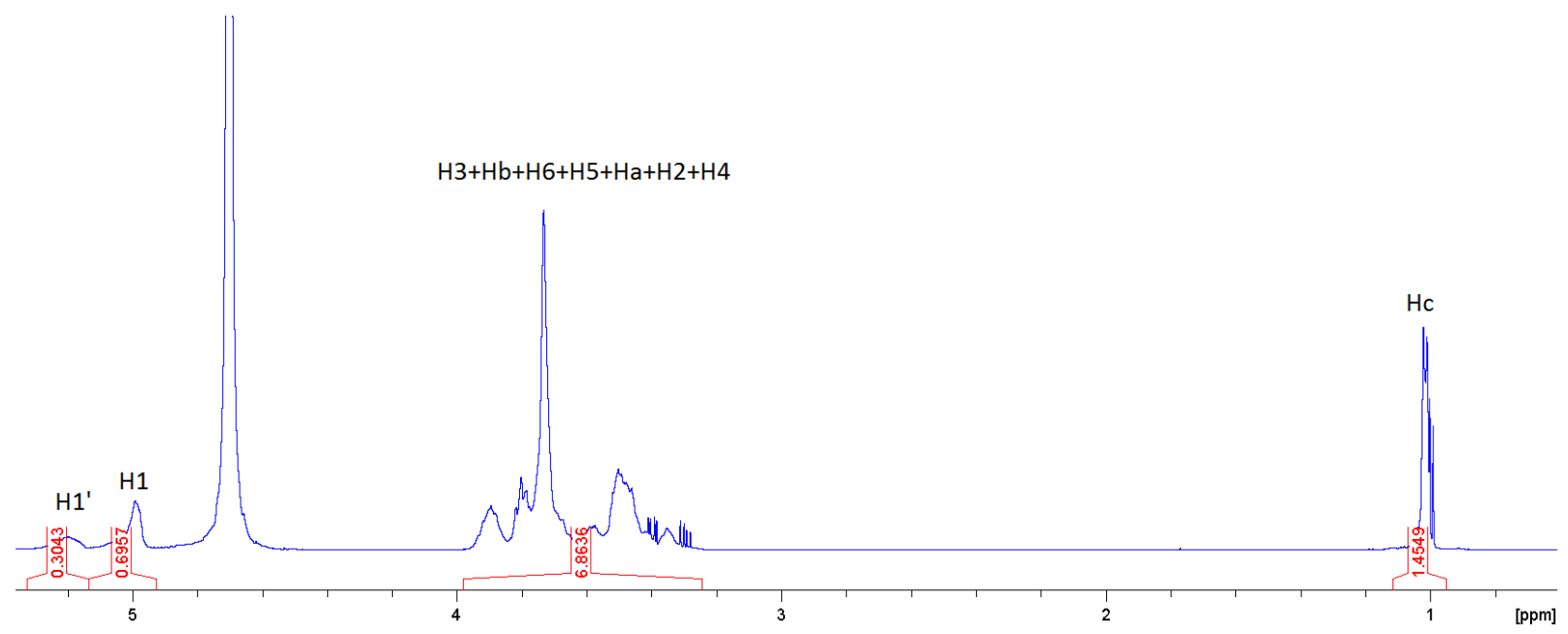

Figure 11S. Assigned ${ }^{1} \mathrm{H}$ NMR spectrum of HP054- $\gamma$ CD. 


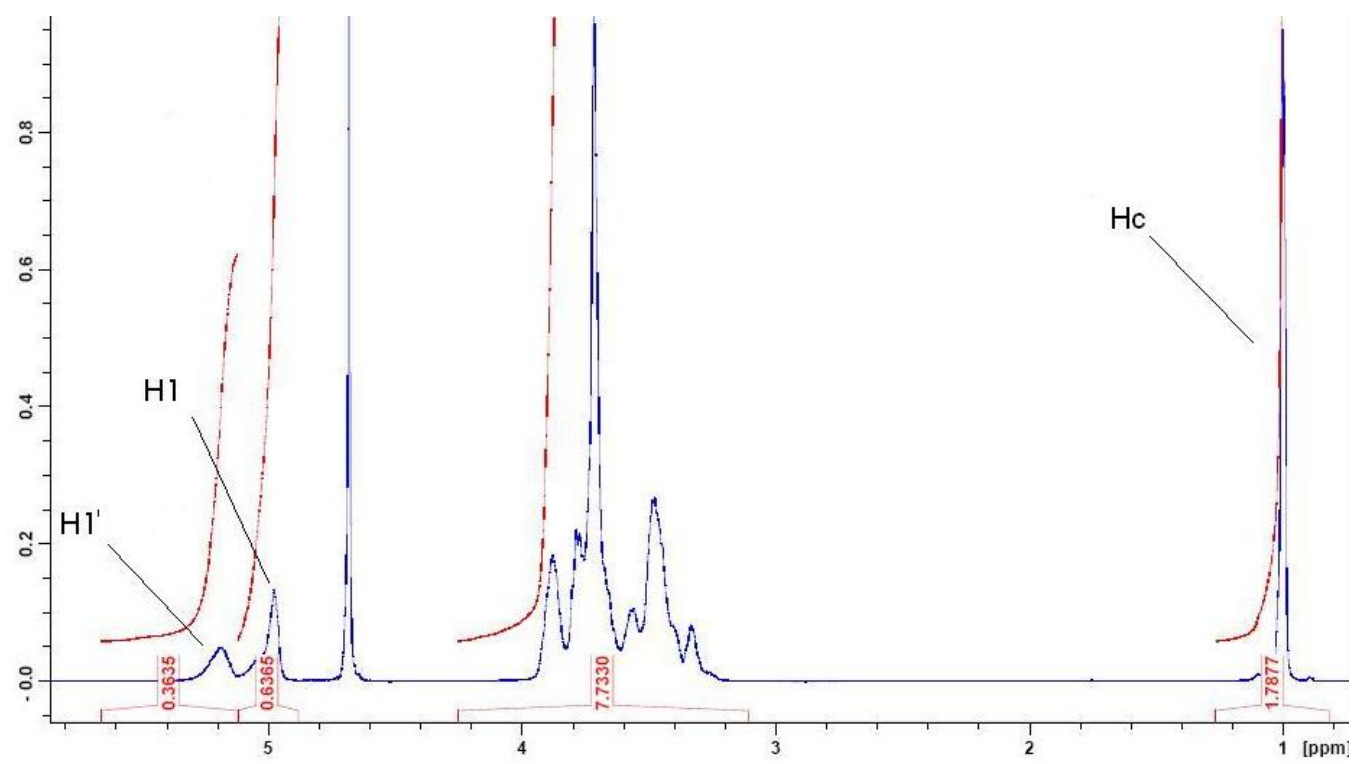

Figure 12S. Assigned ${ }^{1} \mathrm{H}$ NMR spectrum of HP060- $\gamma \mathrm{CD}$.

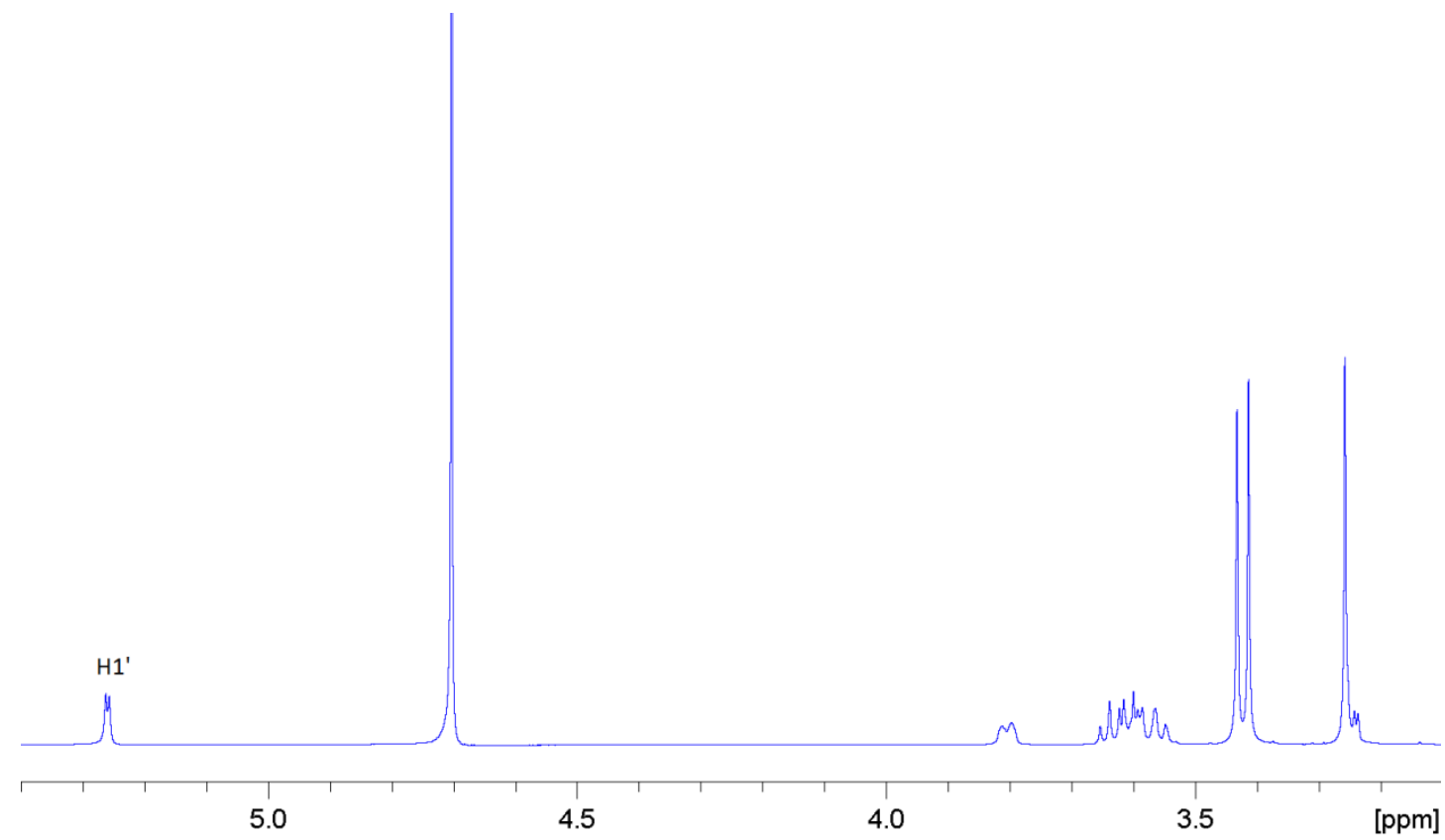

Figure 13S. ${ }^{1} \mathrm{H}$ NMR spectrum of Me300- $\gamma$ CD. No H1 peak is observed confirming that the CD is fully substituted. 


\section{Structural analysis of complexes}

The structures of the CD:BS complexes were investigated using 2D ROESY NMR. This technique provides cross correlation peaks between spatially close $(<4 \AA$ ) protons (Schneider et al., 1998). The technique can, thus, be used to observe, which BS protons that were positioned close to the inner CD protons and, hence, to characterize the structure of the complexes.

The assignments of the protons in the ROESY spectra were based on the HSQC spectra. The HSQC spectra had two main areas of interest, one primarily populated with CD protons (denoted "H") and one with primarily BS protons (denoted "P"). The two areas were largely independent of changes in the other area meaning $\mathrm{CD}$ peaks did not change with changing BS and vice versa. Below are examples of the CD proton area of an $\mathrm{HP}-\gamma \mathrm{CD}$ (HP- $\gamma \mathrm{CD}$ s of varying DS were very similar), an SBE- $\gamma \mathrm{CD}$, and a Me- $\gamma \mathrm{CD}$. Also shown are the areas of BS protons for GC, GDC, and GCDC complexes.

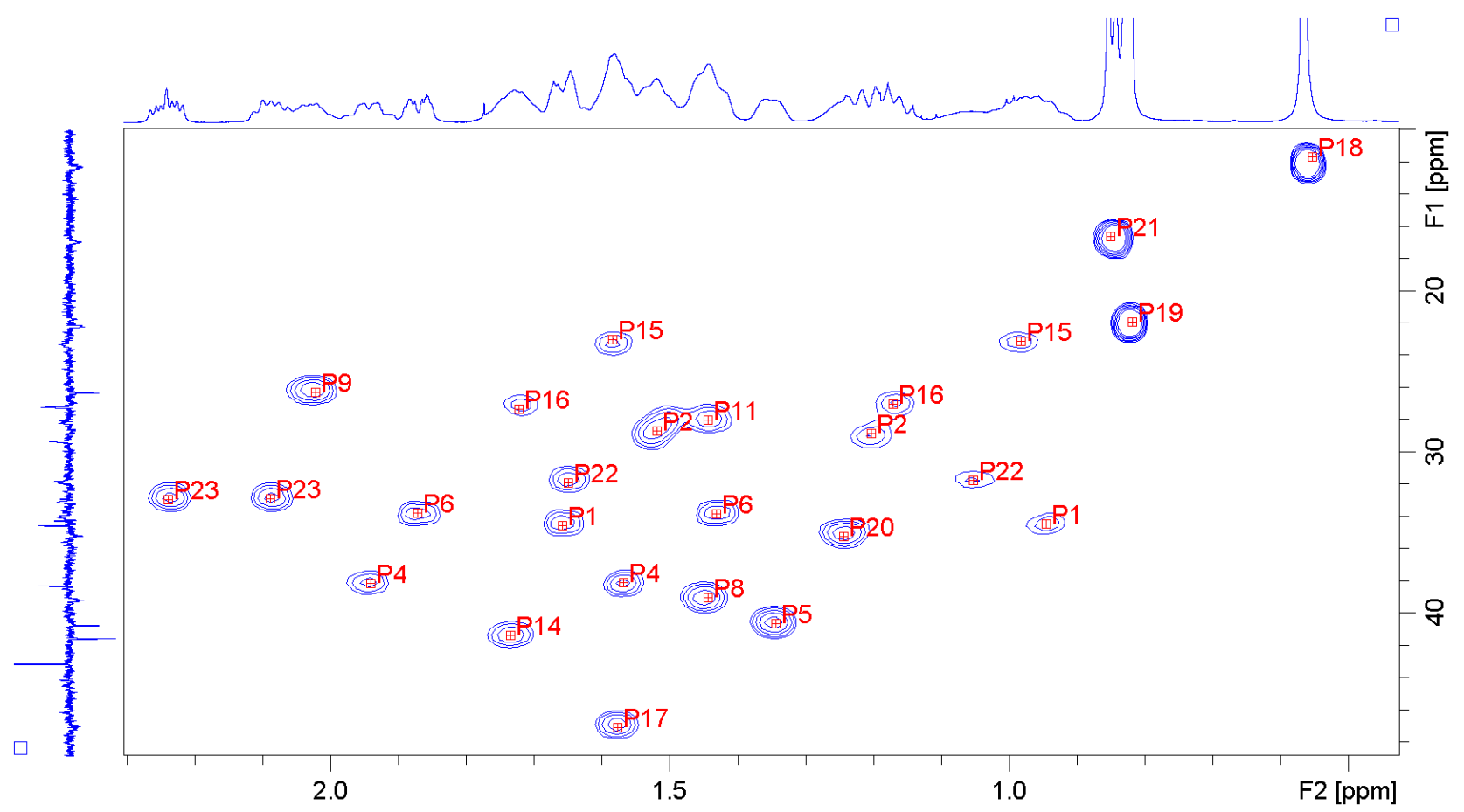

Figure 14S. Partial HSQC spectrum of the Me135- $\gamma \mathrm{CD} / \mathrm{GC}$ complex. The part of the spectrum with most of the BS protons (denoted P) is shown. The assignment of the protons in the complex made the assignment of the peaks in the ROESY spectrum possible. Notice the large degree to which the ${ }^{1} \mathrm{H}$ peaks overlap. 


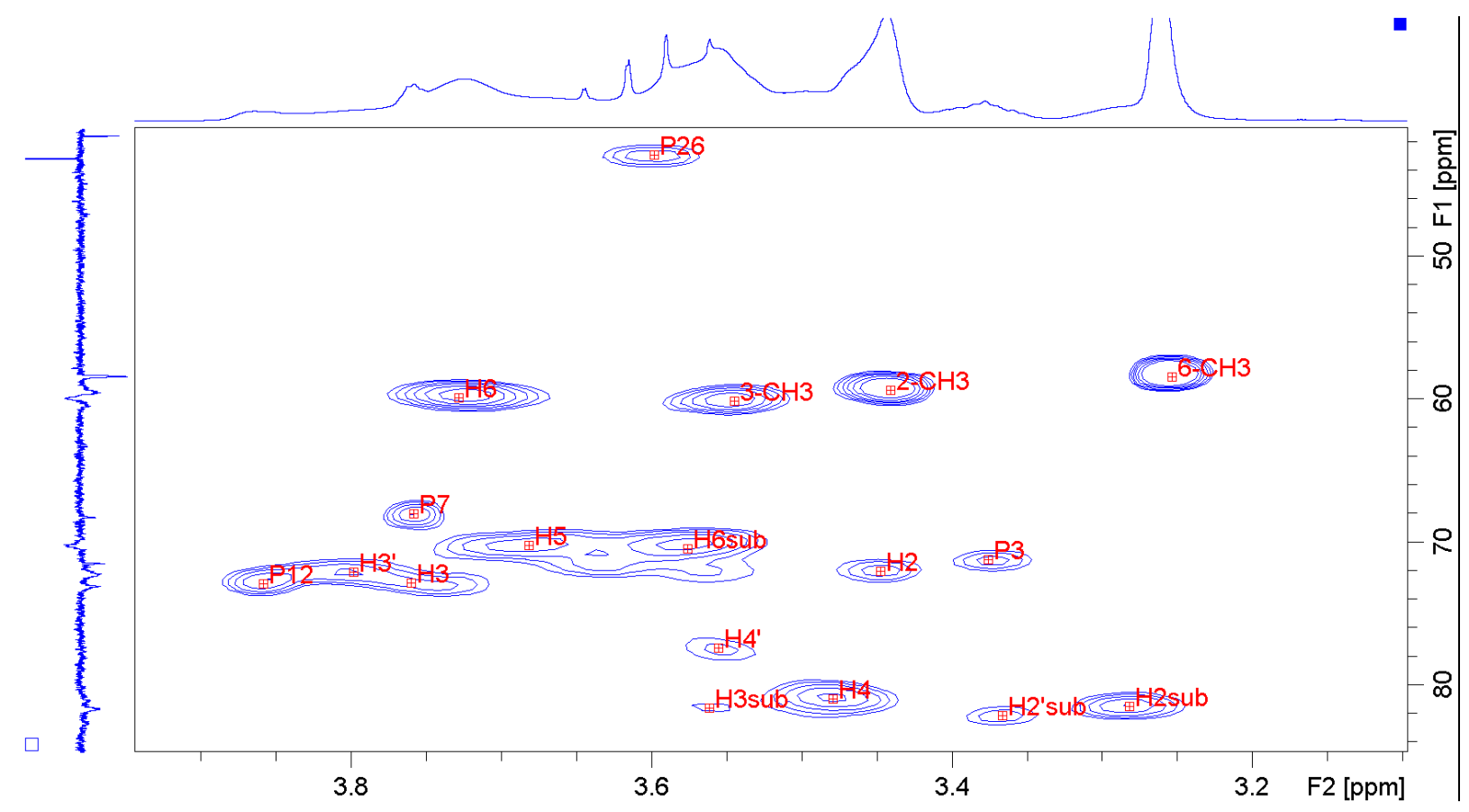

Figure 15S. The part of the Me135- $\gamma \mathrm{CD} / \mathrm{GC}$ complex HSQC spectrum containing most of the CD protons (denoted H).

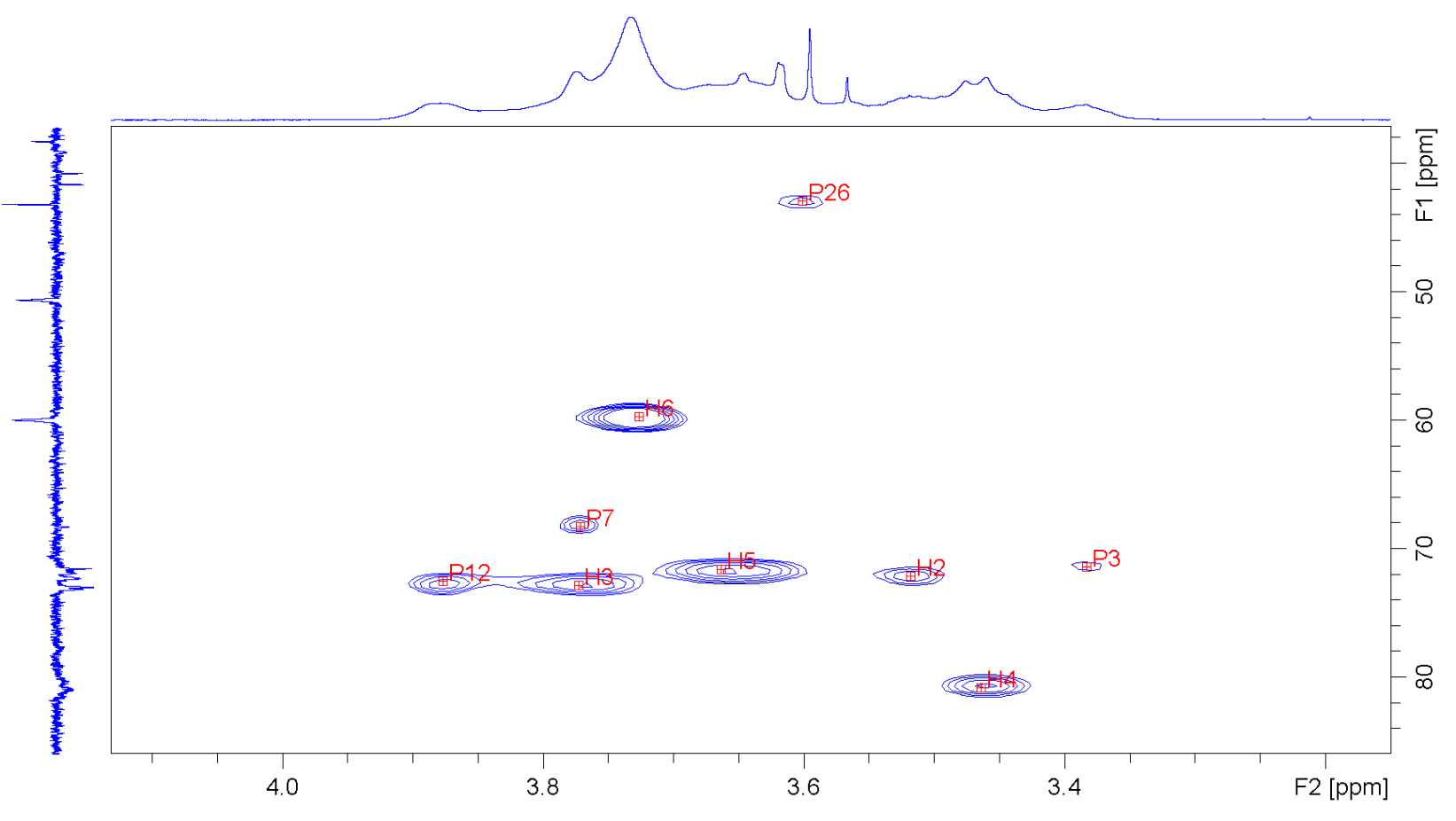

Figure 16S. The CD proton part of the HSQC spectrum of a SBE057- $\gamma \mathrm{CD} / \mathrm{GC}$ complex. 


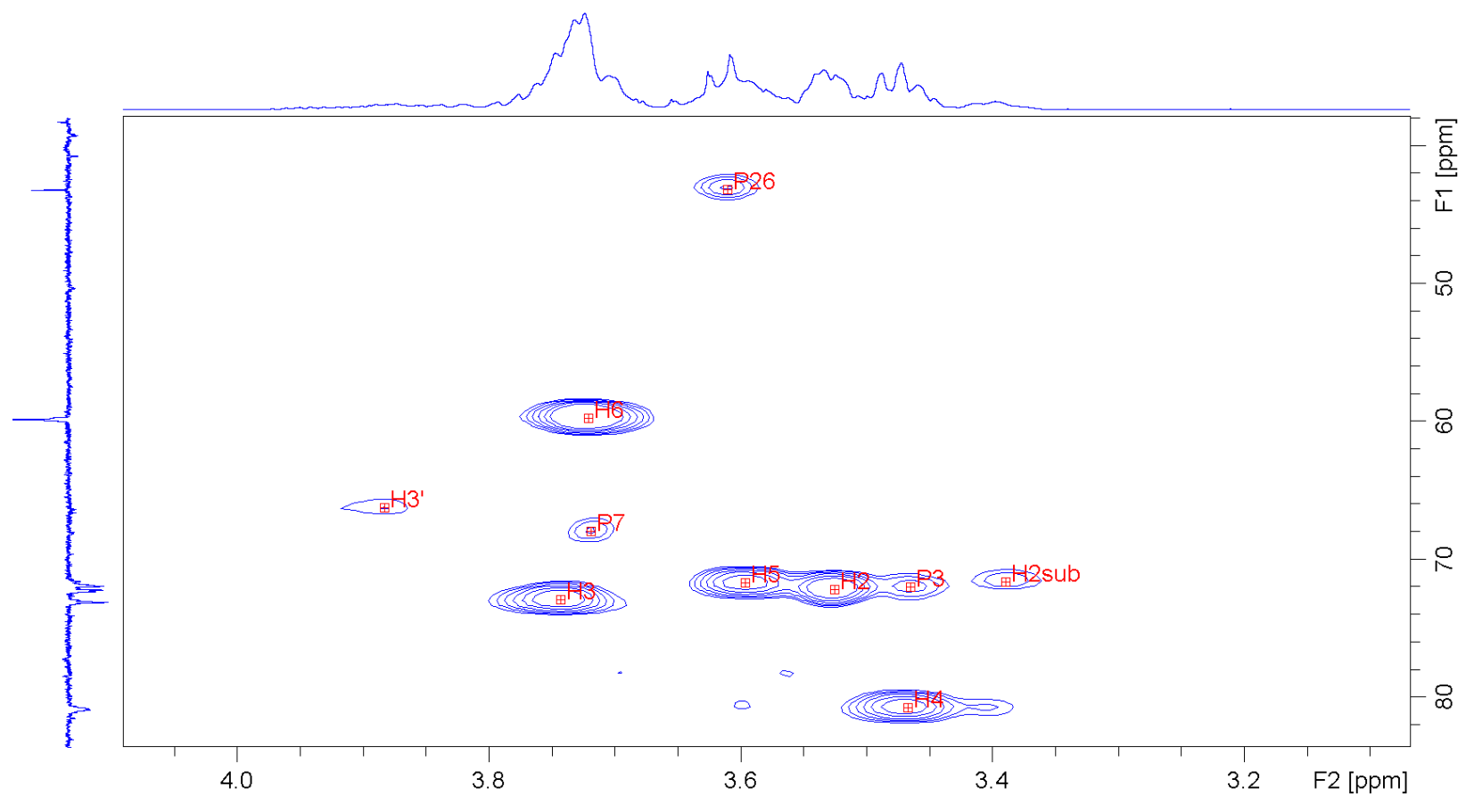

Figure 17S. The CD proton part of the HSQC spectrum of a HP016- $\gamma \mathrm{CD} / \mathrm{GCDC}$ complex.

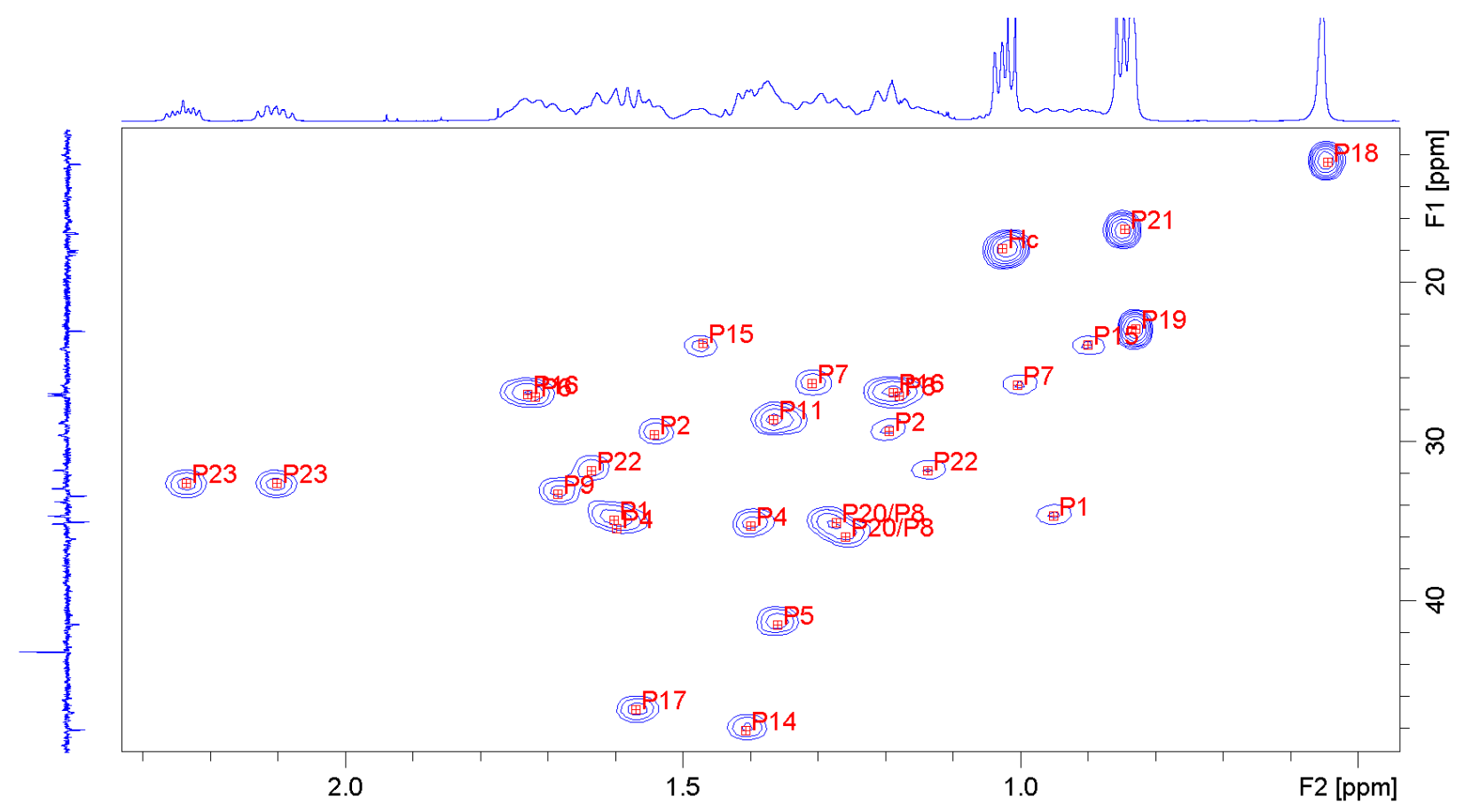

Figure 18S. The BS proton part of the HSQC spectrum of a HP016- $\gamma \mathrm{CD} / \mathrm{GDC}$ complex. 


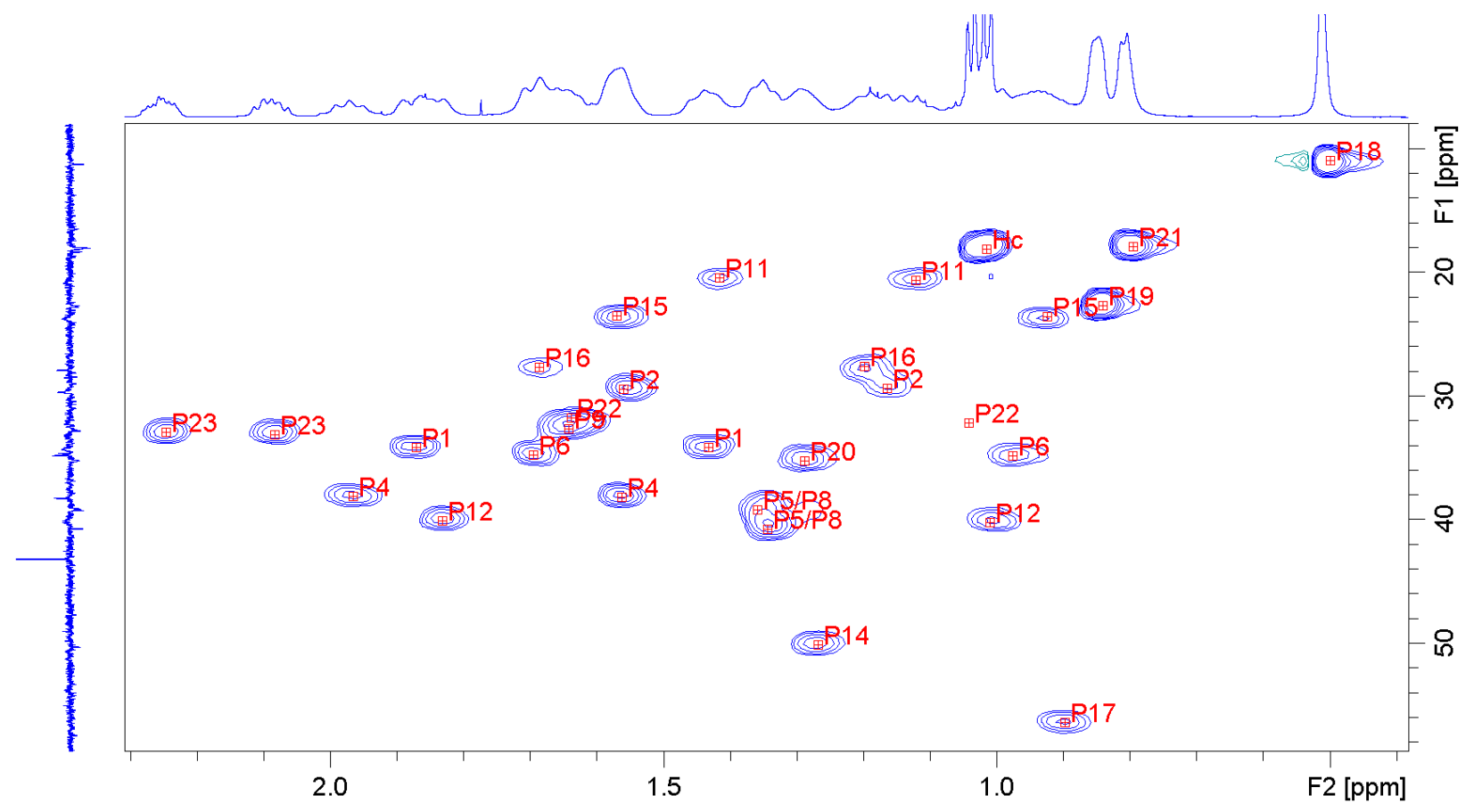

Figure 19S. The BS proton part of the HSQC spectrum of a HP016- $\gamma$ CD/GCDC complex.

\subsection{H ROESY spectra}

With the CD and BS protons of the complexes assigned, the ROESY spectra were analyzed. Examples with various CDs and BSs are given below. Generally, the interactions of the inner CD protons $\mathrm{H} 3$ and $\mathrm{H} 5$ with the BS protons offered the most valuable structural information. For nearly every complex $\mathrm{H} 3$ and H6 had almost identical chemical shifts, and a detailed analysis of the interactions of these protons was further complicated by the overlay of P7 in complexes with GC and GCDC. H5 was always well separated and thus readily analyzed. The analysis demonstrated that Me300- $\gamma$ CD did not form complexes with any of the three BSs.

For all the complexes an interaction at H5, which is located in the middle of the CD cavity, was observed with the methyl groups P18, P19, and P21 and the C- and D-ring protons on the steroid body of the BS, i.e. P11, P12, P15, and P16. H5 also showed weak coupling to some B-ring protons and the sidechain protons at P23. In all complexes with GC, the interaction between H5 and P21 appeared to be much stronger than between H5 and P19. In the situations where H3, located at the wide opening of the CD, could be separated, a cross coupling to many of the same BS protons as for H5 was seen. The B-, C-, and D-ring protons all coupled to $\mathrm{H} 3$. However, $\mathrm{H} 3$ could only be confirmed to interact with one methyl group, namely P19. H6/H3 interacted with P18 and P21 as well, but it seems more likely that H6 was responsible for theses interactions as previously suggested in the literature (Holm et al., 2013). Based on 
these findings it could be concluded that complexes between substituted $\gamma$ CDs and GDC and GCDC had very similar structure, in agreement with previous studies on natural $\gamma \mathrm{CD}$ (Holm et al., 2013). The most likely structure is where the BS has entered the cavity of the CD from the secondary opening and the sidechain protrudes from the primary rim. Complexes with GC have the same overall structure, but GC seems to be positioned slightly more peripherally in the CD cavity when compared to GDC and GCDC, as evidenced by the stronger interaction of H5 with P21 in GC complexes. The relatively large cavity of $\gamma \mathrm{CD}$ seems to include much of the steroid body with the C-ring and D-ring and part of the B-ring included.

When comparing to the much more examined $\beta \mathrm{CD} / \mathrm{BS}$ complexes, it is clear that the larger $\gamma \mathrm{CD}$ was able to include more of the $\mathrm{BS}$ than the typical $\beta \mathrm{CD}$, which resides primarily on the D-ring and sidechain of the BS (Schönbeck et al., 2011; Holm et al., 2009; Holm et al., 2011). The type and amount of substituents on the CDs did not influence the structure of the complexes to a larger extent, if at all. This was in agreement with previous studies reported for substituted $\beta \mathrm{CD} / \mathrm{BS}$ complexes (Schönbeck et al., 2011; Schönbeck et al., 2010). The exception for both $\gamma$ CDs as well as for $\beta C D$ s was the fully methylated Me300- $\gamma$ CD, which did not form stable complexes with any of the BSs, though a very weak complex with GCDC was observed for the Me300- $\beta C D$ (Schönbeck et al., 2011).

GC was seen to be included slightly different positioned in the $\gamma \mathrm{CD}$ cavity than the other BS in accordance with findings reported by Holm et al. (2013), but in contradiction to Cabrer et al. (2003) who both investigated natural $\gamma \mathrm{CD}$ complexes. It's been documented multiple times that the type of BS is important for the structure of complexes with $\beta C D$ (Holm et al., 2009; Tan \& Lindenbaum, 1991; Cabrer et al., 2003). The lesser structural sensibility of $\gamma$ CDs towards BSs, when compared to $\beta C D$ s is most likely a result of the larger hydrophobic cavity, which enables the CDs to accommodate BSs of different structures. 


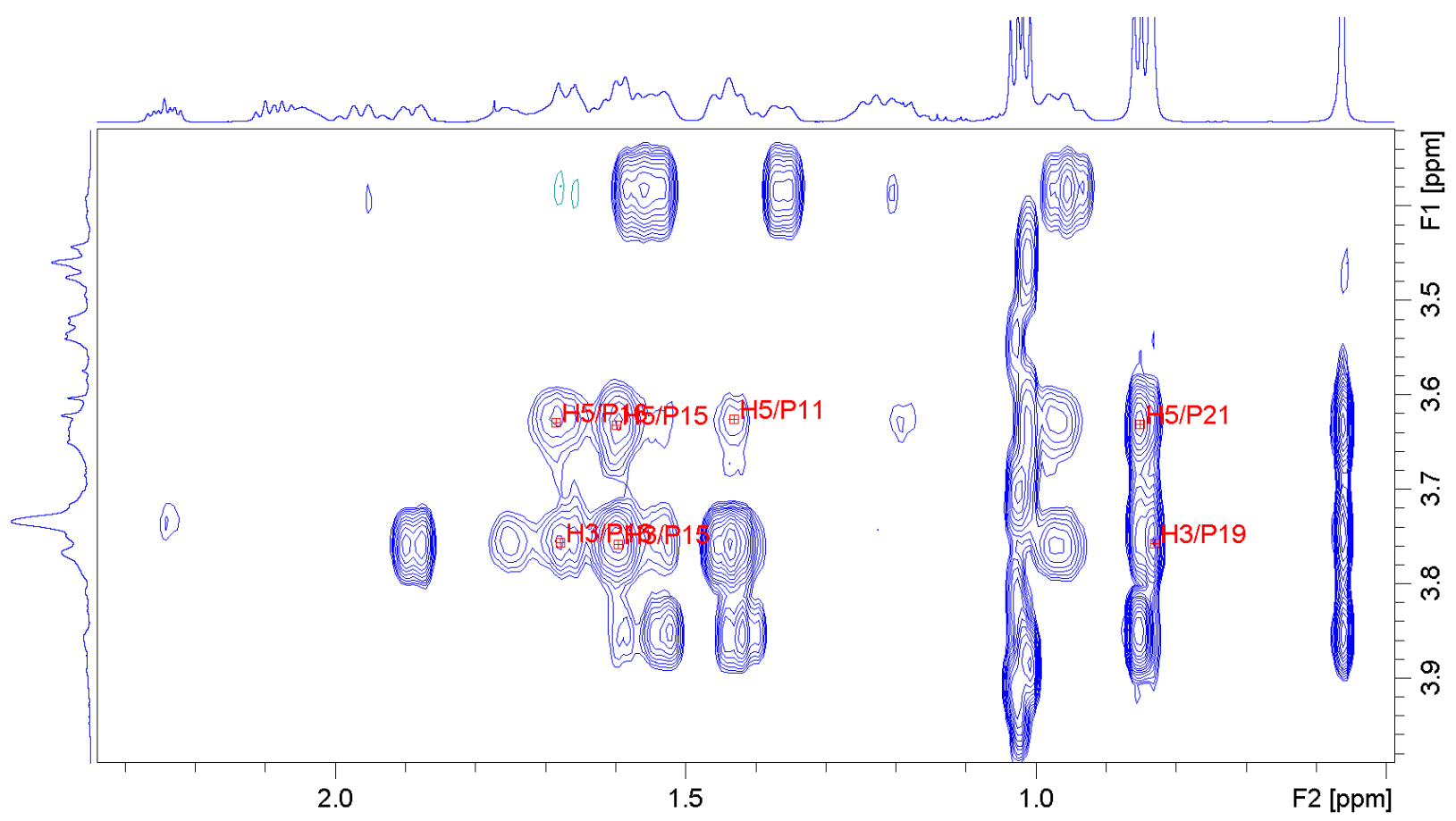

Figure 20S. ROESY spectrum of HP016- $\gamma$ CD/GC complex. A few of the most important peaks are assigned.

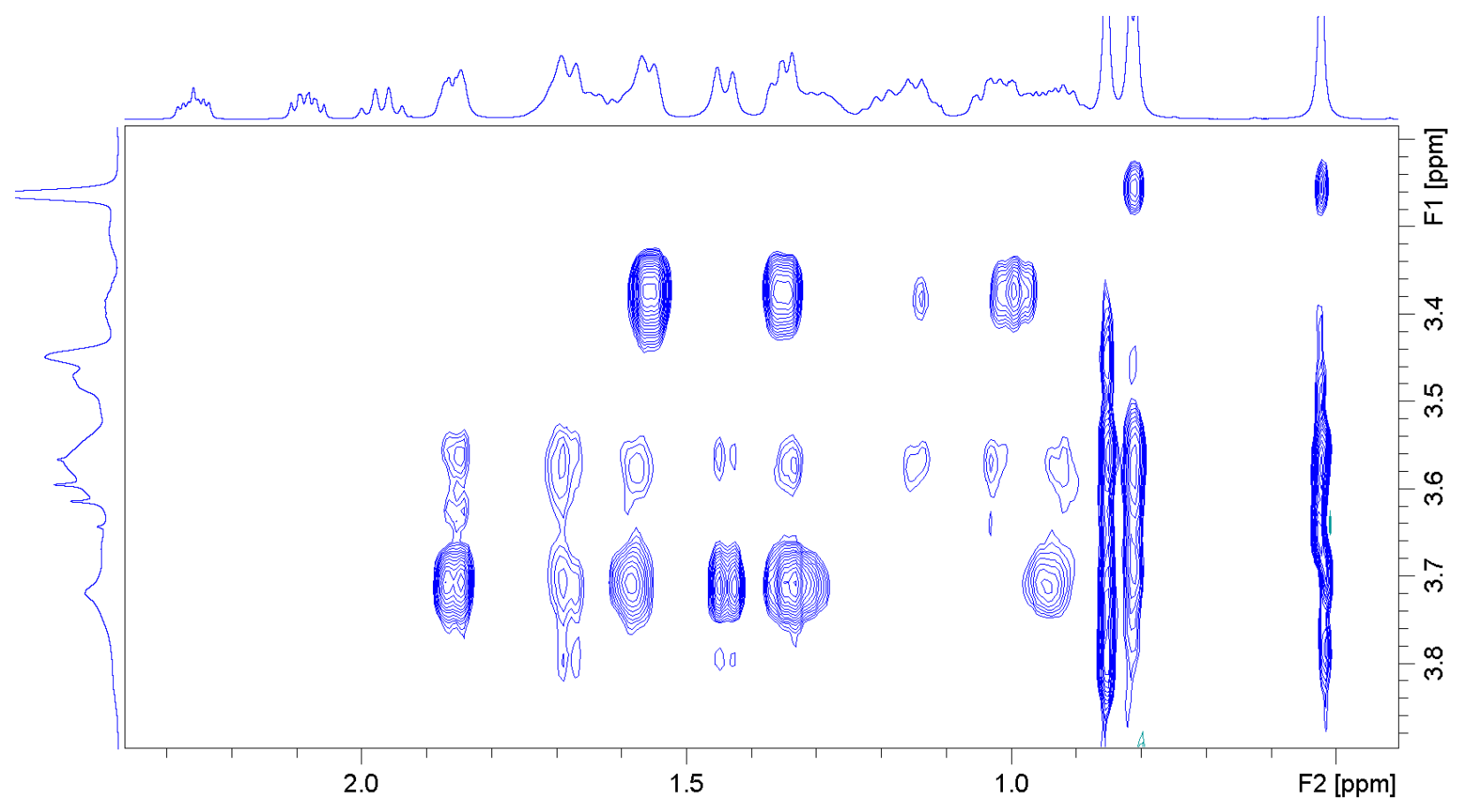

Figure 21S. ROESY spectrum of Me0135- $\gamma \mathrm{CD} / \mathrm{GCDC}$ complex. 


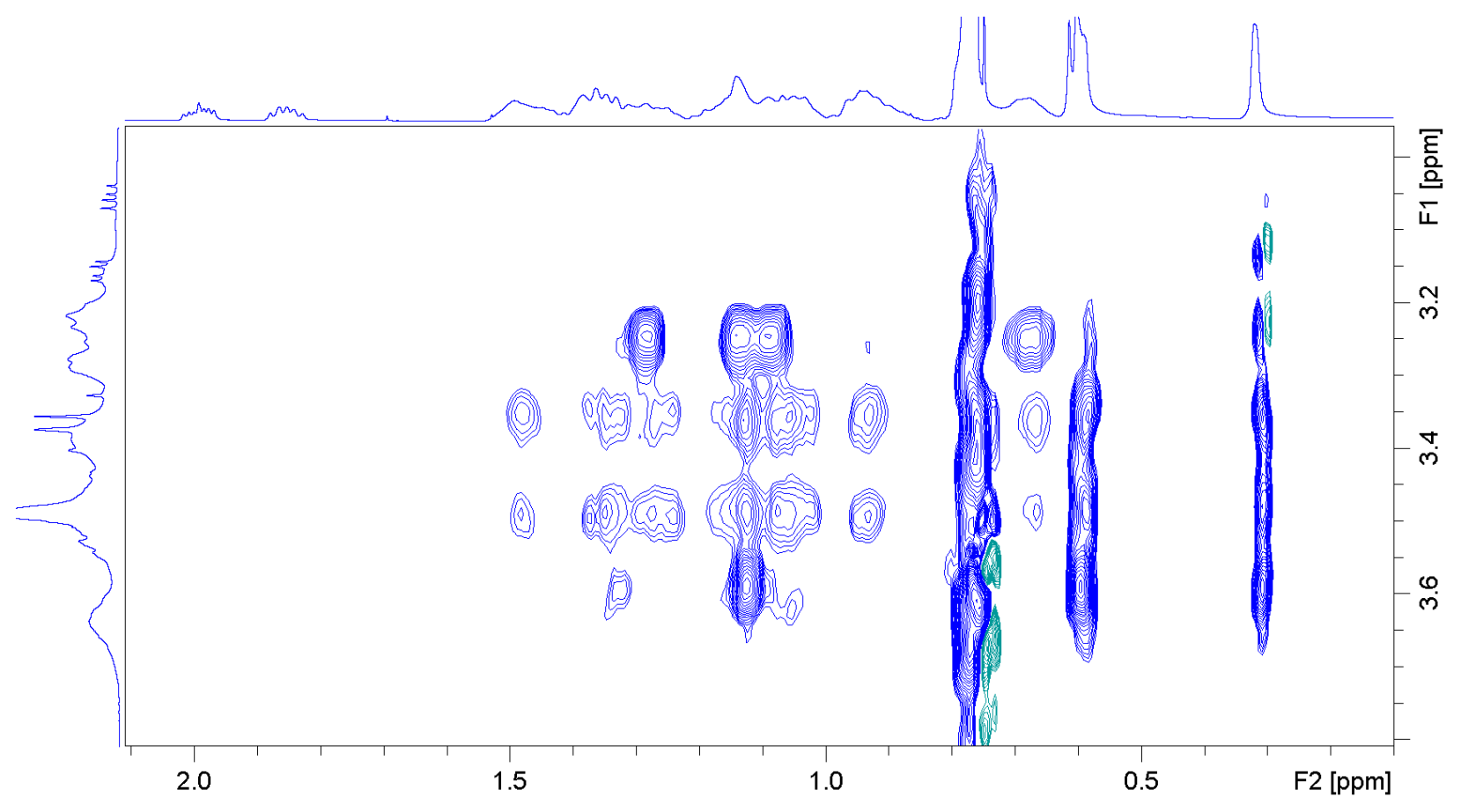

Figure 22S. ROESY spectrum of HP054- $\gamma$ CD/GDC complex.

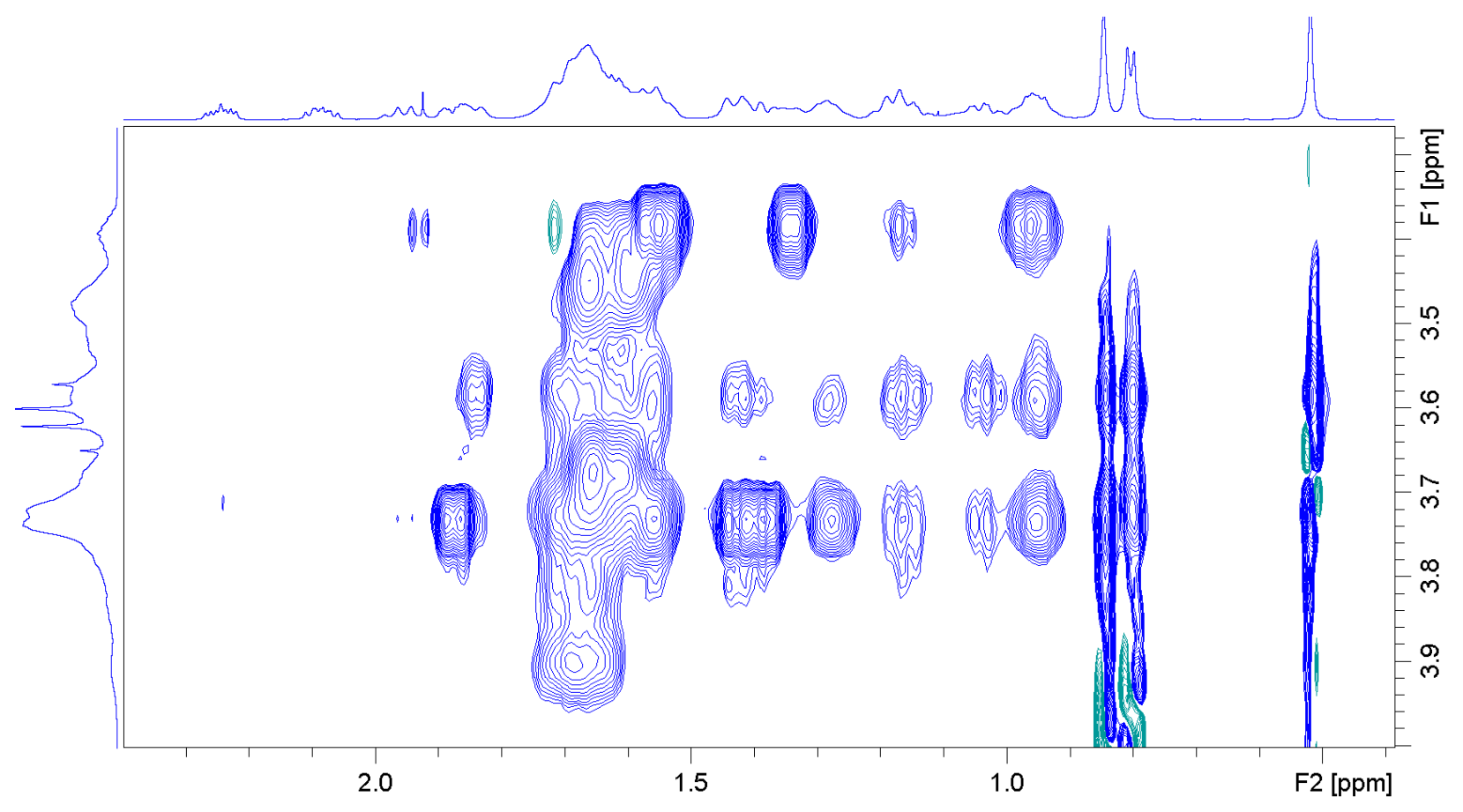

Figure 23S. ROESY spectrum of SBE057- $\gamma \mathrm{CD} / \mathrm{GCDC}$ complex. 


\section{Representative enthalpograms}

Representative examples of the integrated raw data of the ITC measurements are found below. The data is fitted with a one-set-of-sites model and the parameters corresponding to the best fits are shown in text boxes on the enthalpograms.

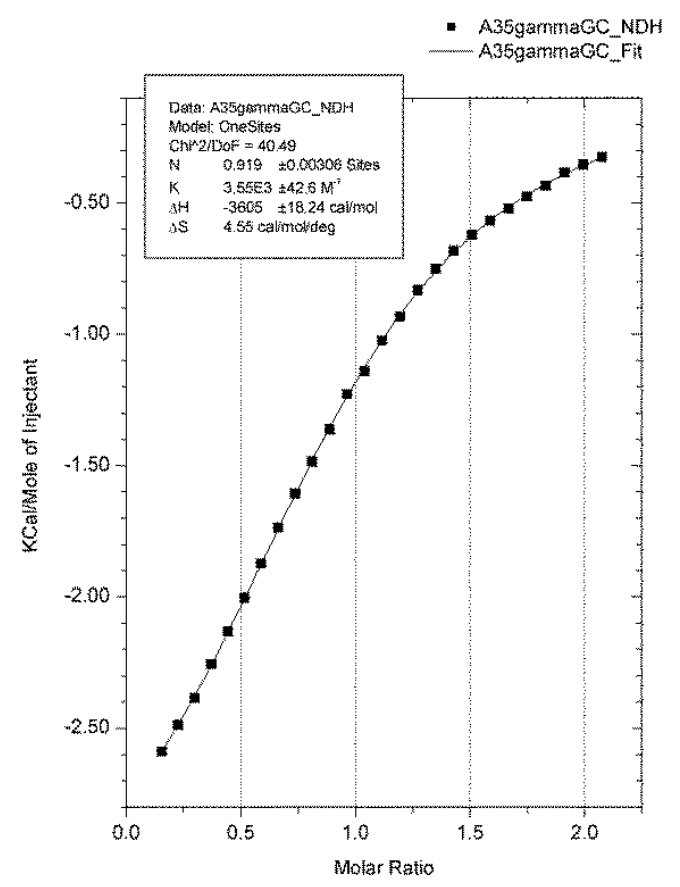

Figure 24S. Enthalpogram of the titration between $\gamma \mathrm{CD}$ and $\mathrm{GC}$ at $35^{\circ} \mathrm{C}$. This is a relatively weakly binding complex.

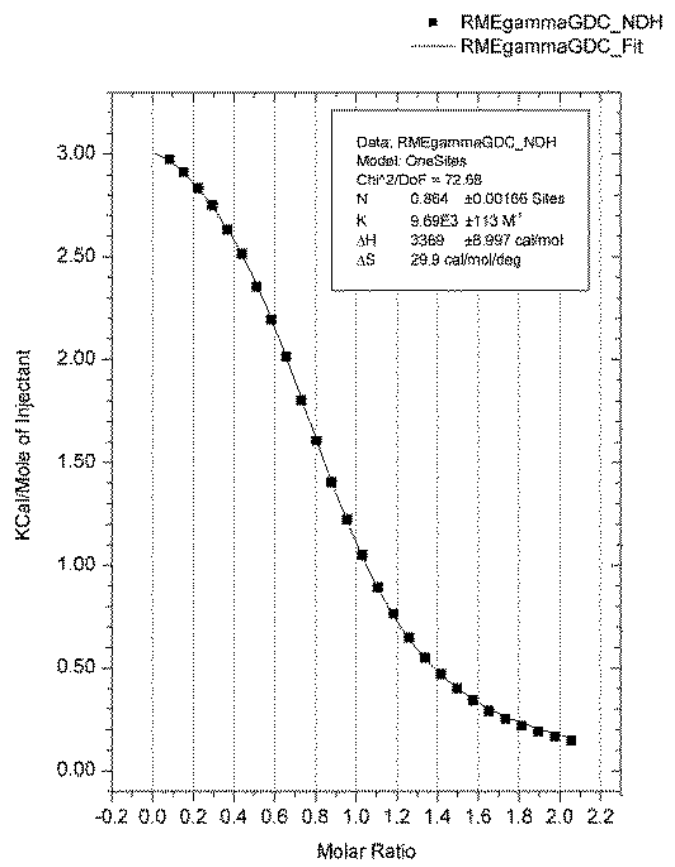

Figure 25S. Enthalpogram of the titration between Me135$\gamma \mathrm{CD}$ and $\mathrm{GDC}$ at $15^{\circ} \mathrm{C}$. At this temperature the reaction is endothermic. 


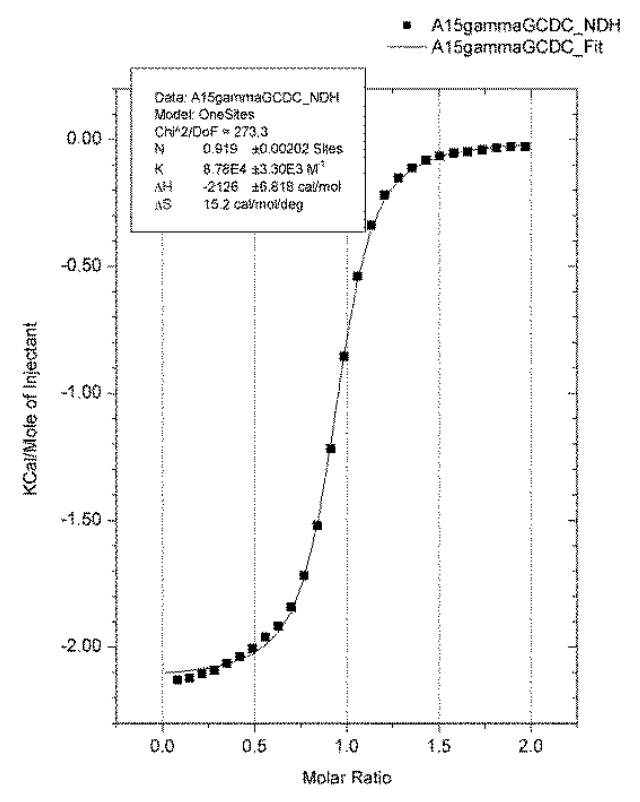

Figure 26S. Enthalpogram of the titration between $\gamma \mathrm{CD}$ and GCDC at $15^{\circ} \mathrm{C}$. This is a relatively strongly binding complex.

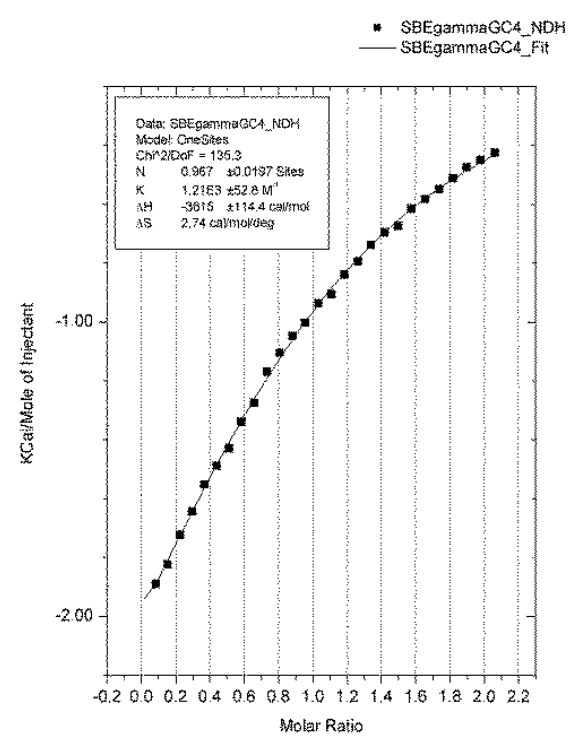

Figure 27S. Enthalpogram of the titration between SBE057- $\gamma \mathrm{CD}$ and $\mathrm{GC}$ at $45^{\circ} \mathrm{C}$. At this temperature the reaction is exothermic.

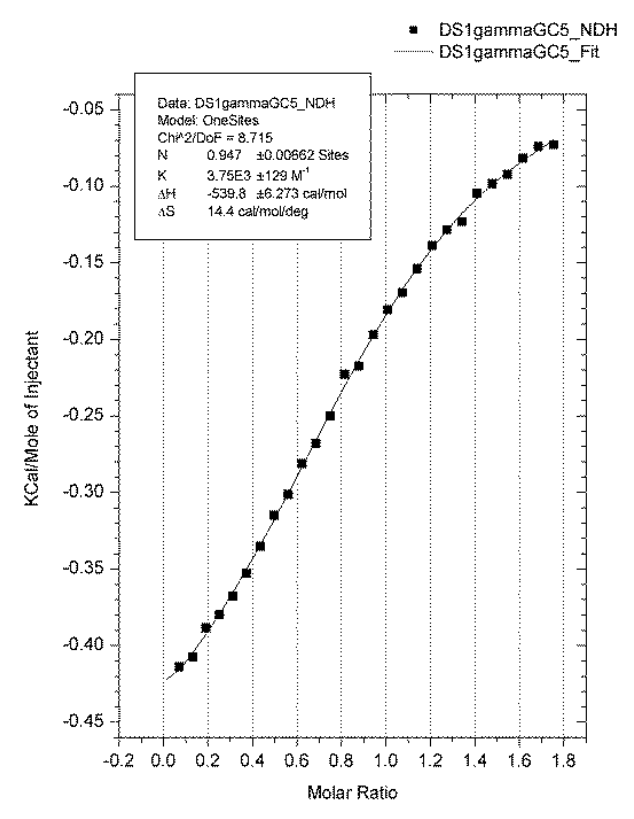

Figure 28S. Enthalpogram of the titration between HP016$\gamma \mathrm{CD}$ and $\mathrm{GC}$ at $5^{\circ} \mathrm{C}$. At this temperature the reaction is exothermic.

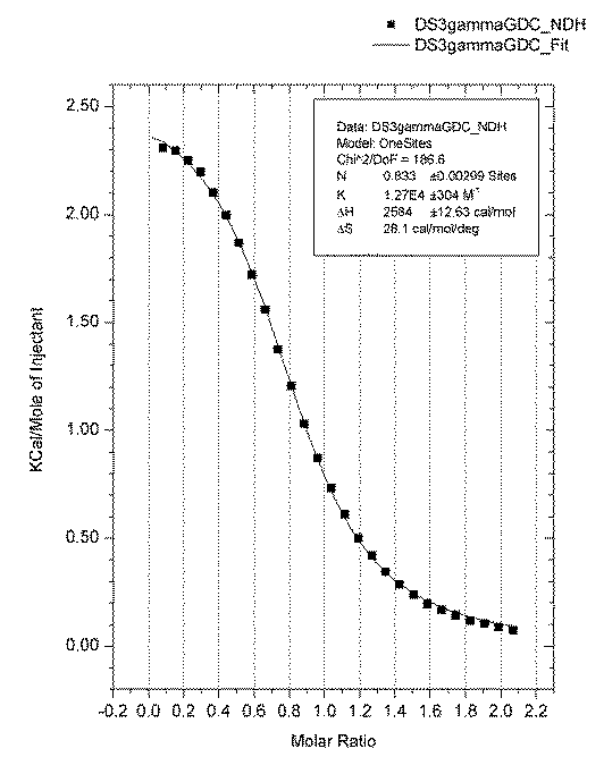

Figure 29S. Enthalpogram of the titration between HP054$\gamma \mathrm{CD}$ and $\mathrm{GDC}$ at $5{ }^{\circ} \mathrm{C}$. At this temperature the reaction is endothermic. 


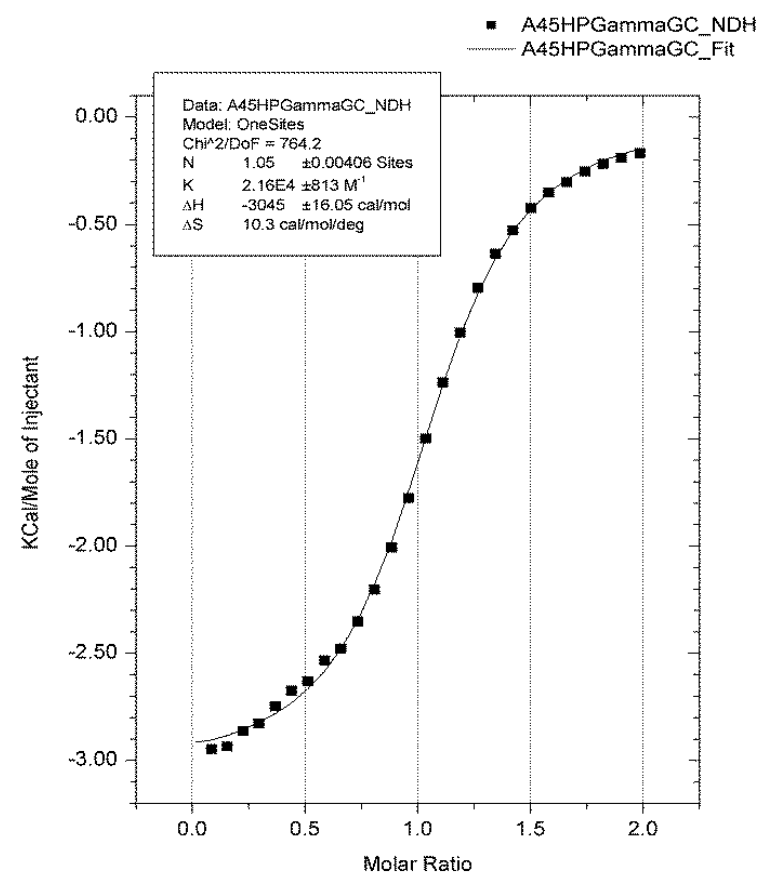

Figure 30S. Enthalpogram of the titration between HP060- $\gamma \mathrm{CD}$ and GCDC at $45^{\circ} \mathrm{C}$. At this temperature the reaction is exothermic, and is an example of a relatively strongly binding complex.

The examples above are all rather well behaved and the fits are able to describe the data well. This was not always the case. Examples of enthalpograms showing data points which for various reasons could not be used to acquire reliable thermodynamic results (and therefore not included in the analysis) are shown below. 


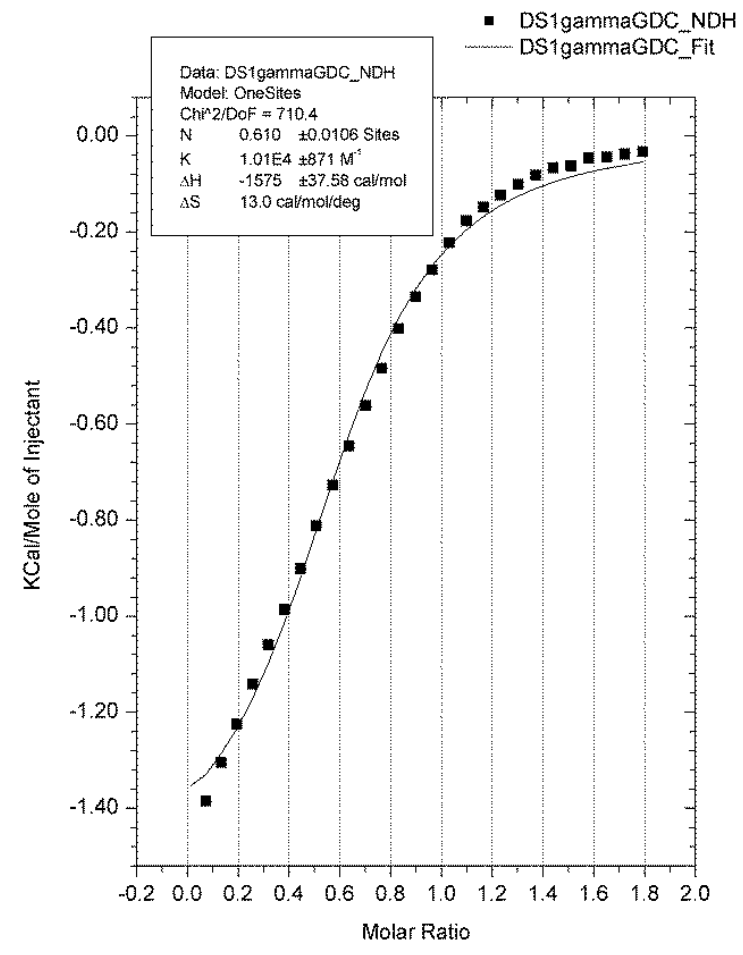

Figure 31S. Enthalpogram of the titration between HP016$\gamma \mathrm{CD}$ and GDC at $25^{\circ} \mathrm{C}$. This fit yields a very low value of $\mathrm{n}$, indicating that the "one set of identical sites" model is insufficient, despite the enthalpogram looking fairly regular.

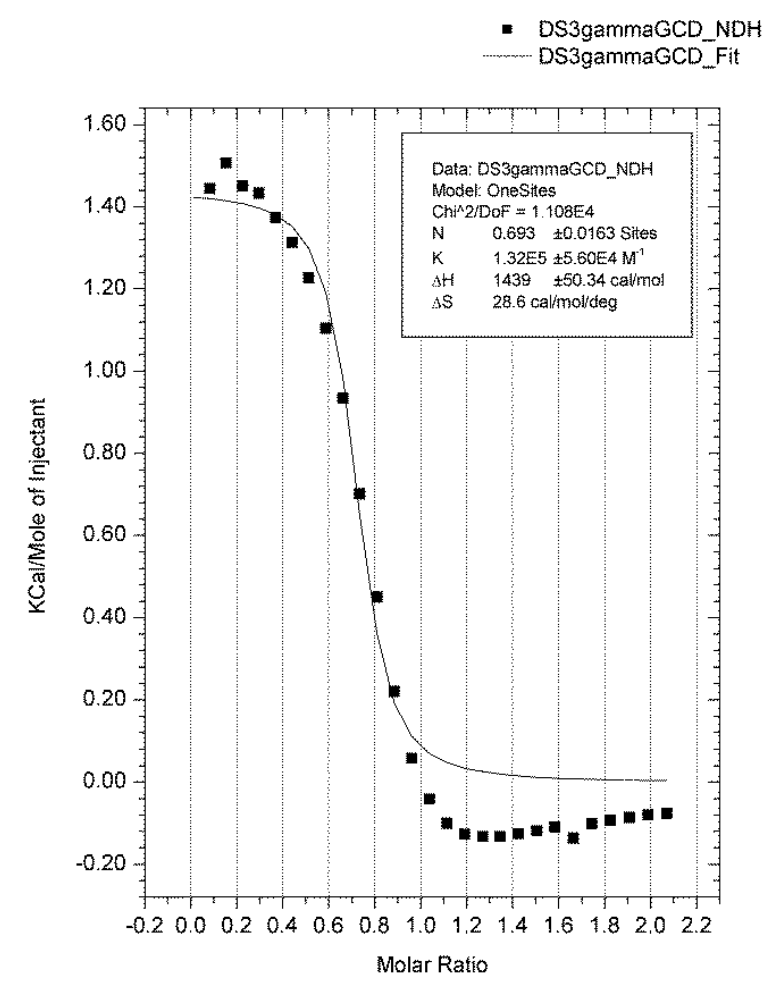

Figure 32S. Enthalpogram of the titration between HP054$\gamma \mathrm{CD}$ and $\mathrm{GCDC}$ at $5{ }^{\circ} \mathrm{C}$. This reaction is seen to show both endothermic and exothermic behavior. This is believed to be due to the contributions from the different CDs in the polydisperse $\mathrm{CD}$ sample, which can be seen when the enthalpy of reactions is low. 


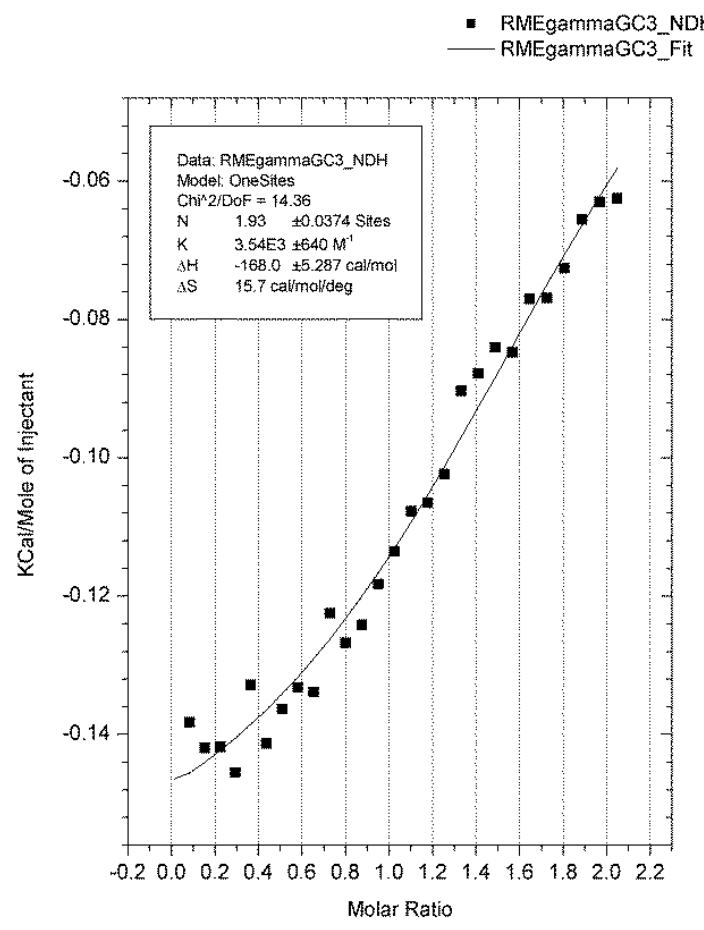

Figure 33S. Enthalpogram of the titration between $\mathrm{Me} 135-\gamma \mathrm{CD}$ and $\mathrm{GC}$ at $35^{\circ} \mathrm{C}$. The enthalpy of reaction is very low, which leads to large uncertainties in the fit and problems with the signal-to-noise ratio.

\section{Stability constants and thermodynamic parameters for the complexation}

Table S1 presents all the obtained stability constants and the thermodynamic parameters obtained for all investigated complexes.

Table S1. Stability constants, $\mathrm{K}$, enthalpy, $\Delta \mathrm{H}^{\circ}$, entropy, $\Delta \mathrm{S}^{\circ}$, and Gibbs free energy, $\Delta \mathrm{G}^{\circ}$ of complexation for all investigated CD-BS complexes. The uncertainties given are the standard error of the non-linear regression obtained by the iterative data fitting procedure.

\begin{tabular}{|c|c|c|c|c|c|c|}
\hline $\begin{array}{c}\text { Temp. } \\
\left({ }^{\circ} \mathrm{C}\right)\end{array}$ & Host & Guest & $K$ & $\Delta H^{\circ}$ & $\Delta S^{\circ}$ & $\Delta G^{\circ}$ \\
& & & $\left(M^{-1}\right)$ & $(\mathrm{kJ} / \mathrm{mol})$ & $(\mathrm{J} / \mathrm{mol} / \mathrm{K})$ & $(\mathrm{kJ} / \mathrm{mol})$ \\
\hline 5 & $\gamma \mathrm{CD}$ & $\mathrm{GC}$ & $6590 \pm 39$ & $-7.4 \pm 0.0$ & 46.5 & -20.3 \\
\hline 15 & & $\mathrm{GC}$ & $5650 \pm 30$ & $-9.6 \pm 0.0$ & 38.6 & -20.7 \\
\hline 25 & & $\mathrm{GC}$ & $4830 \pm 45$ & $-12.9 \pm 0.1$ & 27.4 & -21.0 \\
\hline
\end{tabular}




\begin{tabular}{|c|c|c|c|c|c|c|}
\hline $\begin{array}{l}\text { Temp. } \\
\left({ }^{\circ} \mathrm{C}\right)\end{array}$ & Host & Guest & $\begin{array}{c}K \\
\left(M^{-1}\right)\end{array}$ & $\begin{array}{c}\Delta H^{\circ} \\
(\mathrm{kJ} / \mathrm{mol})\end{array}$ & $\begin{array}{c}\Delta S^{\circ} \\
(\mathrm{J} / \mathrm{mol} / \mathrm{K})\end{array}$ & $\begin{array}{c}\Delta G^{\circ} \\
(\mathrm{kJ} / \mathrm{mol})\end{array}$ \\
\hline 35 & & GC & $3550 \pm 43$ & $-15.1 \pm 0.1$ & 19.0 & -20.9 \\
\hline 45 & & GC & $3510 \pm 41$ & $-20 \pm 0.1$ & 5.0 & -21.6 \\
\hline 55 & & GC & $2100 \pm 36$ & $-20.1 \pm 0.2$ & 2.3 & -20.9 \\
\hline 5 & & GCDC & $82000 \pm 5780$ & $-4.5 \pm 0.0$ & 78.3 & -26.2 \\
\hline 15 & & GCDC & $87800 \pm 3300$ & $-8.9 \pm 0.0$ & 63.6 & -27.3 \\
\hline 25 & & GCDC & $88000 \pm 2360$ & $-13.7 \pm 0.0$ & 49.0 & -28.2 \\
\hline 35 & & GCDC & $65200 \pm 1430$ & $-16.5 \pm 0.0$ & 38.8 & -28.4 \\
\hline 45 & & GCDC & $56200 \pm 861$ & $-21.2 \pm 0.0$ & 24.4 & -28.9 \\
\hline 55 & & GCDC & $36600 \pm 950$ & $-22.4 \pm 0.1$ & 19.1 & -28.7 \\
\hline 5 & & GDC & - & - & - & - \\
\hline 15 & & GDC & - & - & - & - \\
\hline 25 & & GDC & $9930 \pm 826$ & $-9.2 \pm 0.2$ & 46.0 & -22.8 \\
\hline 35 & & GDC & $10800 \pm 650$ & $-12.1 \pm 0.2$ & 37.8 & -23.8 \\
\hline 45 & & GDC & $11300 \pm 472$ & $-15.4 \pm 0.1$ & 29.3 & -24.7 \\
\hline 55 & & GDC & $12700 \pm 393$ & $-21.2 \pm 0.1$ & 14.0 & -25.8 \\
\hline 5 & SBE057- $\gamma$ CD & GC & - & - & - & - \\
\hline 15 & & GC & - & - & - & - \\
\hline 25 & & GC & - & - & - & - \\
\hline 35 & & GC & $1490 \pm 63$ & $-8.9 \pm 0.2$ & 32.0 & -18.7 \\
\hline 45 & & GC & $1210 \pm 53$ & $-15.1 \pm 0.5$ & 11.5 & $\begin{array}{l}-18.8 \\
\end{array}$ \\
\hline
\end{tabular}




\begin{tabular}{|c|c|c|c|c|c|c|}
\hline $\begin{array}{l}\text { Temp. } \\
\left({ }^{\circ} \mathrm{C}\right)\end{array}$ & Host & Guest & $\begin{array}{c}K \\
\left(M^{-1}\right)\end{array}$ & $\begin{array}{c}\Delta H^{\circ} \\
(\mathrm{kJ} / \mathrm{mol})\end{array}$ & $\begin{array}{c}\Delta S^{\circ} \\
(\mathrm{J} / \mathrm{mol} / \mathrm{K})\end{array}$ & $\begin{array}{c}\Delta G^{\circ} \\
(\mathrm{kJ} / \mathrm{mol})\end{array}$ \\
\hline 55 & & GC & $1010 \pm 68$ & $-19.9 \pm 1.3$ & -3.1 & $\begin{array}{l}-18.9 \\
\end{array}$ \\
\hline 5 & & GCDC & - & - & - & - \\
\hline 15 & & GCDC & - & - & - & - \\
\hline 25 & & GCDC & $19900 \pm 1360$ & $-7.4 \pm 0.1$ & 57.3 & -24.5 \\
\hline 35 & & GCDC & $25400 \pm 807$ & $-13.2 \pm 0.1$ & 41.4 & -26.0 \\
\hline 45 & & GCDC & $25500 \pm 528$ & $-19.0 \pm 0.1$ & 24.7 & -26.8 \\
\hline 55 & & GCDC & $23000 \pm 742$ & $-24.2 \pm 0.1$ & 9.7 & -27.4 \\
\hline 5 & & GDC & $12100 \pm 378$ & $9.4 \pm 0.1$ & 111.8 & -21.7 \\
\hline 15 & & GDC & $23700 \pm 1800$ & $3.7 \pm 0.0$ & 96.3 & -24.1 \\
\hline 25 & & GDC & - & - & - & \\
\hline 35 & & GDC & $6340 \pm 217$ & $-8.2 \pm 0.1$ & 46.0 & -22.4 \\
\hline 45 & & GDC & $7250 \pm 144$ & $-13.5 \pm 0.1$ & 31.5 & -23.5 \\
\hline 55 & & GDC & $6100 \pm 149$ & $-19.3 \pm 0.1$ & 13.8 & -23.8 \\
\hline 5 & $\mathrm{Me} 135-\gamma \mathrm{CD}$ & GC & $1580 \pm 30$ & $12.4 \pm 0.2$ & 105.5 & -17.0 \\
\hline 15 & & GC & $2070 \pm 40$ & $8.0 \pm 0.1$ & 91.2 & $\begin{array}{l}-18.3 \\
\end{array}$ \\
\hline 25 & & GC & - & - & - & - \\
\hline 35 & & GC & - & - & - & - \\
\hline 45 & & GC & $1360 \pm 106$ & $-6.7 \pm 0.4$ & 39.09257 & -19.1 \\
\hline 55 & & GC & $1580 \pm 161$ & $-10.7 \pm 0.7$ & 28.54511 & -20.1 \\
\hline 5 & & GCDC & - & - & - & - \\
\hline
\end{tabular}




\begin{tabular}{|c|c|c|c|c|c|c|}
\hline $\begin{array}{l}\text { Temp. } \\
\left({ }^{\circ} \mathrm{C}\right)\end{array}$ & Host & Guest & $\begin{array}{c}K \\
\left(M^{-1}\right)\end{array}$ & $\begin{array}{c}\Delta H^{\circ} \\
(\mathrm{kJ} / \mathrm{mol})\end{array}$ & $\begin{array}{c}\Delta S^{\circ} \\
(\mathrm{J} / \mathrm{mol} / \mathrm{K})\end{array}$ & $\begin{array}{c}\Delta G^{\circ} \\
(\mathrm{kJ} / \mathrm{mol})\end{array}$ \\
\hline 15 & & GCDC & - & - & - & - \\
\hline 25 & & GCDC & - & - & - & - \\
\hline 35 & & GCDC & $13300 \pm 819$ & $-4.5 \pm 0.1$ & 64.5 & -24.3 \\
\hline 45 & & GCDC & $25700 \pm 941$ & $-10.9 \pm 0.1$ & 50.2 & -26.9 \\
\hline 55 & & GCDC & $26500 \pm 831$ & $-17.5 \pm 0.1$ & 31.3 & -27.8 \\
\hline 5 & & GDC & $6700 \pm 92$ & $21.0 \pm 0.1$ & 149.0 & -20.4 \\
\hline 15 & & GDC & $9690 \pm 113$ & $14.1 \pm 0.0$ & 125.1 & -22.0 \\
\hline 25 & & GDC & $15600 \pm 779$ & $7.4 \pm 0.1$ & 105.1 & -23.9 \\
\hline 35 & & GDC & - & - & - & - \\
\hline 45 & & GDC & $7890 \pm 409$ & $-12.0 \pm 0.2$ & 38.1 & -24.5 \\
\hline 55 & & GDC & - & - & - & - \\
\hline 5 & HP016- $\gamma \mathrm{CD}$ & GC & $3750 \pm 129$ & $-2.3 \pm 0.0$ & 60.3 & $\begin{array}{l}-19.0 \\
\end{array}$ \\
\hline 15 & & $\mathrm{GC}$ & $4230 \pm 71$ & $-5.5 \pm 0.0$ & 50.6 & -20.0 \\
\hline 25 & & $\mathrm{GC}$ & $3960 \pm 72$ & $-8.9 \pm 0.1$ & 39.1 & -20.5 \\
\hline 35 & & GC & $3300 \pm 28$ & $-12.8 \pm 0.0$ & 26.0 & -20.8 \\
\hline 45 & & GC & $2990 \pm 117$ & $-15.9 \pm 0.3$ & 16.6 & -21.2 \\
\hline 55 & & GC & $2580 \pm 177$ & $-19.2 \pm 0.6$ & 6.9 & -21.4 \\
\hline 5 & & GCDC & $25900 \pm 2490$ & $-1.2 \pm 0.0$ & 80.4 & -23.5 \\
\hline 15 & & GCDC & $71200 \pm 2480$ & $-5.9 \pm 0.0$ & 72.8 & -26.8 \\
\hline 25 & & GCDC & $71700 \pm 2150$ & $-10.6 \pm 0.0$ & 57.8 & -27.7 \\
\hline
\end{tabular}




\begin{tabular}{|c|c|c|c|c|c|c|}
\hline $\begin{array}{l}\text { Temp. } \\
\left({ }^{\circ} \mathrm{C}\right)\end{array}$ & Host & Guest & $\begin{array}{c}K \\
\left(M^{-1}\right)\end{array}$ & $\begin{array}{c}\Delta H^{\circ} \\
(\mathrm{kJ} / \mathrm{mol})\end{array}$ & $\begin{array}{c}\Delta S^{\circ} \\
(\mathrm{J} / \mathrm{mol} / \mathrm{K})\end{array}$ & $\begin{array}{c}\Delta G^{\circ} \\
(\mathrm{kJ} / \mathrm{mol})\end{array}$ \\
\hline 35 & & GCDC & $65300 \pm 1230$ & $-15.2 \pm 0.0$ & 42.7 & -28.4 \\
\hline 45 & & GCDC & $50800 \pm 1200$ & $-20.0 \pm 0.1$ & 27.2 & -28.7 \\
\hline 55 & & GCDC & $39000 \pm 1230$ & $-24.3 \pm 0.1$ & 14.1 & -28.8 \\
\hline 5 & & GDC & - & - & - & - \\
\hline 15 & & GDC & - & - & - & - \\
\hline 25 & & GDC & - & - & - & - \\
\hline 35 & & GDC & - & - & - & - \\
\hline 45 & & GDC & $12900 \pm 486$ & $-14.9 \pm 0.1$ & 31.9 & -25.0 \\
\hline 55 & & GDC & $12400 \pm 542$ & $-19.2 \pm 0.2$ & 19.8 & -25.7 \\
\hline 5 & HP054- $\gamma \mathrm{CD}$ & GC & - & - & - & - \\
\hline 15 & & GC & - & - & - & - \\
\hline 25 & & GC & - & - & - & - \\
\hline 35 & & GC & $2270 \pm 195$ & $-6.4 \pm 0.3$ & 43.5 & -19.8 \\
\hline 45 & & $\mathrm{GC}$ & $2020 \pm 79$ & $-10.9 \pm 0.2$ & 29.0 & -20.1 \\
\hline 55 & & GC & $2210 \pm 301$ & $-12.5 \pm 0.7$ & 26.0 & -21.0 \\
\hline 5 & & GCDC & - & - & - & - \\
\hline 15 & & GCDC & - & - & - & - \\
\hline 25 & & GCDC & $20700 \pm 2330$ & $-4.9 \pm 0.1$ & 66.5 & -24.6 \\
\hline 35 & & GCDC & $33800 \pm 2060$ & $-10.1 \pm 0.1$ & 54.0 & -26.7 \\
\hline 45 & & GCDC & $32400 \pm 666$ & $-16.0 \pm 0.0$ & 36.1 & -27.5 \\
\hline
\end{tabular}




\begin{tabular}{|c|c|c|c|c|c|c|}
\hline $\begin{array}{l}\text { Temp. } \\
\left({ }^{\circ} \mathrm{C}\right)\end{array}$ & Host & Guest & $\begin{array}{c}K \\
\left(M^{-1}\right)\end{array}$ & $\begin{array}{c}\Delta H^{\circ} \\
(\mathrm{kJ} / \mathrm{mol})\end{array}$ & $\begin{array}{c}\Delta S^{\circ} \\
(\mathrm{J} / \mathrm{mol} / \mathrm{K})\end{array}$ & $\begin{array}{c}\Delta G^{\circ} \\
(\mathrm{kJ} / \mathrm{mol})\end{array}$ \\
\hline 55 & & GCDC & $28700 \pm 1140$ & $-21.4 \pm 0.1$ & 20.3 & -28.0 \\
\hline 5 & & GDC & $12700 \pm 304$ & $10.8 \pm 0.1$ & 117.6 & -21.9 \\
\hline 15 & & GDC & $23300 \pm 1650$ & $5.3 \pm 0.1$ & 102.1 & -24.1 \\
\hline 25 & & GDC & - & - & - & - \\
\hline 35 & & GDC & - & - & - & - \\
\hline 45 & & GDC & $8300 \pm 162$ & $-10.6 \pm 0.1$ & 41.9 & -23.9 \\
\hline 55 & & GDC & $7750 \pm 188$ & $-16.4 \pm 0.1$ & 24.6 & -24.4 \\
\hline 5 & HP060- $\gamma \mathrm{CD}$ & GC & $2570 \pm 65$ & $4.9 \pm 0.1$ & 82.9 & -18.2 \\
\hline 15 & & GC & - & - & - & - \\
\hline 25 & & GC & - & - & - & - \\
\hline 35 & & GC & $1370 \pm 77$ & $-5.9 \pm 0.2$ & 40.9 & -18.5 \\
\hline 45 & & GC & $1380 \pm 42$ & $-9.7 \pm 0.2$ & 29.5 & $\begin{array}{l}-19.1 \\
\end{array}$ \\
\hline 55 & & GC & $1040 \pm 90$ & $-12.9 \pm 0.9$ & 18.4 & -19.0 \\
\hline 5 & & GCDC & - & - & - & - \\
\hline 15 & & GCDC & - & - & - & - \\
\hline 25 & & GCDC & - & - & - & - \\
\hline 35 & & GCDC & $21000 \pm 1170$ & $-8.6 \pm 0.1$ & 54.8 & -25.5 \\
\hline 45 & & GCDC & $21600 \pm 813$ & $-12.7 \pm 0.1$ & 43.1 & -26.4 \\
\hline 55 & & GCDC & $25200 \pm 655$ & $-19.7 \pm 0.1$ & 24.2 & -27.7 \\
\hline 5 & & GDC & $6770 \pm 201$ & $12.7 \pm 0.1$ & 119.3 & $\begin{array}{l}-20.4 \\
\end{array}$ \\
\hline
\end{tabular}




\begin{tabular}{|c|c|c|c|c|c|c|}
\hline $\begin{array}{l}\text { Temp. } \\
\left({ }^{\circ} \mathrm{C}\right)\end{array}$ & Host & Guest & $\begin{array}{c}K \\
\left(M^{-1}\right)\end{array}$ & $\begin{array}{c}\Delta H^{\circ} \\
(\mathrm{kJ} / \mathrm{mol})\end{array}$ & $\begin{array}{c}\Delta S^{\circ} \\
(\mathrm{J} / \mathrm{mol} / \mathrm{K})\end{array}$ & $\begin{array}{c}\Delta G^{\circ} \\
(\mathrm{kJ} / \mathrm{mol})\end{array}$ \\
\hline 15 & & GDC & $11300 \pm 260$ & $7.2 \pm 0.0$ & 102.5 & -22.4 \\
\hline 25 & & GDC & - & - & - & - \\
\hline 35 & & GDC & - & - & - & - \\
\hline 45 & & GDC & $5550 \pm 219$ & $-7.8 \pm 0.1$ & 47.3 & -22.8 \\
\hline 55 & & GDC & $7610 \pm 348$ & $-15.1 \pm 0.2$ & 28.3 & -24.4 \\
\hline
\end{tabular}




\section{Van't Hoff plots}

Van't Hoff plots for all CDs are found below. The van't Hoff plots are used to predict K at temperatures where it was not measured by using known values of $\Delta \mathrm{H}^{\circ}$ and $\mathrm{K}$ at a reference temperature (usually 45 ${ }^{\circ} \mathrm{C}$ in the present study) as well as $\Delta \mathrm{C}_{\mathrm{p}}{ }^{\circ}$. The equation used is:

$$
\ln (K(T))=\frac{\Delta H_{R}^{\circ}-T_{R} \Delta C_{P}^{\circ}}{R}\left[\frac{1}{T_{R}}-\frac{1}{T}\right]+\frac{\Delta C_{P}^{\circ}}{R} \ln \left(\frac{T}{T_{R}}\right)+\ln \left(K_{R}\right)
$$

In this case the subscript on $\mathrm{T}_{\mathrm{R}}$ and $\Delta \mathrm{H}_{\mathrm{R}}{ }^{\circ}$ means reference temperature. The reference temperature can be seen in the plots as the point through which the curve exactly goes. In theory all measured data points should be on the curve achieved when plotting the equation. In this way the van't Hoff plot can be used to validate the empirical data or to find if there are huge differences between theory and experiential data indicating some sort of experimental problem or thermodynamic irregularity.

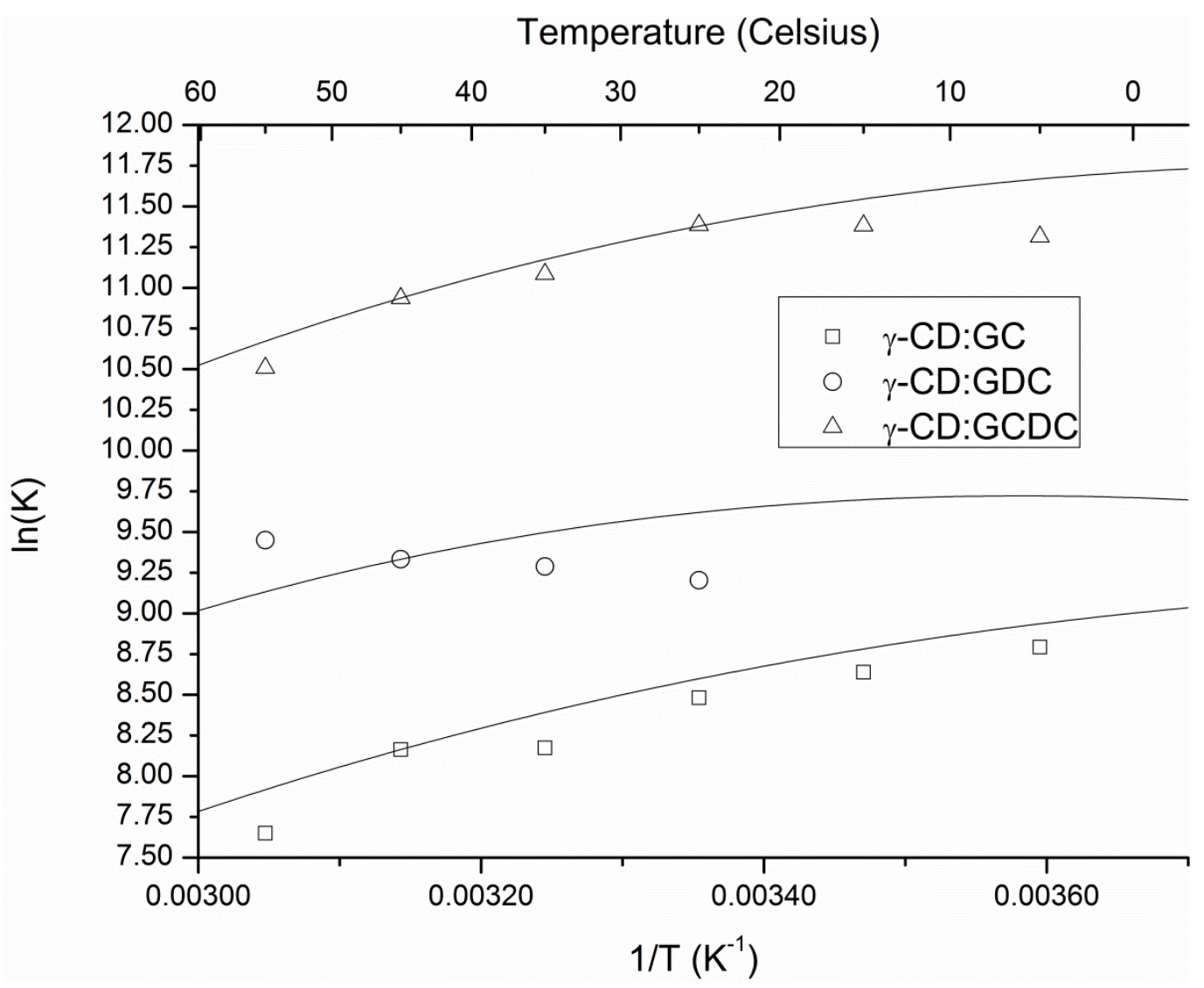

Figure 34S. Van't Hoff plot of the $\gamma \mathrm{CD} / \mathrm{BS}$ complexes. The data points are close to theoretical values for at least the GC and GCDC complexes. 


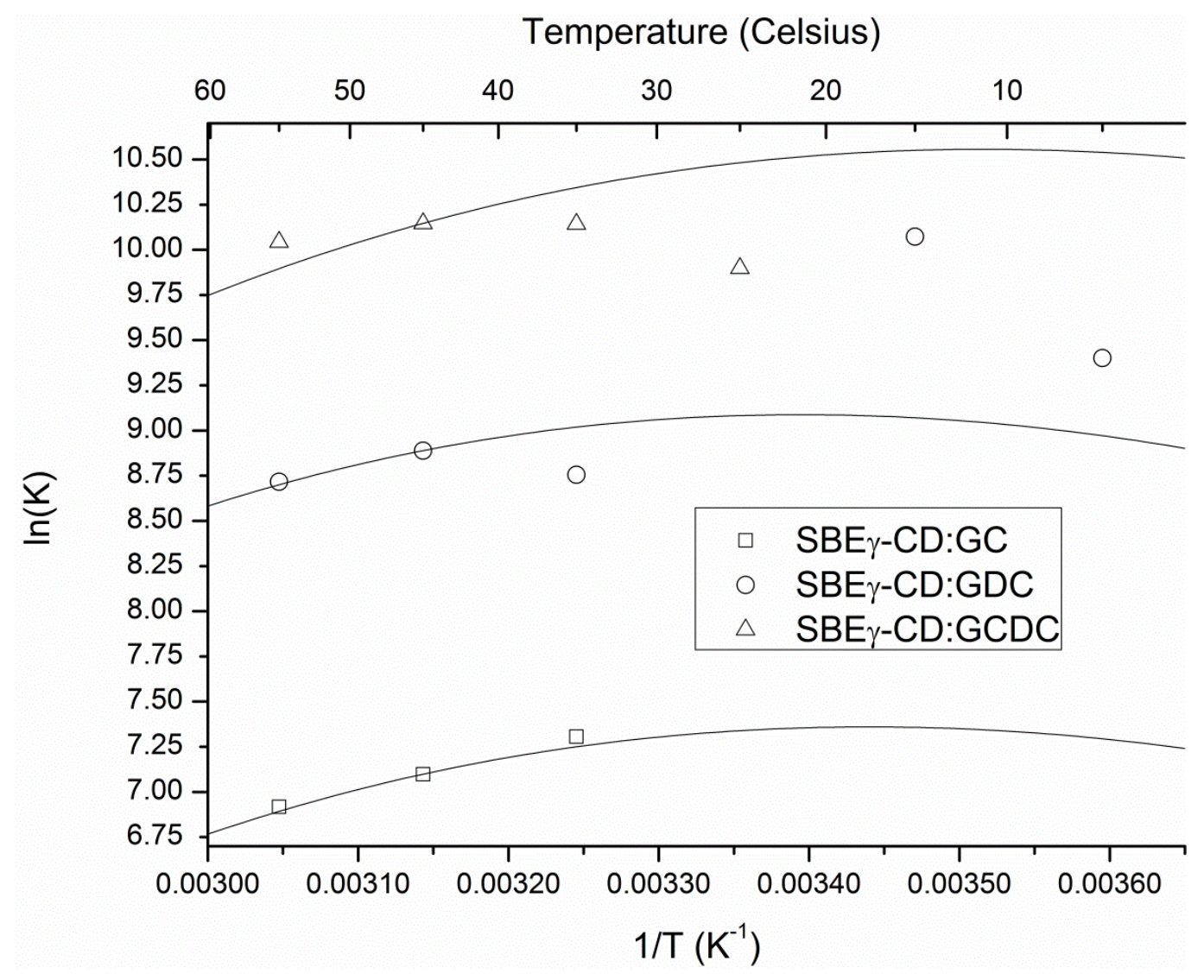

Figure 35S. Van't Hoff plot of the SBE057- $\gamma$ CD/BS complexes. The data points are close to theoretical values for the GCDC complexes. A jump between data points of high- and low temperature GDC not predicted by the van't Hoff plot is seen. 


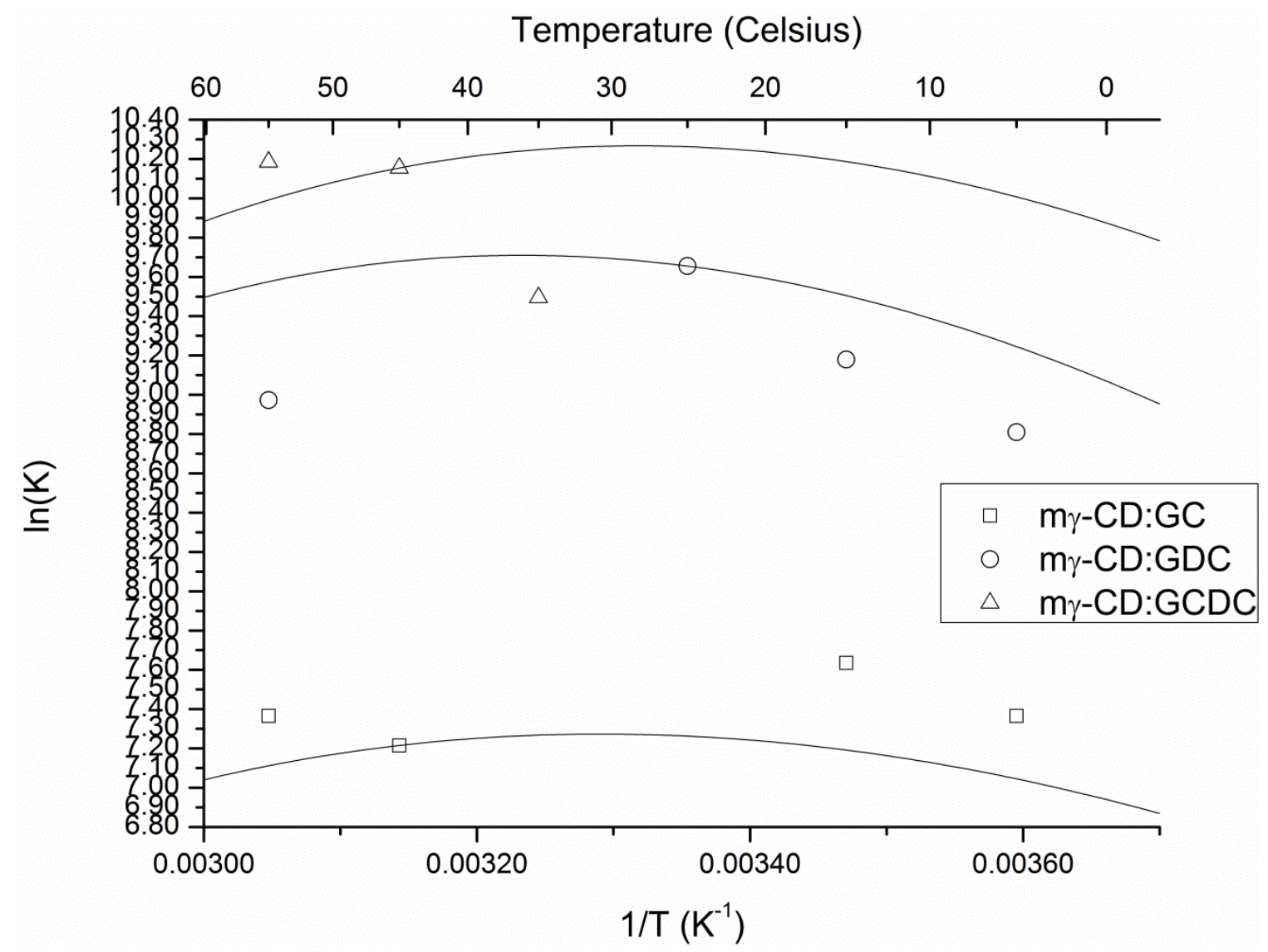

Figure 36S. Van't Hoff plot of the Me135- $\gamma \mathrm{CD} / \mathrm{BS}$ complexes. The data points are not predicted very well by the plot. A lot of data points are missing making it difficult to draw conclusions based on the plot. 


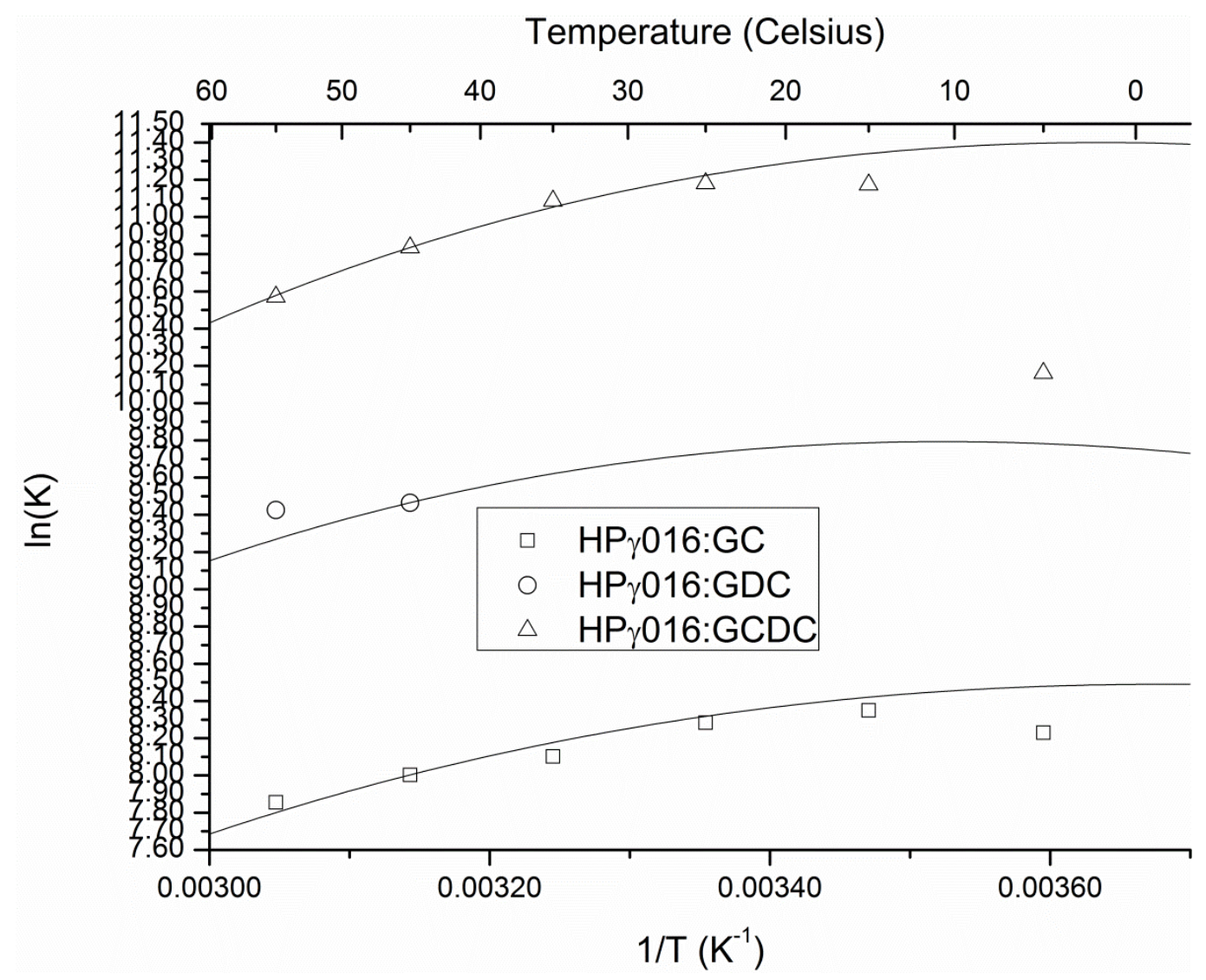

Figure 37S. Van't Hoff plot of the HP016- $\gamma \mathrm{CD} / \mathrm{BS}$ complexes. The data points fit well with the theoretical values except for the GCDC complex at $5{ }^{\circ} \mathrm{C}$. 


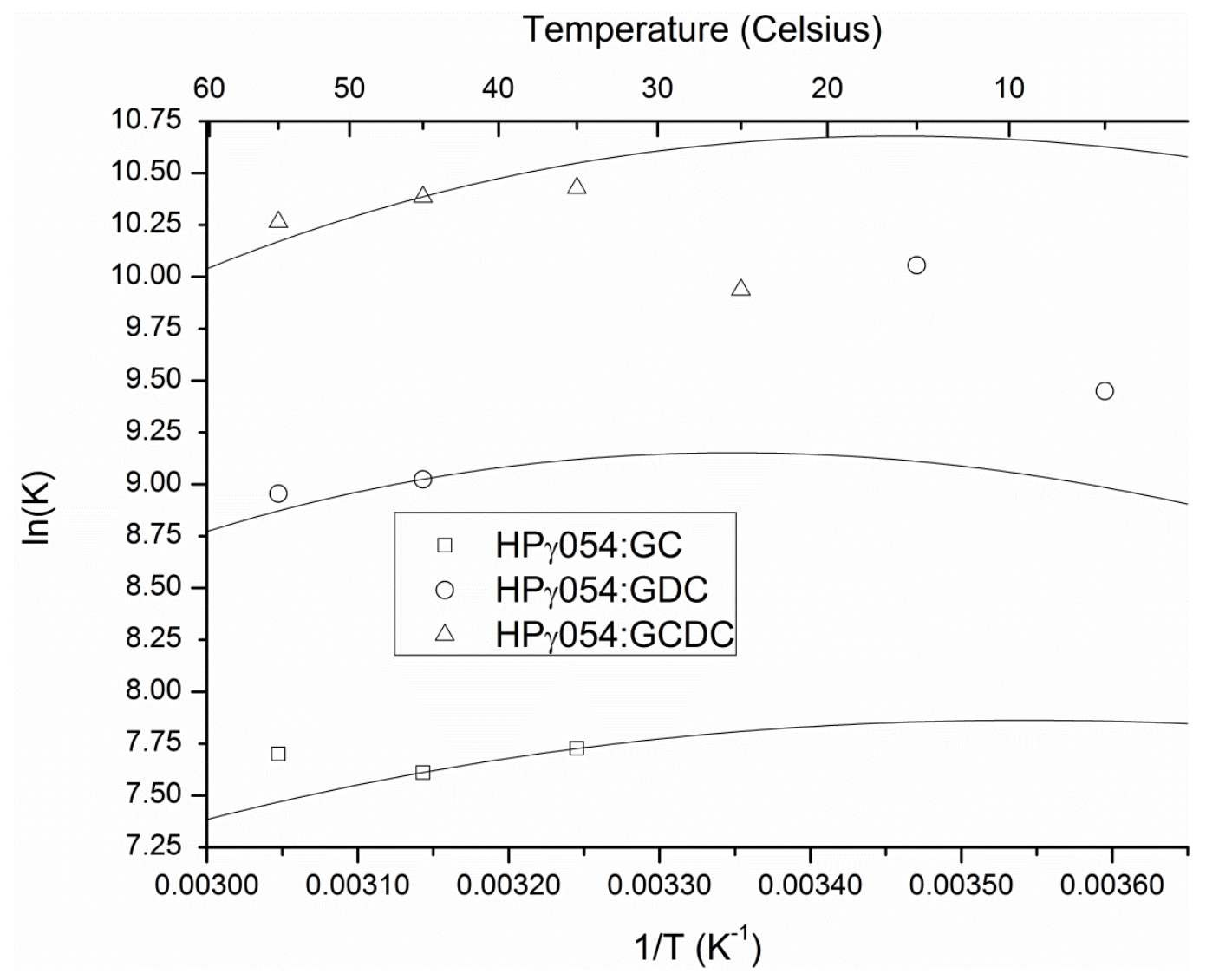

Figure 38S. Van't Hoff plot of the HP054- $\gamma \mathrm{CD} / \mathrm{BS}$ complexes. Most of the data points fit well with the theoretical values, but low temperature values seem to follow other trends than high temperature values for the GC and GDC complexes. 


\section{8. $\Delta G^{\circ}$ as function of $T$}

All values of $\Delta \mathrm{G}^{\circ}$ are plotted as a function of temperature below. The relatively weak dependence on temperature is seen.

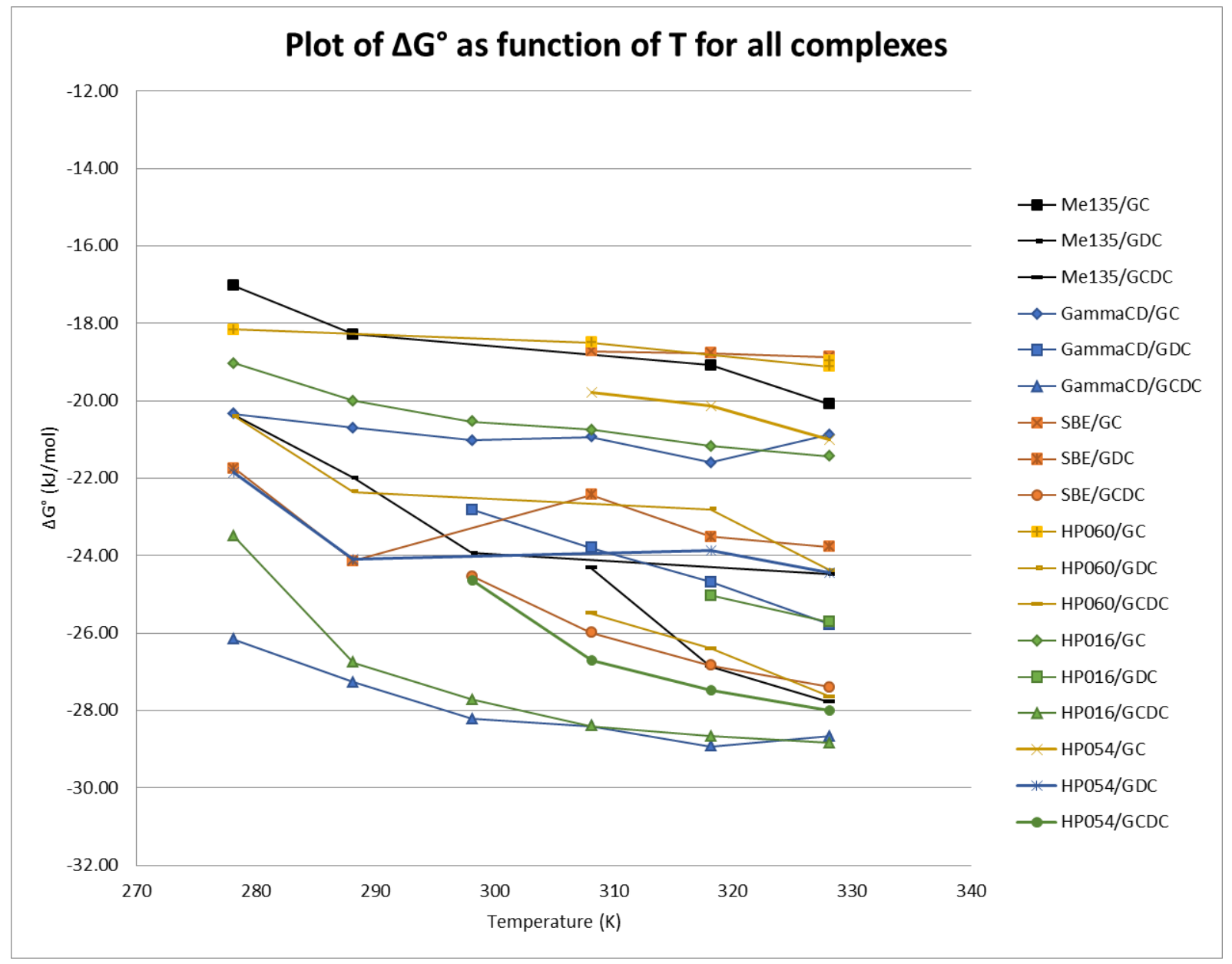

Figure 39S. Plot of $\Delta \mathrm{G}^{\circ}$ as function of $\mathrm{T}$ for all complexes. All complexes are on one plot to illustrate the relatively small variations in $\Delta \mathrm{G}^{\circ}$ among the CDs. 


\section{Global enthalpy-entropy compensation plot}

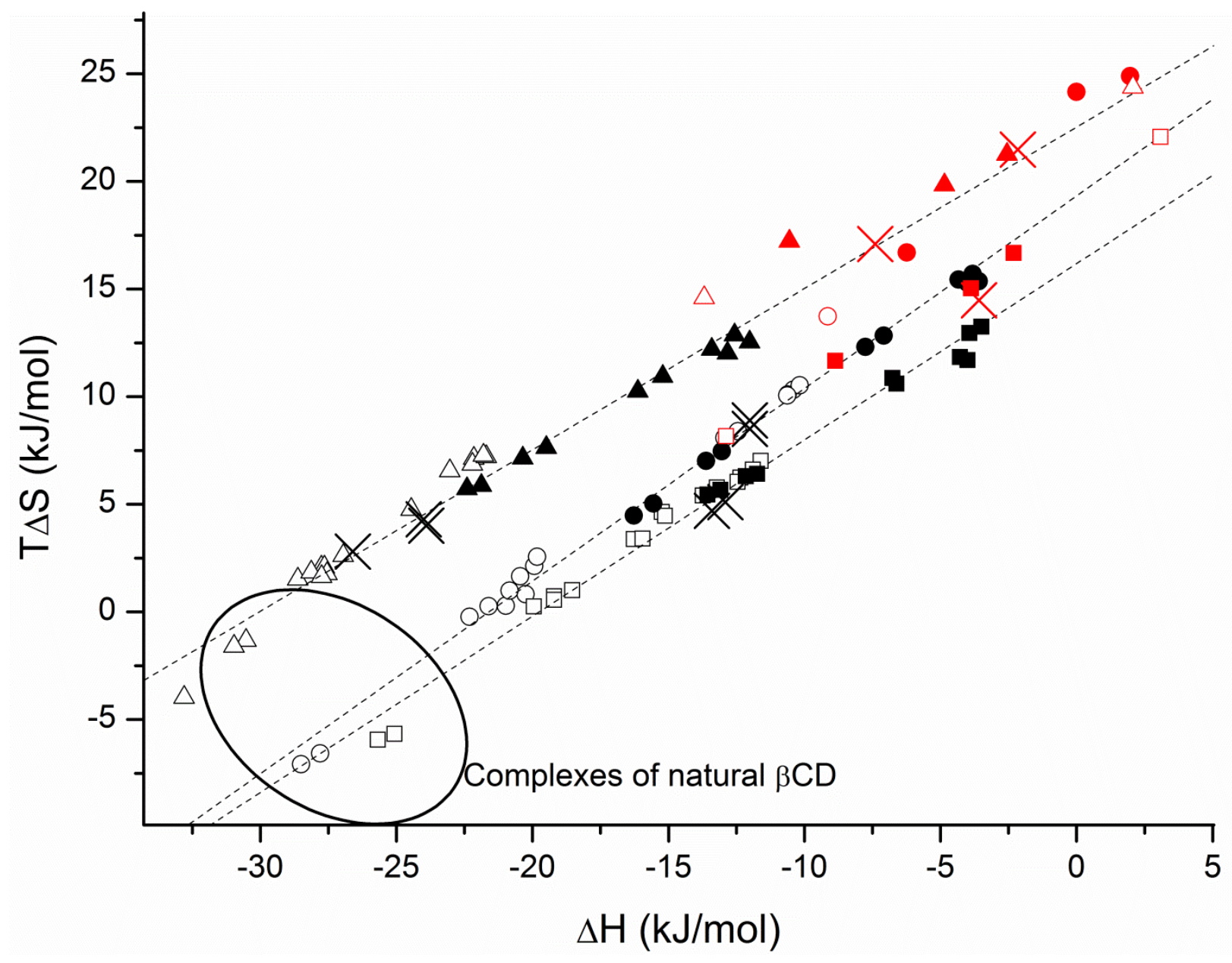

Figure 40S. Enthalpy-entropy compensation of $\gamma \mathrm{CD}$ and $\beta C D$ complexes. Data points in red represent $\gamma \mathrm{CD}$ complexes and are from the present study, and data points in black represent $\beta C D$ complexes and are obtained from Schönbeck et al. (2010),

Schönbeck et al. (2011), Holm et al. (2009), and Holm et al. (2014). Open symbols represent methyl- and natural CD complexes and closed symbols HP complexes. Squares represent GC/TC complexes, circles GDC/TDC complexes, and triangles GCDC/TCDC complexes. Crosses represent SBE complexes. The dashed lines are fitted to each of the three groups of BS for the $\beta C D$ data, and it can be seen that $\gamma \mathrm{CD}$ complexes do not follow the same trends. 


\section{Plots and regressions of $\Delta H^{\circ}$ vs $T$ and $\Delta S^{\circ}$ vs $\ln (T)$}

Given that stability constants were measured at various temperatures, they could be evaluated by a van't Hoff plot. If the experimental data follows theory they should theoretically lie on the line created by Schönbeck et al., 2012):

$$
\ln (K(T))=\frac{\Delta H_{R}^{\circ}-T_{R} \Delta C_{P}^{\circ}}{R}\left[\frac{1}{T_{R}}-\frac{1}{T}\right]+\frac{\Delta C_{P}^{\circ}}{R} \ln \left(\frac{T}{T_{R}}\right)+\ln \left(K_{R}\right)
$$

where the subscript on $\mathrm{T}_{\mathrm{R}}$ and $\Delta \mathrm{H}_{\mathrm{R}}{ }^{\circ}$ refers to the reference temperature. The reference temperature was defined to $45^{\circ} \mathrm{C}$, given that all complexes provided measurable data at this temperature. Differences between theory and empiric data were observed for complexes containing modified $\gamma \mathrm{CDs}$, indicating experimental difficulties or thermodynamic irregularities in the data set, see data below. In general, the empirical data deviated randomly from the theoretical values and could be a reflection of the polydisperse $\gamma \mathrm{CD}$ samples and the uncertainties associated with the use of results obtained from small heats of complexation. Most studies investigating the interaction between CDs and BSs reported in the literature were performed at $25{ }^{\circ} \mathrm{C}$. The van't Hoff plots could be used to obtain the theoretical values of the stability constants at $25{ }^{\circ} \mathrm{C}$. However, the small enthalpies around $25{ }^{\circ} \mathrm{C}$ makes the slope of the van't Hoff plots almost zero in that temperature range, consequently making the differences between the stability constants obtained at $45{ }^{\circ} \mathrm{C}$ and $25{ }^{\circ} \mathrm{C}$ relatively small, which enables a more direct comparison to previously reported stabilities. Graphs of $\Delta \mathrm{H}^{\circ}$ as function of $\mathrm{T}$ are shown below with the equations of the linear fits shown on the right side. The regressions were used to predict the values of $\Delta \mathrm{H}^{\circ}$ at $25^{\circ} \mathrm{C}$. The slopes of the linear fits are the values of $\Delta \mathrm{C}_{\mathrm{p}}{ }^{\circ}$ in the unit of $\mathrm{kJ} / \mathrm{mol} / \mathrm{K}$. 


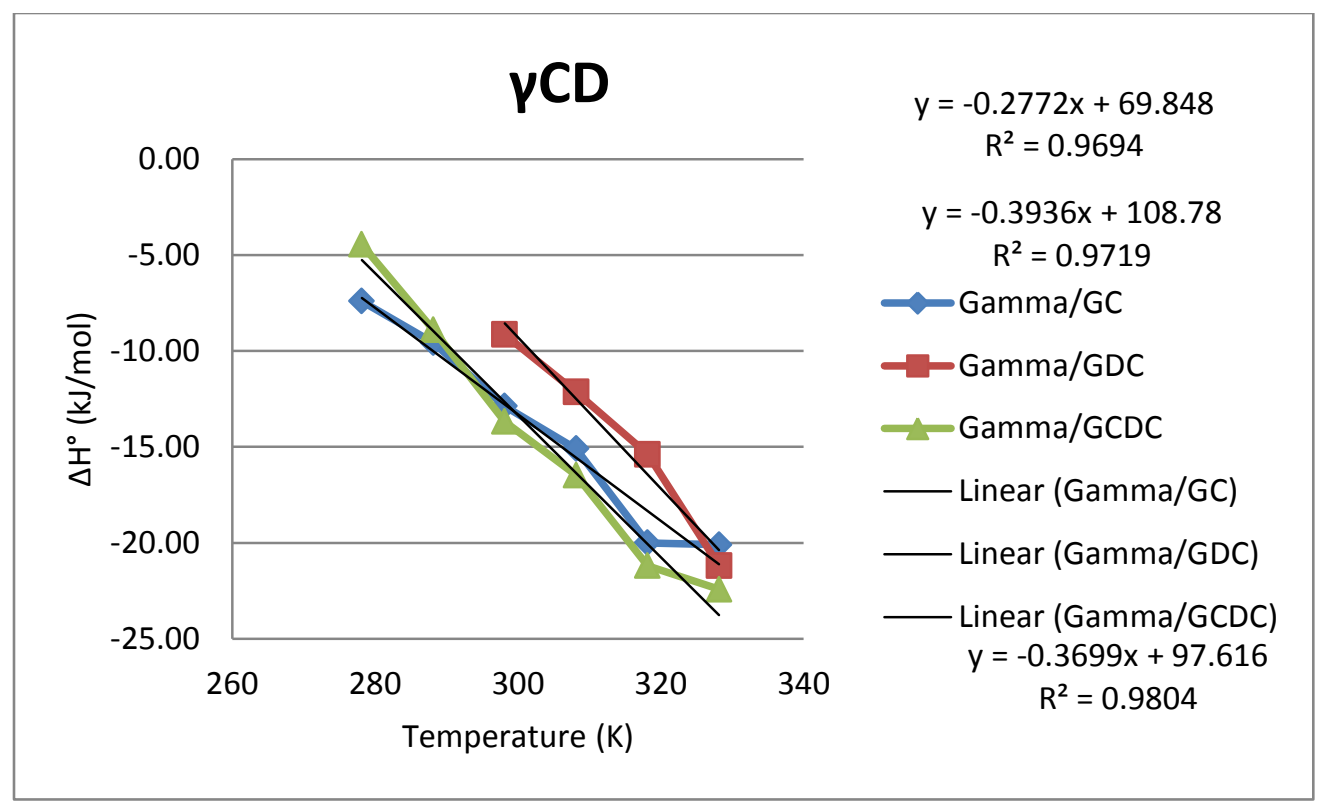

Figure 41S. Graph of $\Delta \mathrm{H}^{\circ}$ values as function of $\mathrm{T}$ in the $\gamma \mathrm{CD} / \mathrm{BS}$ complexes. The equations of the linear fits and their corresponding $\mathrm{R}^{2}$ values are seen on the right side of the graph.

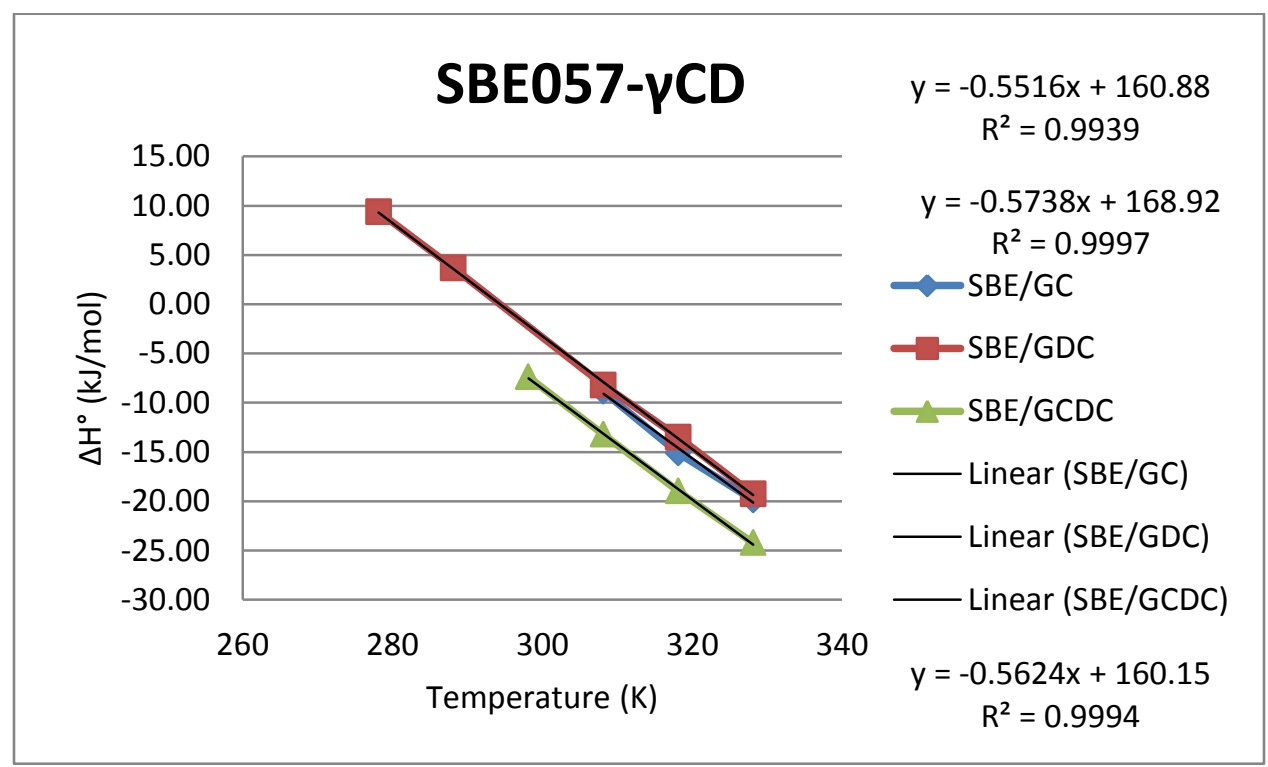

Figure 42S. Graph of $\Delta \mathrm{H}^{\circ}$ values as function of $\mathrm{T}$ in the SBE057- $\gamma \mathrm{CD} / \mathrm{BS}$ complexes. The equations of the linear fits and their corresponding $\mathrm{R}^{2}$ values are seen on the right side of the graph. 


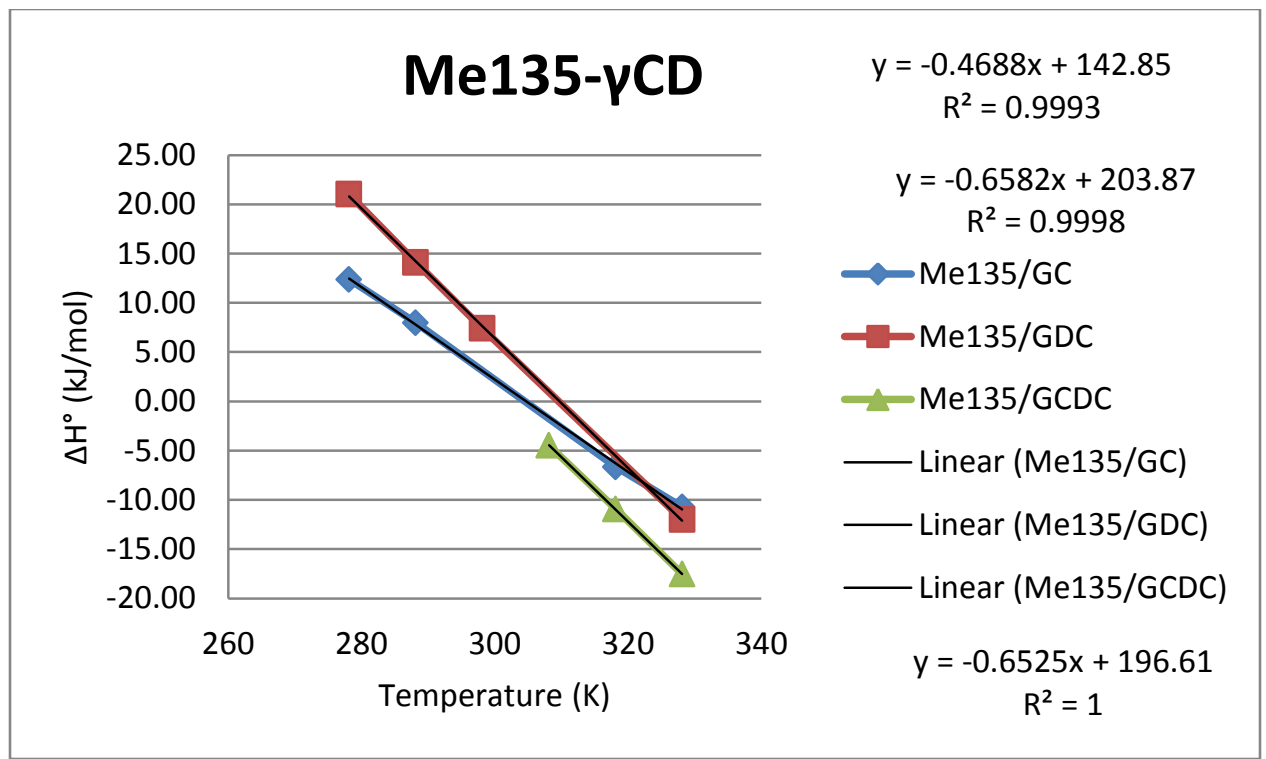

Figure 43S. Graph of $\Delta \mathrm{H}^{\circ}$ values as function of $\mathrm{T}$ in the Me135- $\gamma \mathrm{CD} / \mathrm{BS}$ complexes. The equations of the linear fits and their corresponding $\mathrm{R}^{2}$ values are seen on the right side of the graph.

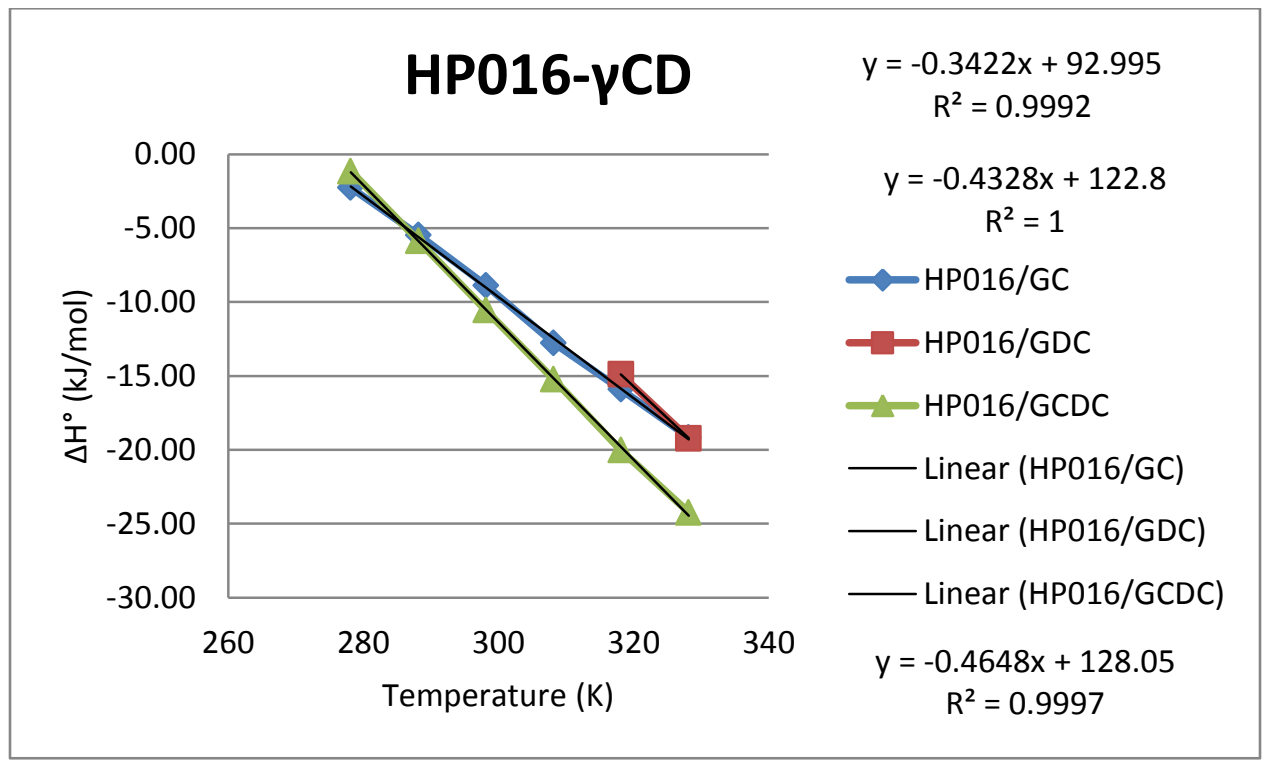

Figure 44S. Graph of $\Delta \mathrm{H}^{\circ}$ values as function of $\mathrm{T}$ in the HP016- $\gamma \mathrm{CD} / \mathrm{BS}$ complexes. The equations of the linear fits and their corresponding $\mathrm{R}^{2}$ values are seen on the right side of the graph. 


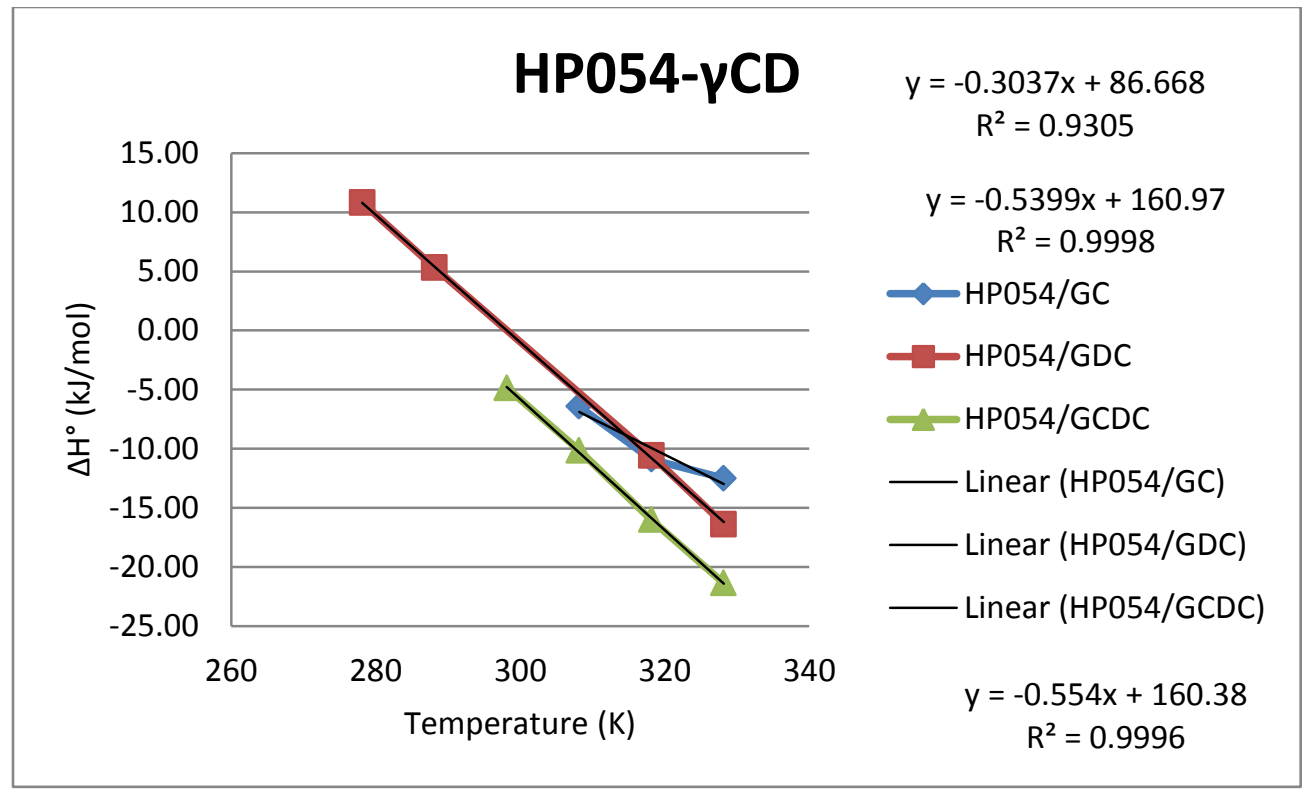

Figure 45S. Graph of $\Delta \mathrm{H}^{\circ}$ values as function of $\mathrm{T}$ in the HP054- $\gamma \mathrm{CD} / \mathrm{BS}$ complexes. The equations of the linear fits and their corresponding $\mathrm{R}^{2}$ values are seen on the right side of the graph.

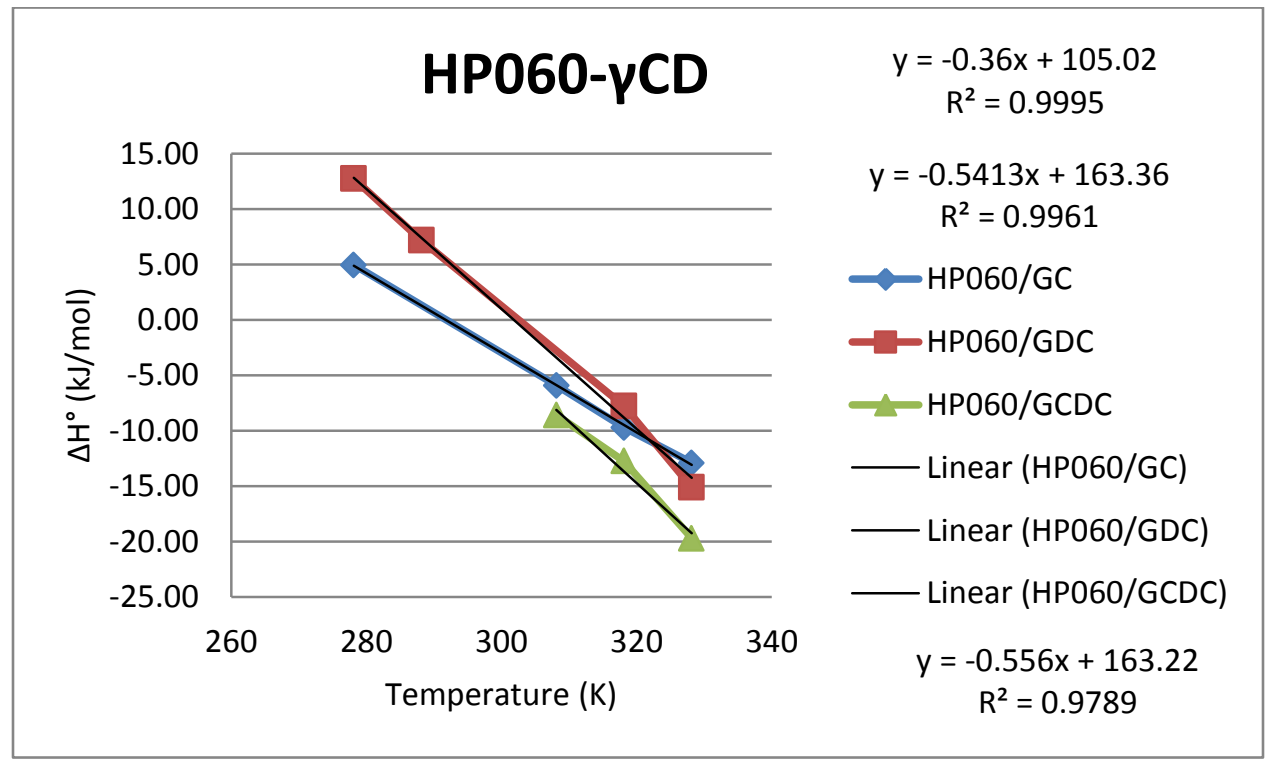

Figure 46S. Graph of $\Delta \mathrm{H}^{\circ}$ values as function of $\mathrm{T}$ in the $\mathrm{HP} 060-\gamma \mathrm{CD} / \mathrm{BS}$ complexes. The equations of the linear fits and their corresponding $\mathrm{R}^{2}$ values are seen on the right side of the graph.

Graphs of $\Delta \mathrm{S}^{\circ}$ as function of $\ln (\mathrm{T})$ are shown below with the equations of the linear fits shown on the right side. The regressions were used to predict the values of $\Delta \mathrm{S}^{\circ}$ at $25{ }^{\circ} \mathrm{C}$ and are only shown when a 
value of $\Delta \mathrm{S}^{\circ}$ is not available at $25^{\circ} \mathrm{C}$. For the natural $\gamma \mathrm{CD} \Delta \mathrm{S}^{\circ}$ is plotted against $\mathrm{T}$ since all data was obtained in the ITC measurements.

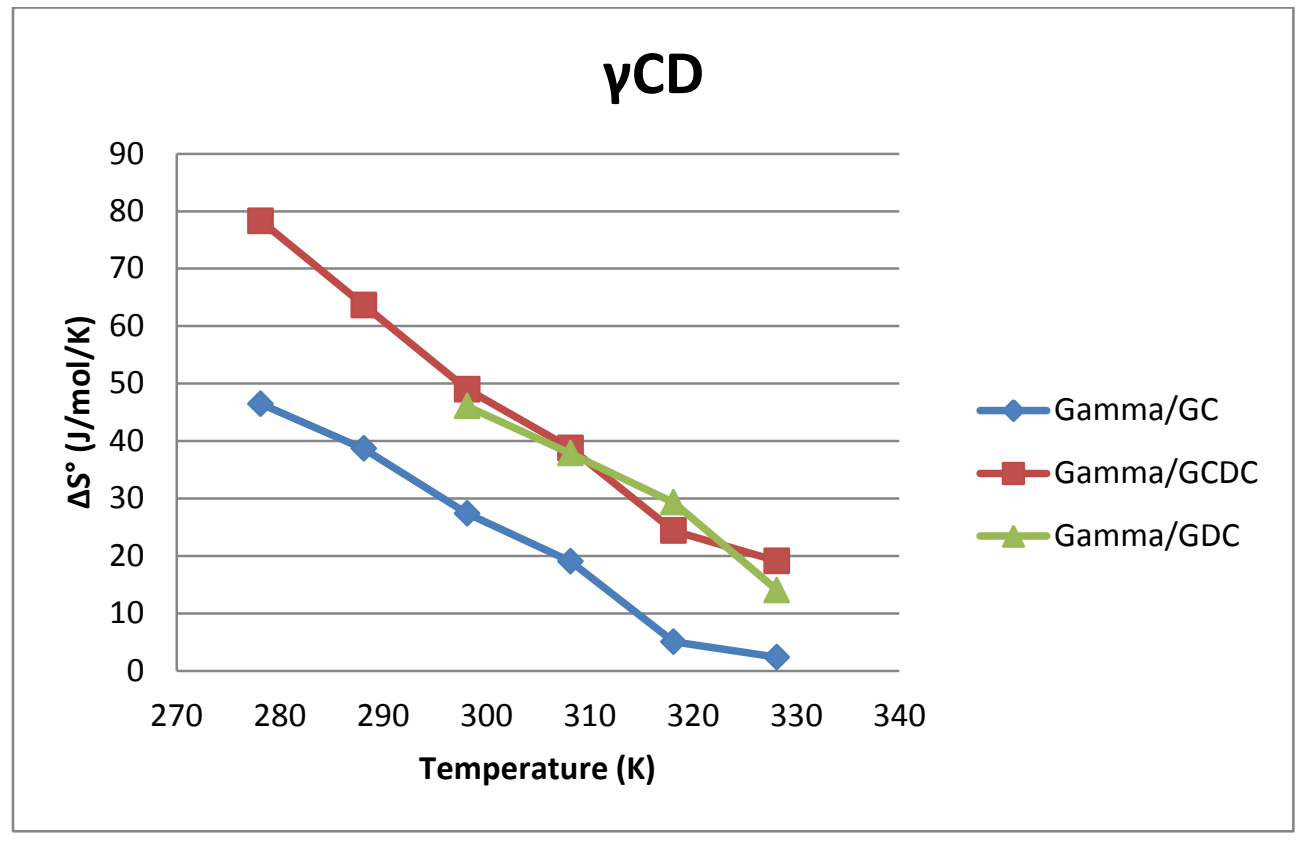

Figure 47S. Graph of $\Delta \mathrm{S}^{\circ}$ values as function of $\mathrm{T}$ in the $\gamma \mathrm{CD} / \mathrm{BS}$ complexes.

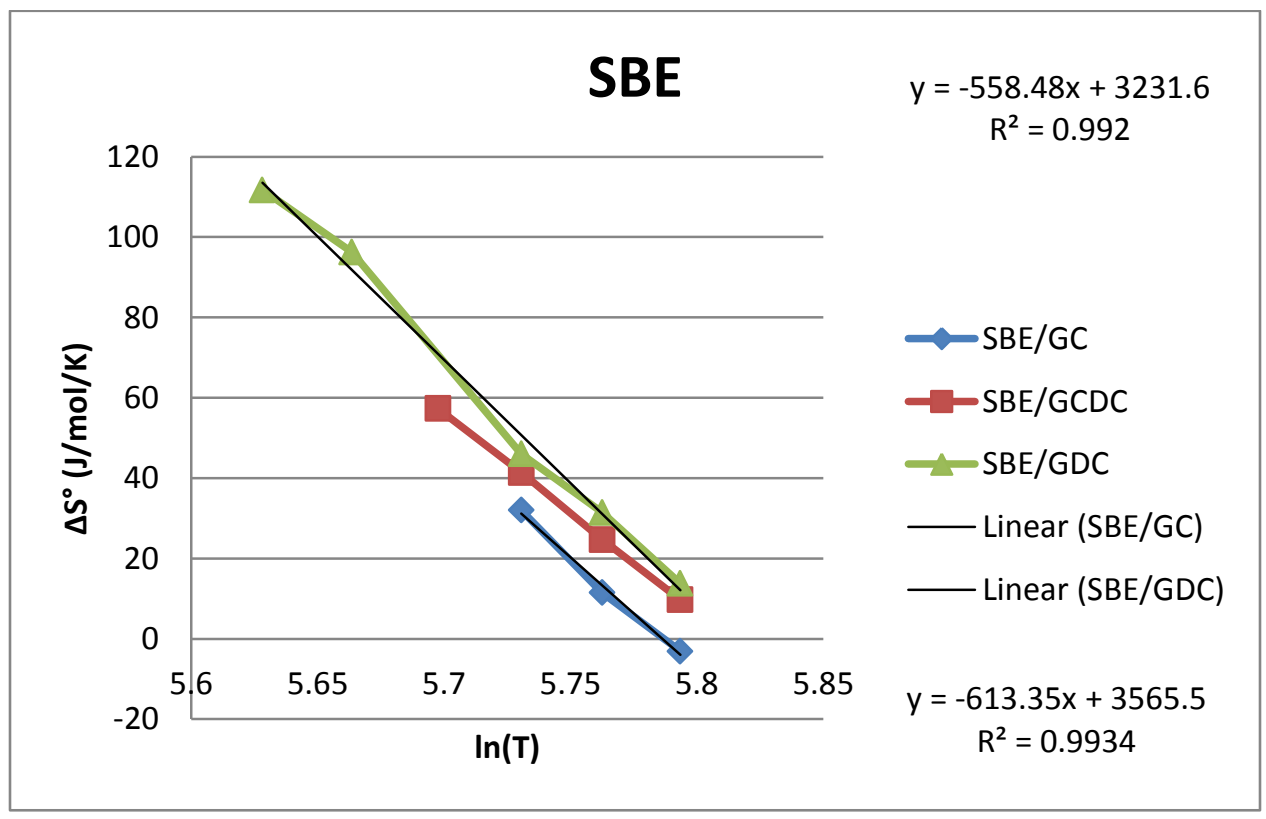

Figure 48S. Graph of $\Delta \mathrm{S}^{\circ}$ values as function of $\ln (\mathrm{T})$ in the SBE057- $\gamma \mathrm{CD} / \mathrm{BS}$ complexes. 


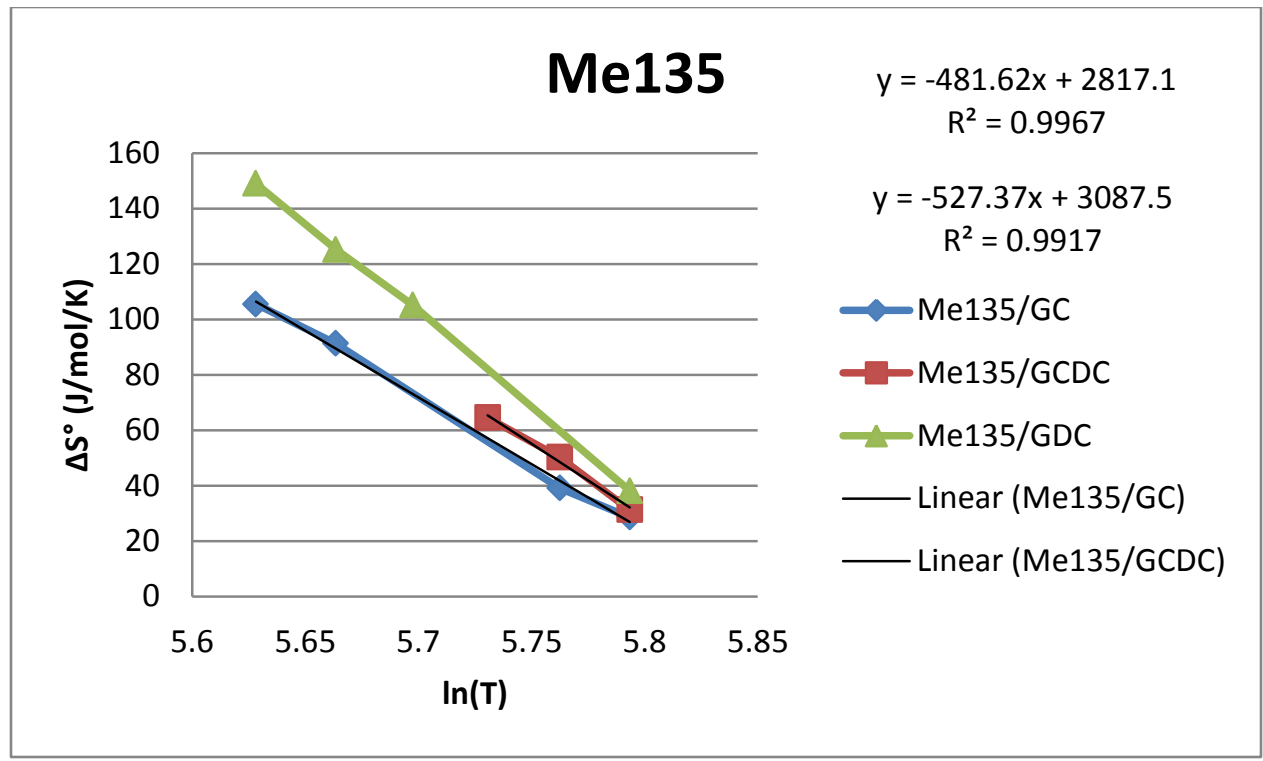

Figure 49S. Graph of $\Delta \mathrm{S}^{\circ}$ values as function of $\ln (\mathrm{T})$ in the Me135- $\gamma \mathrm{CD} / \mathrm{BS}$ complexes.

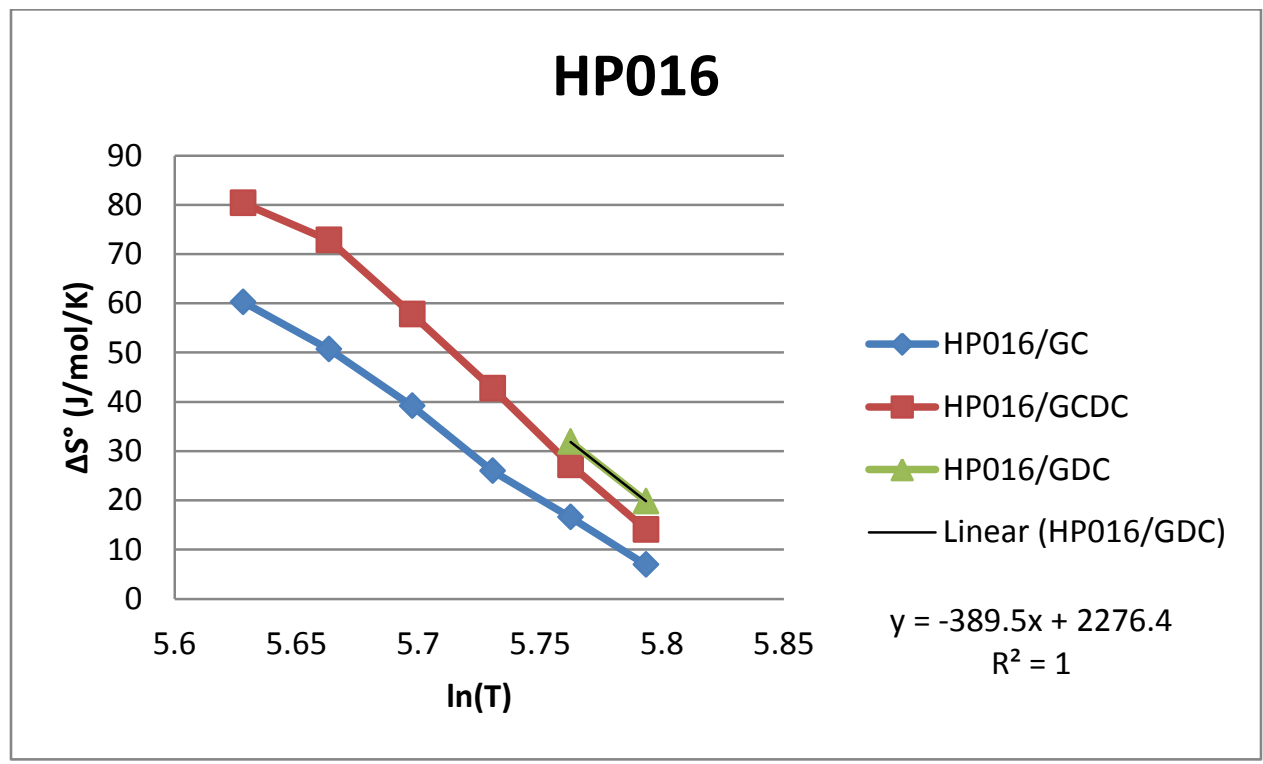

Figure 50S. Graph of $\Delta \mathrm{S}^{\circ}$ values as function of $\ln (\mathrm{T})$ in the HP016- $\gamma \mathrm{CD} / \mathrm{BS}$ complexes. 


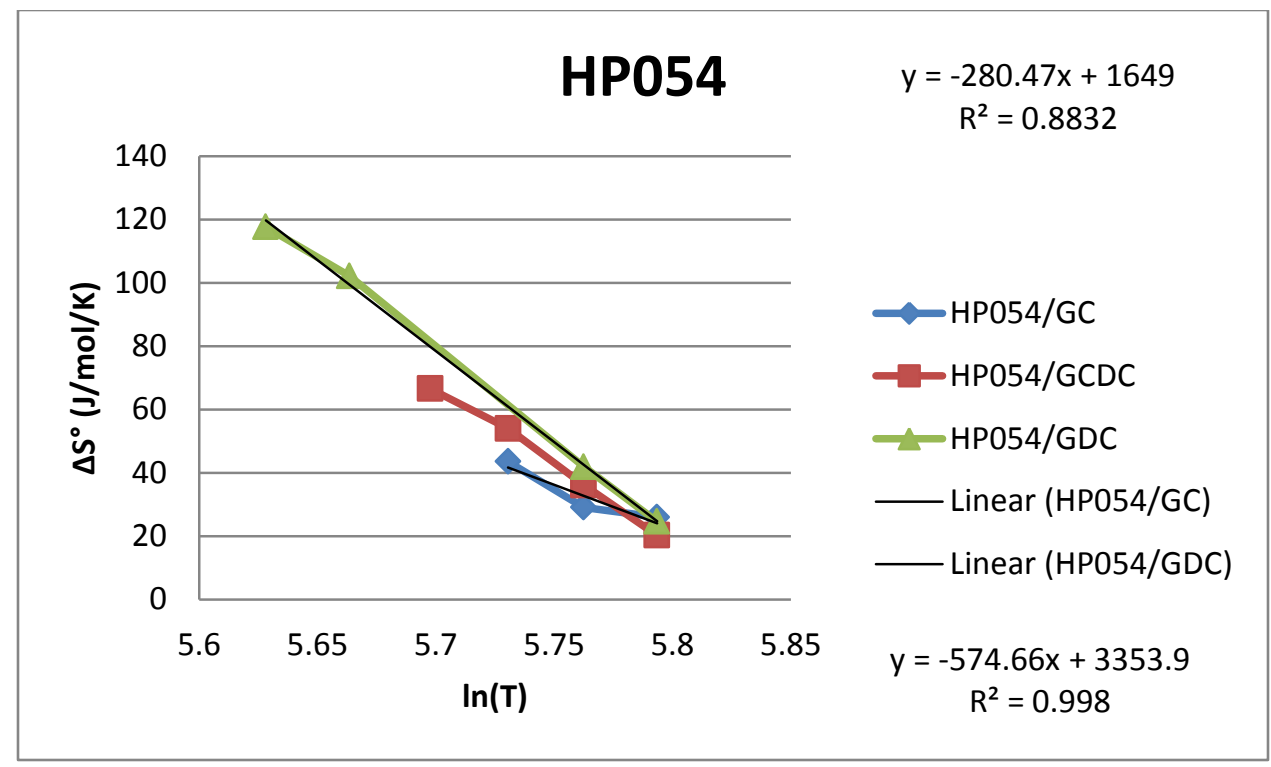

Figure 51S. Graph of $\Delta \mathrm{S}^{\circ}$ values as function of $\ln (\mathrm{T})$ in the HP054- $\gamma \mathrm{CD} / \mathrm{BS}$ complexes.

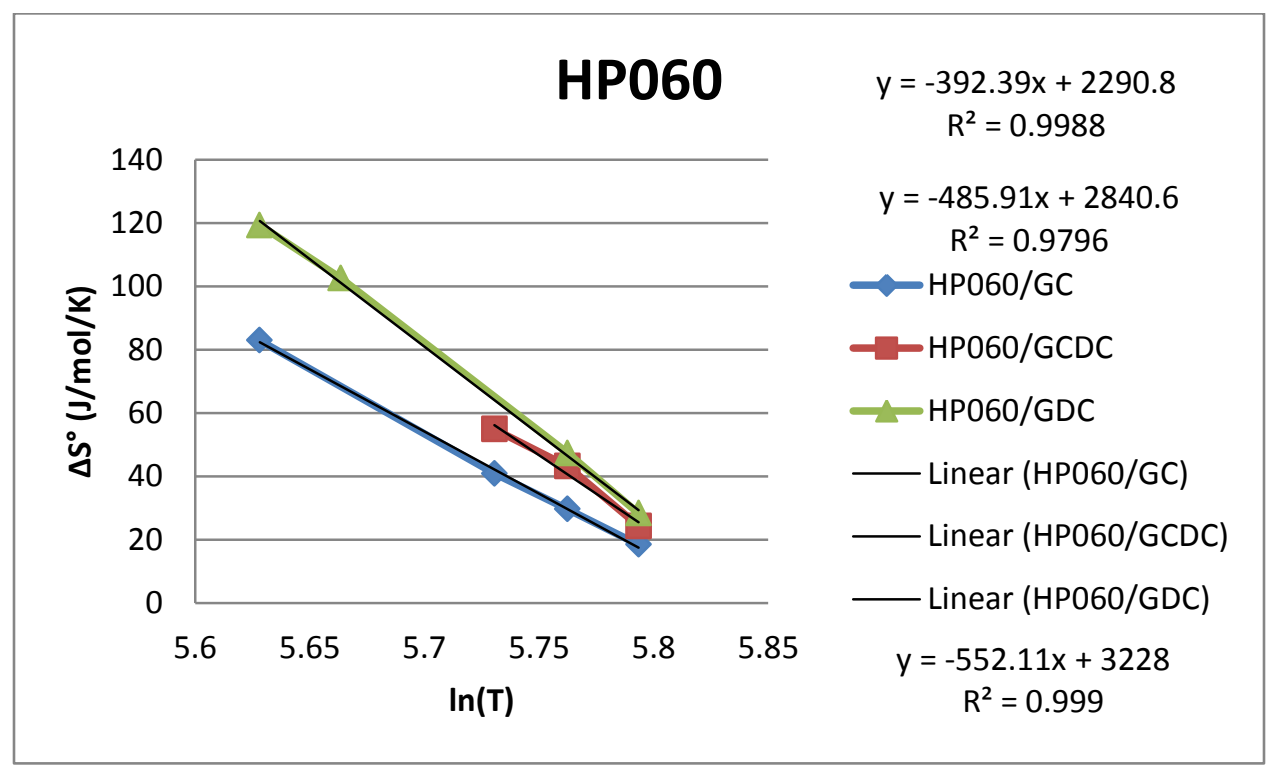

Figure 52S. Graph of $\Delta \mathrm{S}^{\circ}$ values as function of $\ln (\mathrm{T})$ in the HP060- $\gamma \mathrm{CD} / \mathrm{BS}$ complexes. 


\section{Plots and regressions used to calculate dehydrated surface area}

Below $\mathrm{T} \Delta \mathrm{S}^{\circ}$ vs DS of HP- $\gamma \mathrm{CD}$ s is shown. The results of the linear regression, which are shown next to the graph, show the dependence of $\mathrm{T} \Delta \mathrm{S}^{\circ}$ on DS. By dividing the slope values with 8 , the dependence of $\mathrm{T} \Delta \mathrm{S}^{\circ}$ on number of HP chains is yielded.

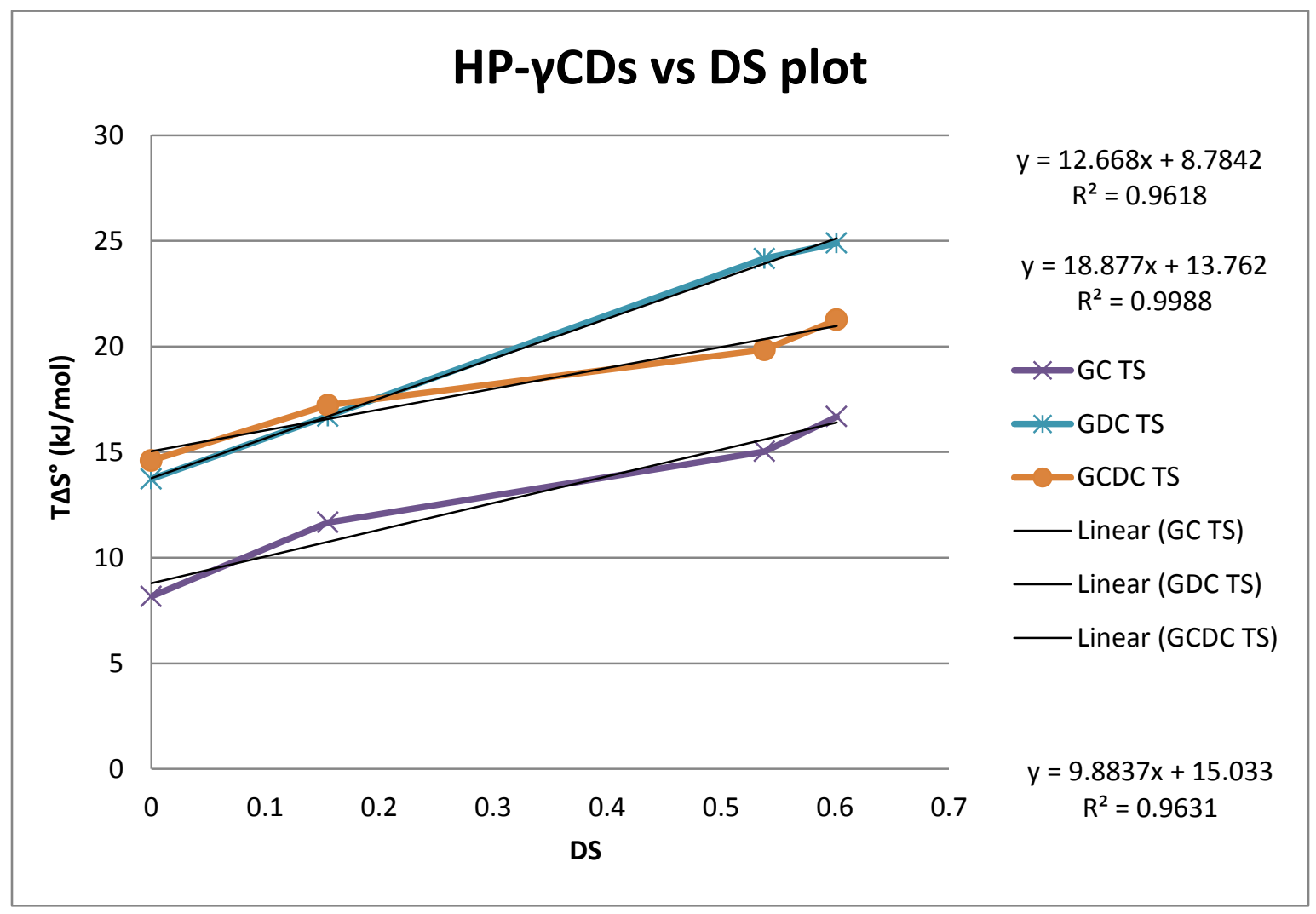

Figure 53S. Plot of $\mathrm{T} \Delta \mathrm{S}^{\circ}$ values as a function of DS for the examined HP- $\gamma \mathrm{CD}$. Fitted equations are shown to the right of the graph. The values of $\Delta \mathrm{S}^{\circ}$ used in the plot are the values observed or extrapolated to $25^{\circ} \mathrm{C}$.

Below $\Delta \mathrm{C}_{\mathrm{p}}{ }^{\circ}$ values are plotted as function of the DS of the HP- $\gamma$ CDs. The equations of the linear fits are shown next to the graph. Once again the slope values must be divided by 8 to give the dependence of $\Delta \mathrm{C}_{\mathrm{p}}{ }^{\circ}$ on the number of HP chains, rather than on the DS. Below that, $\Delta \mathrm{C}_{\mathrm{p}}{ }^{\circ}$ vs DS is shown for all methyl and SBE complexes. 


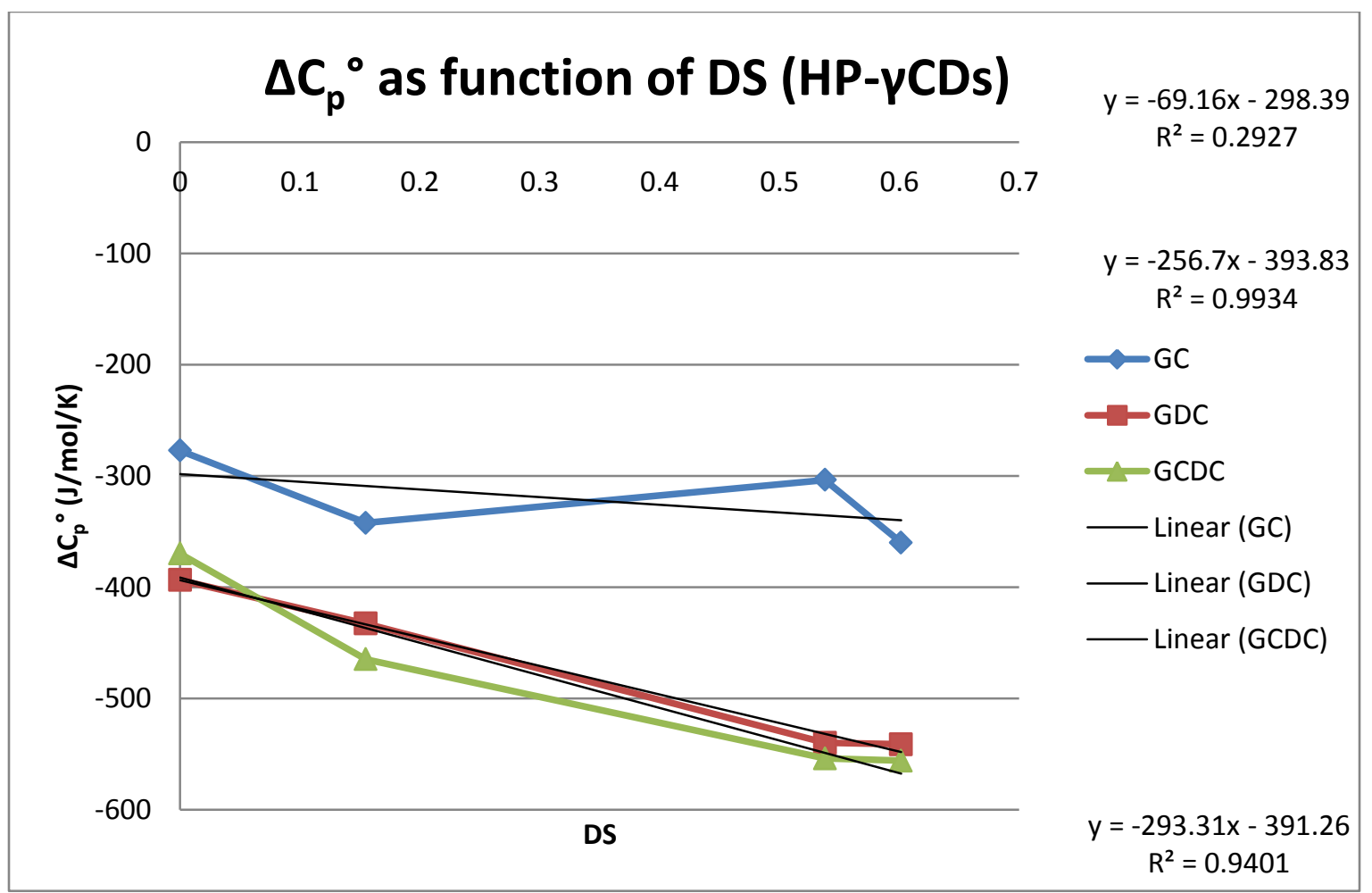

Figure 54S. Plot of $\Delta \mathrm{C}_{\mathrm{p}}{ }^{\circ}$ as function of DS for the examined HP- $\gamma$ CDs. Equations of the linear fits are shown on the right side of the graph. As can be seen from the $\mathrm{R}^{2}$ values of the fits, the fit for the complexes with $\mathrm{GC}$ is very poor. From the data points available the complexes with GC cannot be described as linearly dependent on DS. 


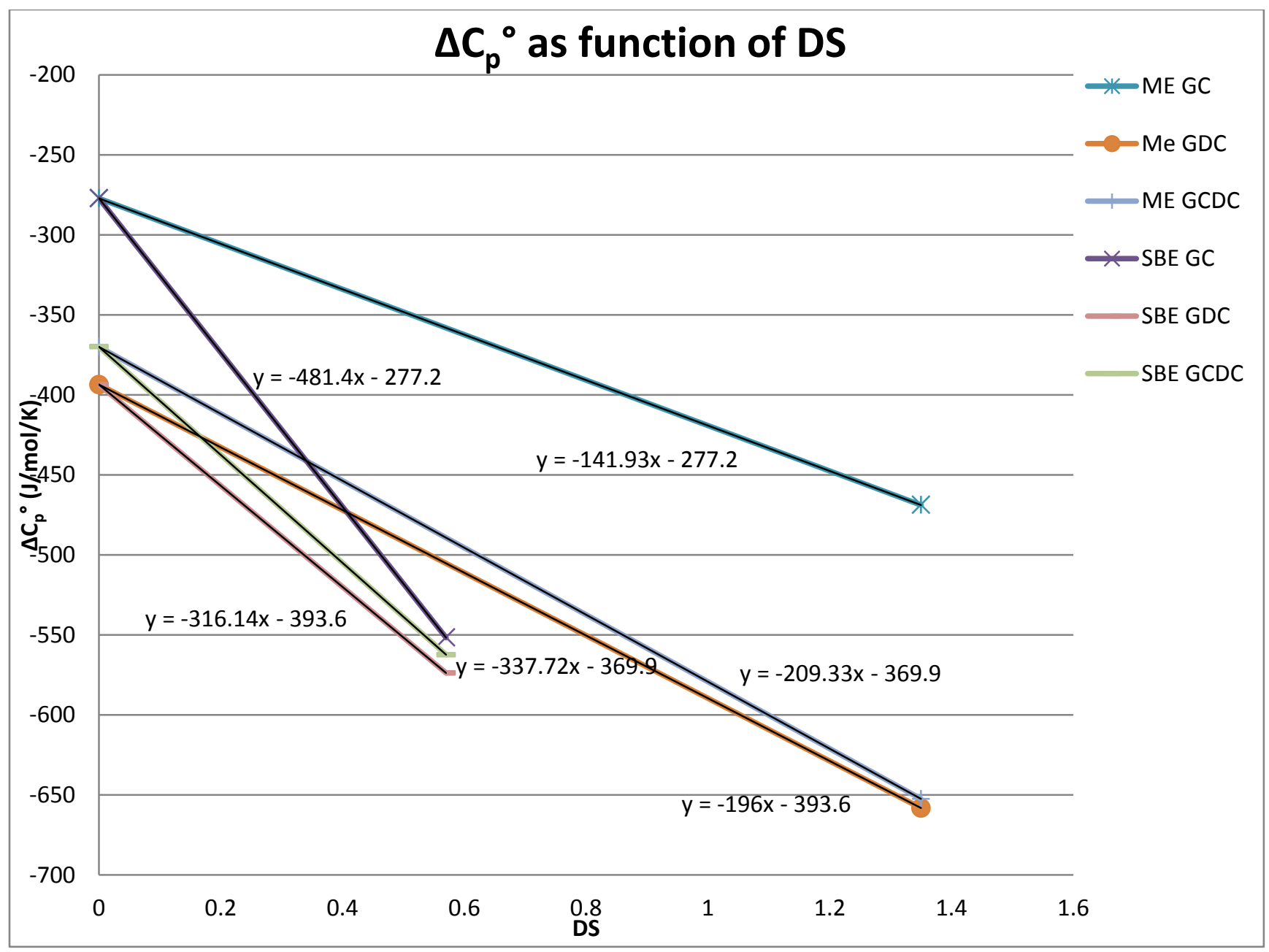

Figure 55S. Plot of $\Delta \mathrm{C}_{\mathrm{p}}{ }^{\circ}$ as function of DS for the examined Me- $\gamma \mathrm{CD}$ and SBE- $\gamma \mathrm{CD}$. Equations of the linear fits are shown next to the respective fits. Each regression relies on only two data points naturally resulting in large uncertainties. 
The summery of the regressions above are in Table $\mathrm{S} 2$

Table S2. Effect of different substituents on $\gamma \mathrm{CD}$. The regressions leading to the result are found in the supporting information. All substituents were seen to have a negative effect on $\Delta \mathrm{C}_{\mathrm{p}}{ }^{\circ}$. No reliable value could be obtained for the HP- $\gamma \mathrm{CD}-\mathrm{GC}$ complexes.

\begin{tabular}{|l|c|c|c|}
\hline Change of $\Delta \mathrm{C}_{\mathrm{p}}{ }^{\circ}$ per substituent $(\mathrm{J} / \mathrm{mol} / \mathrm{K} / \mathrm{molecule})$ & $\mathrm{HP}$ & $\mathrm{SBE}$ & $\mathrm{Me}$ \\
\hline $\mathrm{GC}$ & - & -60.2 & -17.7 \\
\hline GDC & -32.1 & -39.5 & -24.5 \\
\hline GCDC & -36.7 & -42.2 & -26.2 \\
\hline
\end{tabular}

\section{Alternative way of calculating amount of dehydrated surface area per HP chain}

A way of calculating $\triangle \mathrm{ASA}_{\text {non }}$ exploits the linear relation between $\mathrm{T} \Delta \mathrm{S}^{\circ}$ and the DS of the HP- $\gamma \mathrm{CD}$ and was done by Schönbeck et al. (2010) for HP- $\beta C D$ s. The values achieved by linear regressions of the data in Figure 53S are 1.58, 2.36, and 1.24 kJ/mol/HP for GC, GDC, and GCDC complexes, respectively. If this increase in $\mathrm{T} \Delta \mathrm{S}^{\circ}$ was assumed to mainly stem from $\Delta \mathrm{ASA}_{\text {non }}$, the area dehydrated by each $\mathrm{HP}$ chain could be calculated. Schönbeck et al. (2014b) compared the hydration entropies of linear alkanes (ethane to hexane) (Plyasunov \& Shock, 2000) to their water-accessible surface areas (Gallicchio et al., 2000) to find that hydration of surface area adds $-0.120 \mathrm{~kJ} / \mathrm{mol} / \AA^{2}$ to $\mathrm{T} \Delta \mathrm{S}^{\circ}$ at $298.15 \mathrm{~K}$. Combining these values, it was found that each HP chain contribute $13.17,19.67$, and $10.33 \AA^{2}$ to $\triangle \mathrm{ASA}_{\text {non }}$ for GC, GDC and GCDC complexes, respectively. 


\section{References}

Cabrer, P.R., Alvarez-Parrilla, E., Al-Soufi, W., Meijide, F., Núñez, E.R. \& Tato, J.V. 2003, "Complexation of Bile Salts by Natural Cyclodextrins", Supramolecular Chemistry, vol. 15, no. 1, pp. 33-43.

Gallicchio, E., Kubo, M.M. \& Levy, R.M. 2000, "Previous Article Next Article Table of Contents Enthalpy-Entropy and Cavity Decomposition of Alkane Hydration Free Energies: Numerical Results and Implications for Theories of Hydrophobic Solvation", The Journal of Physical Chemistry B, vol. 104, no. 26, pp. 6271-6285.

Holm, R., Madsen, J.C., Shi, W., Larsen, K.L., Städe, L.W. \& Westh, P. 2011, "Thermodynamics of complexation of tauro- and glyco-conjugated bile salts with two modified $\beta$-cyclodextrins", Journal of inclusion phenomena and macrocyclic chemistry, vol. 69 , no. $1-2$, pp. 201-211.

Holm, R., Østergaard, J., Schönbeck, C., Jensen, H., Shi, W., Peters, G.H. \& Westh, P. 2014, "Determination of stability constants of tauro- and glyco-conjugated bile salts with the negatively charged sulfobutylether- $\beta$-cyclodextrin: comparison of affinity capillary electrophoresis and isothermal titration calorimetry and thermodynamic analysis of the interaction", Journal of inclusion phenomena and macrocyclic chemistry, vol. 78, no. 1-4, pp. 185-194.

Holm, R., Schönbeck, C., Askjær, S. \& Westh, P. 2013, "Thermodynamics of the interaction of $\gamma$-cyclodextrin and tauro- and glyco-conjugated bile salts", Journal of inclusion phenomena and macrocyclic chemistry, vol. 75, no. 1-2, pp. 223-233.

Holm, R., Shi, W., Hartvig, R.A., Askjær, S., Madsen, J.C. \& Westh, P. 2009, "Thermodynamics and structure of inclusion compounds of tauro- and glyco-conjugated bile salts and $\beta$-cyclodextrin", Physical Chemistry Chemical Physics, vol. 11, pp. 5070-5078.

Plyasunov, A.V. \& Shock, E.L. 2000, "Thermodynamic functions of hydration of hydrocarbons at $298.15 \mathrm{~K}$ and $0.1 \mathrm{MPa}$ ", Geochimica et Cosmochimica Acta, vol. 64, no. 3, pp. 439-468.

Schneider, H-J., Hacket, F. \& Rüdiger, V. 1998, "NMR Studies of Cyclodextrins and Cyclodextrin Complexes", Chemical Reviews, vol. 98, pp. 1755-1785.

Schönbeck, C., Westh, P. \& Holm, R. 2014b, "Complexation Thermodynamics of Modified Cyclodextrins: Extended Cavities and Distorted Structures", The Journal of Physical Chemistry B, vol. 118, pp. 10120-10129.

Schönbeck, C., Westh, P., Madsen, J.C., Larsen, K.L., Städe, L.W. \& Holm, R. 2011, "Methylated $\beta$-Cyclodextrins: Influence of Degree and Pattern of Substitution on the Thermodynamics of Complexation with Tauro- and Glyco-Conjugated Bile Salts", Langmuir, vol. 27, pp. 5832-5841.

Schönbeck, C., Westh, P., Madsen, J.C., Larsen, K.L., Städe, L.W. \& Holm, R. 2010, "Hydroxypropyl-Substituted $\beta$ Cyclodextrins: Influence of Degree of Substitution on the Thermodynamics of Complexation with Tauroconjugated and Glycoconjugated Bile Salts", Langmuir, vol. 26, no. 23, pp. 17949-17957.

Tan, X. \& Lindenbaum, S. 1991, "Studies on complexation between $\beta$-cyclodextrin and bile salts", International Journal of Pharmaceutics, vol. 74, no. 2-3, pp. 127-135. 